\title{
IMPACT EVALUATION OF A 'BRIEF INTERVENTION PROGRAM' FOR CLIENTS WHO DELIBERATELY SELF HARM
}

\author{
by
}

Edward Herman Aquin

A thesis submitted to the Victoria University of Wellington

in partial fulfilment of the

requirements for the degree of

Master of Nursing (Clinical)

Victoria University of Wellington

2009 


\section{Abstract}

Deliberate self harm (DSH) and suicide rates are recognised internationally, nationally and locally as an increasing trend. The financial and emotional cost to society highlights the need for providing services that aim to reduce the likelihood of further deliberate self harm. The emergency department $(E D)$ is often the entry point for service provision to clients who deliberate self harm. A reduction in re-presentations for acts of $D S H$ to the $E D$ would greatly reduce the strain on this essential part of the public healthcare system. It is vital that the services developed to address $D S H$ are evaluated to facilitate informed decisions regarding program sustainability or improvement.

Study aim: This study aims to evaluate a 'brief intervention program' $(B I P)$ designed to address the needs of clients who presented with or were at risk of engaging in act(s) of deliberate self harm. The intention of the program was to reduce repetitive acts of $D S H$ and to assist the clients in developing better coping strategies.

Study design: This study uses a pluralistic evaluation research design to conduct a program evaluation. The 'line of enquiry' is guided by the Impact Evaluation framework by Owen (2006).The seven steps of the framework were used to organise, categorise, analyse and discuss the program's outcomes in this study. The pluralistic or mixed design used pre-existing quantitative client file data and qualitative data collected from a staff questionnaire. A total number of 40 client files were examined for the data analysis. Six out of the ten staff members agreed to participate in a survey that sought information about the program's implementation.

Findings: Results from the quantitative data analysis found that $82.1 \%$ of clients did not re-present to the $E D$ with a repeated act of $D S H$ for a period of six months following initial referral and treatment. The mean average of days to follow up was 5.54.

Outcome measurements via pre and post PANSI scores found an improvement in the client's resiliency. Results from the repeated measures $\underline{t}$-test: $p<.05$.

Qualitative data analysis found that by expanding the referral base that stakeholders perceived it was more difficult for clients to be followed up within five days from their referral date. Other suggestions pertained to increasing the resources of the program for sustainability. 
Contribution: The use of program evaluation strategies compliments current trends in healthcare to employ pluralistic or mixed method designs. Broader lines of enquiry lead to more informed decisions regarding program sustainability or improvement.

\section{Keywords}

evaluation; emergency department; deliberate self-harm; self injury; suicide 


\section{Acknowledgements}

Sole BIP Clinician: Bill Fallon

This thesis is based upon the great work that you have done in constructing and providing a viable and useful service for clients when 'they need it the most.' You are testimony of the skill and commitment that bring credit to the field of psychiatric nursing.

Clinical Coordinator May Nobel and Consultant Psychiatrist Dr. Joe Black

Thanks for your contribution to the construction of the BIP and the full cooperation and support given to conduct this research project.

\section{Mental Health Triage Team}

To my colleagues that took the time from their busy clinical work to participate in the questionnaire. This thesis study acknowledges the challenges and enormous responsibilities that are associated with the triage role.

\section{Victoria University of Wellington}

Prof. Jo Walton: initial supervisor and head of school for the length of the project: for your leadership and commitment in assisting me through the lengthy ethics process, your wit, wisdom, encouragement and patience in seeing this project to completion.

Chris Walsh: secondary supervisor: for all of your moral support, direct honesty and enthusiasm in helping to see this project to completion.

Dr. Cheryle Moss and Dr. Kathy Nelson: for your input, support and knowledge which aided in the selection of methodology. Thelma Puckey: for seeing this project go straight through to the finish line.

\section{Others of special note:}

Julie Long: my wife; for all the evenings and weekends you sacrificed, your unconditional love and support that maintained my motivation to complete this project for our future. 
Flora and Herman Aquin; for my parents that provided moral and spiritual support for this project from a distance in central Canada. My brother Charles who is my only whanau this side of the Pacific that provided a base whilst in NZ.

To Pat; my statistics guru that helped de-mystify working with SPSS.

My colleagues from PsychNET; Rebecca, Jodie, Shirley, Leslie, Leo and Barb for all your moral and practical support; thank you John for your humour, experience and morale boosting through this process.

Dr. Seetal Dodd from the Research Department and the staff of the Barwon Health Hospital Library; for your input, experience, kindness and support for 'last minute' resources.

Ainsley Hebert; thanks for being such a great role model and mentor in the formative years of my practice.

For my former colleagues of the Southland Mental Health Emergency Team: Colin, Regan, Iorrie, Susan, Nic, Steve, Deb, Shelley, Diane \& Tony; for all the call-outs to places 'where angels feared to tread,' and the wealth of experience that resulted from our time spent together. Your friendship and camaraderie helped to make SMHET one of the most influential and memorable parts of my career. 
Title Page

Abstract II

Acknowledgements

Table of Contents $\quad$ VI

List of Tables $\quad$ IX

List of Figures $\quad$ IX

Chapter 1:

Introduction 1

Positioning this study 2

Clinical Setting 2

My background 2

$\begin{array}{ll}\text { The evaluation framework } & 2\end{array}$

Research aim and focus $\quad 4$

Overview of thesis 4

Summary 5

$\begin{array}{ll}\text { Chapter } 2 \text { Literature Review } & 7\end{array}$

$\begin{array}{ll}\text { Search Strategy } & 7\end{array}$

$\begin{array}{lr}\text { Suicide } & 9\end{array}$

$\begin{array}{ll}\text { Suicide Prevention } & 11\end{array}$

$\begin{array}{ll}\text { Deliberate self-harm } & 11\end{array}$

The scope of DSH 12

$\begin{array}{ll}\text { Underlying causes for DSH } & 13\end{array}$

DSH figures and profile in Australia $\quad 14$

Staff and family reaction to DSH 14

Management of intoxication and / or aggression in the ED 15

$\begin{array}{ll}\text { Acknowledging the problems from a state-wide perspective } & 17\end{array}$

$\begin{array}{ll}\text { The Brief Intervention Program } & 18\end{array}$

Ensuring prompt access to the emergency department 19

Ensuring prompt access to a mental health assessment 21

Encourage treatment engagement and follow-up attendance 23

Teach new coping and problem solving skills 25

Treat underlying mental disorders in those who self-harm 26

Avoid approaches where there is evidence of harmful effects 27 
Summary and link to Owen's framework: 28

$\begin{array}{ll}\text { Chapter } 3 \text { Methodology and Study Design } & 31\end{array}$

$\begin{array}{ll}\text { Introduction } & 31\end{array}$

$\begin{array}{ll}\text { Background } & 31\end{array}$

$\begin{array}{ll}\text { Ethics process } & 32\end{array}$

Ethical considerations during the study 33

Methodology 34

Pluralistic methods and evaluation research $\quad 35$

Pluralistic method and program logic within an existing framework 37

$\begin{array}{ll}\text { Typical Issues } & 40\end{array}$

Use of the qualitative method for data collection $\quad 40$

$\begin{array}{ll}\text { Thematic analysis of qualitative findings } & 41\end{array}$

$\begin{array}{ll}\text { Recruiting participants } & 41\end{array}$

$\begin{array}{ll}\text { Data collection and storage } & 42\end{array}$

State of Program 42

Major focus $\quad 43$

Quantitative data sets 43

Client file data collection $\quad 44$

Data collected from PANSI $\quad 44$

Data compilation and storage $\quad 45$

Statistical analysis: rigour / validity strategy 46

Timing (vis-à-vis program delivery) 47

$\begin{array}{ll}\text { Summary } & 47\end{array}$

$\begin{array}{ll}\text { Chapter } 4 \text { Findings } & 48\end{array}$

$\begin{array}{ll}\text { Objectives-based } & 49\end{array}$

To engage clients who present with DSH behaviours into treatment 49

DSH presentations from PIMS file audit $\quad 49$

Descriptive statistics for age and gender 51

Timeframe from referral to appointment 52

Sessions attended $\quad 52$

Correlations $\quad 53$

To reduce the likelihood of further incidents of self-harm 54

Seeking support versus not seeking support $\quad 55$

Assisting clients in developing a greater understanding of DSH 55 
Positive and Negative Suicide Inventory $\quad 55$

$\begin{array}{lr}\text { Needs-based evaluation } & 59\end{array}$

$\begin{array}{ll}\text { Goal-free evaluation } & 60\end{array}$

Summary discussion of the goal-free evaluation $\quad 67$

$\begin{array}{ll}\text { Process-outcome studies } & 68\end{array}$

Age deviation from the BIP policy document 69

Change to referral process $\quad 69$

$\begin{array}{ll}\text { Change to exclusion criteria } & 70\end{array}$

$\begin{array}{ll}\text { Realistic evaluation } & 70\end{array}$

$\begin{array}{ll}\text { Performance audit } & 71\end{array}$

$\begin{array}{ll}\text { Summary } & 71\end{array}$

$\begin{array}{ll}\text { Chapter } 5 \text { Discussion } & 72\end{array}$

To determine the range and extent of the BIP's outcomes 72

Has the BIP been implemented as planned and how has the implementation affected outcomes? $\quad 73$

To provide evidence to the stakeholders how the allocated $\begin{array}{ll}\text { program resources were utilised } & 74\end{array}$

$\begin{array}{ll}\text { Methodological reflections } & 74\end{array}$

$\begin{array}{ll}\text { Implications for Nursing Practice } & 75\end{array}$

Limitations of this research 76

$\begin{array}{ll}\text { Significance of this study } & 77\end{array}$

Contribution to mental health nursing research 77

Recommendations

To inform the decision whether to replicate or extend the BIP 77

$\begin{array}{ll}\text { Suggestions for further research } & 78\end{array}$

$\begin{array}{ll}\text { Conclusion } & 78\end{array}$

$\begin{array}{ll}\text { List of Appendices } & 79\end{array}$

Appendix A: Information package to participants $\quad 80$

Appendix B: Barwon Health ethics approvals 84

Appendix C: Victoria University of Wellington ethics approval 90

Appendix D: Information package to participants 91

Appendix E: Contact and permission from Dr. John Owen 99

$\begin{array}{ll}\text { References } & 101\end{array}$ 
Table 1.1: Owen's Impact Evaluation Framework (reprinted with permission) 3

Table 2.1: Aims / Objectives of the Brief Intervention Program 18

Table 2.2: Triage tool 20

Table 3.1: Owen's Impact Evaluation Framework (reprinted with permission) 39

Table 4.1: Owen's key approaches and assembly of evidence 48

Table 4.2: Number and categories of deliberate self harm

BIP attendees $2006 \quad 50$

Table 4.3: Age group presentations $\quad 51$

Table 4.4: Range of days from referral to first BIP appointment 52

Table 4.5: Session attendance $\quad 53$

Table 4.6: Frequency of DSH within six months from first presentation $\quad 54$

Table 4.7: PANSI descriptive statistics 56

Table 4.8: Male and female pre and post PANSI 56

Table 4.9: Completed pre and post PANSI scores $\quad 57$

Table 4.10: Paired Samples $\quad 58$

Table 4.11: BIP profile of clients outside age criteria $\quad 69$

$\begin{array}{ll}\text { Table 4.12: Referral sources for BIP } & 70\end{array}$

\section{List of Figures}

Figure 1: Scatter plot of days from referral and sessions attended by clients 


\section{Chapter 1 Introduction}

Deliberate self harm $(D S H)$ and attempted suicide are a familiar clinical presentation for mental health nurse clinicians. The emergency department $(E D)$ is often the point of service entry for clients who deliberately self harm. In the $E D$, mental health nurse clinicians play a key role in providing assessment, referral and treatment to the client that has engaged in deliberate self harm. They can also provide liaison services to hospital staff and support to concerned public / family members (Sharrock, Grigg, Happell, Keeble-Devlin \& Jennings, 2006).

The role of the mental health nurse is not limited to the delivery of clinical services. Modern mental health care environments call for their participation in quality assurance and improvement activities that aim to provide the best available care to clients and their families (McMillen, Zaya, Books \& Lee, 2008). Research can be a means to identify if a particular intervention is achieving the desired outcome. To facilitate the ongoing development of mental health nursing, current research trends have emphasised areas such as professional development, practice development and the development of evaluation practices. Choosing an evaluation method to fit a particular clinical setting can be challenging amidst the variety of available research methodologies and complexities of the healthcare environment (Walsh, Duke, Foureur \& MacDonald, 2007). A major challenge faced in this study was to select an evaluation method for a local clinical program developed to reduce re-presentations of deliberate self harm to the emergency department.

By undertaking this study and accessing peer reviewed literature I increased my global awareness of the enormity of the problem of $D S H$ and suicide. According to a recent Cochrane review, (Hawton et al, 1999) certain approaches to address DSH are viewed as promising. Unfortunately, due to the insufficient numbers of patients in the study trials to date no conclusive evidence is available to indicate which approach is better than another. There is also no conclusive evidence that even offering a service to clients will reduce further act(s) of deliberate self harm. According to the World Health Organisation (2000a) what is conclusive is that global presentations of $\mathrm{DSH}$ and attempted suicide are on the increase and have become a major public health concern to be addressed by health care providers and the general community. 


\section{Positioning this study}

\section{Clinical Setting}

This study takes place in a regional public funded mental health service in Victoria, Australia. In 2005, a local program was developed to provide a follow up service to clients who presented with or were at risk of engaging in deliberate self harm. The Brief Intervention Program $(B I P)$ was based on current clinical practice guidelines for clients that present with or are at risk of deliberate self harm. The psychiatric triage service based out of the $E D$ was initially the sole referral source for the new Brief Intervention Program. After the program had been running for a year, stakeholders of the BIP, namely hospital management and psychiatric triage clinicians began to question how this program could be evaluated for effectiveness. The opportunity to conduct this study resulted from the question: How could a program that was already established be evaluated?

\section{My Background}

My interest in this study culminated from being one of the mental health triage clinicians that referred clients to the Brief Intervention Program. I have been working in the mental health field nearly 20 years and 15 of these years have been as a Registered Psychiatric Nurse. My roles have included being a community mental health clinician in a remote northern Canadian community, working on crisis and therapy teams in New Zealand and more recently as a psychiatric triage clinician based out of the $E D$ in a regional Australian city. Over the past four years I have pursued post graduate studies and have also moved into a Clinical Nurse Educator role. This study provided an opportunity to pursue my Master's Degree in Nursing and to identify a framework that would be suitable to evaluate a clinical program that I was associated with.

\section{The evaluation framework}

Evaluating a program involves many lines of enquiry that may have an influence on future planning, delivery and / or sustainability. For the purposes of this study, a program evaluation approach was selected to construct the process of evaluating preexisting data collected from BIP clinical work. The main focus of the study is to evaluate the program through mixed method analysis of existing quantitative and collected qualitative data sets. 
Following some significant deliberations regarding methodology, this study was based upon John M. Owen's multi-dimensional framework (see Table 1.1) for conducting an Impact Evaluation (Owen, 2006). The evaluation framework consists of seven dimensions- orientation, typical issues, state of program, major focus, timing (vis-à-vis program delivery), key approaches and assembly of evidence. The properties section(s) attached to each dimension provide a description of each step and form the line of questioning for each step of the approach. It is important to note that Owen refers to his method as a form / approach. For the purpose of clarity and consistency, the term framework will be used throughout this study when referring to Owen's work.

\section{Table 1.1: Owen's Impact Evaluation framework}

\begin{tabular}{|c|c|}
\hline Dimension & Properties \\
\hline Orientation & $\begin{array}{l}\text { - } \text { Establishment of program worth } \\
\text { - Justification of decisions to mount the program } \\
\text { - } \\
\text { Accountability to funders and other stakeholders }\end{array}$ \\
\hline Typical issues & $\begin{array}{l}\text { - Has the program been implemented as planned? } \\
\text { - Have the stated goals of the program been achieved? } \\
\text { - Have the needs of those served by the program been met? } \\
\text { - } \quad \text { Does the implementation strategy lead to intended outcomes? } \\
\text { - How do differences in implementation affect program outcomes? } \\
\text { - What are the benefits of the program given the costs? }\end{array}$ \\
\hline State of program & Settled \\
\hline Major focus & $\begin{array}{l}\text { Focus on delivery and/or outcomes. Most comprehensive studies combine both } \\
\text { delivery and outcomes known as process-outcome studies }\end{array}$ \\
\hline $\begin{array}{l}\text { Timing (vis-à-vis } \\
\text { program delivery) }\end{array}$ & $\begin{array}{l}\text { Nominally 'after' the program has completed at least one cycle with program } \\
\text { beneficiaries. In practice, impact studies could be undertaken at any time after } \\
\text { program is 'settled'. }\end{array}$ \\
\hline Key approaches & $\begin{array}{ll}\text { - } & \text { Objectives-based } \\
\text { - } & \text { Needs based } \\
\text { - } & \text { Goal-free } \\
\text { - } & \text { Process-outcome studies } \\
\text { - } & \text { Realistic evaluation } \\
\text { - } & \text { Performance audit }\end{array}$ \\
\hline $\begin{array}{l}\text { Assembly of } \\
\text { evidence }\end{array}$ & $\begin{array}{l}\text { Traditionally required use of pre-ordinate research designs, where possible the } \\
\text { use of treatment and control groups, and the use of tests and other quantitative } \\
\text { data. Studies of implementation generally require observational data. } \\
\text { Determining all the outcomes requires use of more exploratory methods and the } \\
\text { use of qualitative evidence. }\end{array}$ \\
\hline
\end{tabular}


Note: From Program evaluation forms and approaches $3^{\text {rd }}$ edition (p.254), by J.M.

Owen, 2006, Crows Nest, NSW, Australia: Allen \& Unwin. Copyright 2006 by J.M.

Owen. Reprinted with permission.

\section{Research aim and focus}

The Impact Evaluation framework is used in this study:

- to determine the range and extent of the Brief Intervention Program's outcomes

- to ascertain whether the $B I P$ was implemented as planned, and how changes in the implementation affected outcomes

- to provide evidence to the stakeholders how program resources were used to inform the decision whether to replicate or extend the Brief Intervention. Program.

\section{Overview of thesis}

This chapter is a general introduction to the study providing an overview of the clinical setting and positioning of the study. Although this study places an emphasis on the topics of deliberate self harm, suicide and the Brief Intervention Program, the primary aim of the study is to evaluate the effectiveness of the program through the use of a prescribed evaluation approach.

In Chapter Two, the Literature Review I describe the Orientation dimension of Owen's Impact Evaluation approach. Initially the Literature Review emphasises the topics of suicide and deliberate self harm. The information from the literature review supports the logic for providing a program aimed at reducing re-presentations of $D S H$, helps to establish the program's worth and to justify the decisions to mount the program. The literature review also focuses on the Brief Intervention Program and the clinical practice guidelines that it was designed upon. Adherence to practice guidelines and links to other state initiatives demonstrates the program's accountability to funding streams i.e. state government and other stakeholders.

Chapter Three sets out the methodology and justifies the selection of the pluralistic study design. The Impact Evaluation approach is essentially a pluralistic study design that informs the line of questioning used to evaluate the Brief Intervention Program. Throughout the chapter the next four dimensions of Owen's approach-typical issues, state of program, major focus and timing (vis-à-vis program delivery) are discussed. 
These dimensions are important in relation to the data collection and analysis in this study. This will involve an exploration of the program's method of delivery and measurement of outcomes through mixed sets of quantitative and qualitative data. With the exception of the data extracted from the questionnaire to clinical staff, the data utilised was retrospective in nature.

Chapter Four focuses on the study findings in relation to Owen's six prescribed impact evaluation approaches- objectives-based, needs based, goal-free, process-outcome studies, realistic evaluation and performance audit. A description of each of these approaches will accompany each heading as it appears in the chapter. Of the six approaches, three were found suitable for application in this study.

Chapter Five provides a reflection about the methodology. There is a limited scope and timeframe allocated for this study and the limitations of this research will be discussed. Implications for nursing practice and the significance of this study will also be discussed in relation to contributions to the fund of knowledge for mental health nursing. Recommendations for the stakeholders of the BIP will conclude the study.

\section{Summary}

Evaluation of programs is an important part of health service delivery. Increasingly services are expected to monitor and provide evidence that programs they are providing are effective and achieving the desired outcomes. This chapter was a general introduction to the study entitled: Impact evaluation of a 'brief intervention program' for clients who deliberately self harm. Although this study places an emphasis on the topics of deliberate self harm, suicide and the brief intervention program, the primary aim of the study is to evaluate the effectiveness of the program through the use of a prescribed evaluation approach.

In the next chapter the Literature Review forms an important link between suicide and the many different types of $D S H$ presentations. Clients who $D S H$ are at greater risk for repeated attempts and at a higher risk to eventually complete a suicide. The statistics from a local and global perspective regarding suicide and $D S H$ will be discussed to highlight the extent of the problem and its impact on health services and communities. This information supports the rationale given by the regional service to developing and 
implementing the $B I P$ to address the needs of clients that were at risk of or had engaged in $\operatorname{act}(\mathrm{s})$ of deliberate self harm.

An emphasis is placed on local policy, initiatives and clinical practice guidelines that helped to guide the development of the Brief Intervention Program. The Royal Australian and New Zealand College of Psychiatrists guidelines will be used in the chapter to form the headings for discussion of the many aspects of the BIP and the relevant links to the literature. Under these headings is discussion pertaining to the variety of short-term treatments suggested for $D S H$ and the continued need for further studies in this area of concern. 


\section{Chapter 2 Literature Review}

In Chapter One the topic of evaluation was introduced along with the evaluation framework and an overview of the chapter content contained in this study. In following Owen's (2006) Impact Evaluation framework (see p.3), the evaluation process begins by establishing the program's worth, justifying the decisions to mount the program and being accountable to the funding stream and stakeholders of the program.

The literature review helps to justify why the clinical service area made the decision to establish the Brief Intervention Program and therefore why an evaluation framework was sourced to do this. The topics of suicide and deliberate self harm are explored and differentiated to give evidence to their tremendous impact on the individual, their family and the wider community.

The literature review will also focus on the Brief Intervention Program and the clinical practice guidelines that it was designed upon. What I found interesting was that the BIP and the psychiatric triage service were closely aligned to the suggested clinical practice guidelines for management of $\mathrm{DSH}$ and other state initiatives suggested for improving service response to mental health clients. The adherence and close alignment to relevant literature helps to demonstrate the program's accountability to funding streams i.e. state government and other stakeholders.

\section{Search Strategy}

The first step of the literature review consisted of reviewing full-text journals available through the regional hospital's library service. I relied heavily upon the Clinicians Health Channel search engine that provided valuable links to full text journals through Ovid. The Clinicians Health Channel provided links to databases that included Cochrane, CINAHL, Medline, Publisher and ProQuest. Broad search terms that were used included: emergency department, deliberate self harm, self injury, suicide, impact and evaluation.

The people written about in this study ranged in age from 16 to 65 years. In Victoria mental health services, this age range constitutes the adult client group. The articles in the search strategy were selected on the basis that the information was pertinent to the adult mental health population. The search also focused on articles about adult 
presentations to the $E D$ with a mental health focus. By using the broad search terms of emergency department, deliberate self harm and self injury I sourced several articles and identified a number of themes. I also used the terms 'mental health' and 'psychiatric' in combination with the broad search terms which I found helpful to search for articles.

The themes that emerged from the articles included descriptions of $D S H$, practice guidelines for management, treatment suggestions and staff / client / family attitudes about treatment. A number of relevant state government policy documents were also located on the Victorian Government Department of Human Services website and cited in this study.

Owing to the enormous amount of material available on the subject of suicide the search was limited to general information about the topic. Many of the aforementioned peer reviewed articles made reference to the World Health Organisation's (WHO) suicide prevention programs and statistics. I found that this information was useful in providing background information to illustrate the extent that suicide affects the global population. A national study was also sourced pertaining to suicide and $D S H$ presentations to emergency health services. The information from this study helps to position the impact of $D S H$ and suicide in Australia.

The information sourced for the topic of deliberate self harm focused on articles that gave descriptions of $\mathrm{DSH}$ and treatments indicated for clients that engage in this behaviour. Significant articles included the Cochrane review entitled Psychosocial and pharmacological treatments for deliberate self harm (Hawton et al., 1999) and the Summary Australian and New Zealand clinical practice guideline for the management of adult deliberate self-harm (Boyce, Carter, Penrose-Wall, Wilhelm, \& Goldney, 2003). What was significant about these articles for this study is that citations from the Cochrane Review were relevant to this study and sourced for their original content. This included the use of manual searching and an interstate loan on one occasion from New South Wales.

The Royal Australian New Zealand College of Psychiatrists (RANZCP) clinical practice guidelines described by Boyce et al (2003) were used by the service to guide the creation of the Brief Intervention Program. The RANZCP set guidelines consist of six 
practice recommendations. In the latter half of this chapter each recommendation will be used to explain how the $B I P$ attempts to follow the RANZCP guidelines.

The information that was sourced pertaining to program evaluation was selected on the basis that it could be applied to discussion in a health context. Some of the articles selected had a distinct mental health nursing focus that promotes the use of mixed design methods for research purposes in the mental health sector. This information will be discussed further in Chapter Three. The most influential resource in the topic area of evaluation came from Owen's book entitled Program evaluation: Forms and Approaches $3^{\text {rd }}$ Edition (2006). As mentioned previously, the Impact Evaluation framework will be used to guide the line of questioning and overall structure of this study.

Reflecting on the search strategy in relation to the topics of $D S H$ and suicide, I noted that a trend existed in the literature in differentiating the two topics. The main difference between the two relies on the client's intention whether to end their life or to engage in an act of $D S H$ in response to psycho-social distress. The factors leading up to either form of attempt are incredibly complex as are the suggested strategies to assist individuals that are at risk to engage or re-attempt in acts of $D S H$ or suicide. I will begin this discussion by providing some general facts regarding suicide.

\section{Suicide}

It is important to acknowledge that suicide and deliberate self harm are different clinical presentations. To differentiate between the two presentations often involves complex lines of questioning and understanding about the individual's circumstances that lead to either an attempt to end their life or to self harm in response to psycho-social distress. Notwithstanding these different presentations the extent of the problem of suicide is globally well documented.

According to the WHO (2000b) the statistics gathered from the 2000 WHO SUPREMISS (World Health Organisation Suicide Prevention Multi-site Intervention Study on Suicide Behaviours) initiative suggested that in the year 2000, approximately one million people had died from suicide. This indicates a global mortality rate of 16 people per 100,000 . Another way to put this figure in perspective is that a death by suicide occurred every 40 seconds that year. Over the last 45 years suicide rates have increased 
by $60 \%$ worldwide. Suicide is now among the three leading causes of death among both sexes for those aged 15-44 years.

By comparison, in Australia the 1998 suicide rate per 100000 population was 14.3. In 2007, the rate per 100000 had dropped to 8.9. Suicide is currently ranked as the fifteenth leading cause of death in the country. By comparing the causes of death between men and women however, suicide jumped in rank to being the tenth leading cause of death in males. There were 1881 suicide deaths reported in 2007 with $77 \%$ of these deaths occurring in the male population. The median age for suicide death in males was 41.7 and 44.5 years for females (Australian Bureau of Statistics (ABS), 2009).

According to the WHO (2000c) traditionally suicide rates have been highest among the male elderly. Comparably in Australia, the ABS (2009) reported a similar finding with the highest age specific suicide rate being males aged 85 years and older accounting for 23 deaths per 100,000. The ABS also notes that this number is relative to the low population numbers that exist within this age group. Alternatively, the WHO notes that rates among young people have been increasing to such an extent that they are now the group at highest risk in a third of both developed and developing countries. The Australian statistics also indicate that males aged 15 to 24 years of age are an increased high risk group as suicide accounted for 20.2 percent of the cause of death within this age group.

The WHO (2000c) estimates that suicide represented $1.8 \%$ of the total global burden of disease in 1998 and $2.4 \%$ in countries with market and former socialist economies in 2020. Mental health disorders (particularly depression and substance abuse) are associated with more than $90 \%$ of all cases of suicide. The WHO indicates that these figures do not include the suicide attempts that amount to 20 times more in frequency than completed suicide attempts. This view is also shared by Repper (1999) who argues that people who have engaged in act(s) of $D S H$ are at a greater risk for completed suicide at a future date. Morgan, Coleman, Farrar, Hill, Kerfoot, and Williams (1994), in their thematic review for the NHS Health Advisory Service reported that 30 to $40 \%$ of suicides have a previous history of deliberate self harm. There is a one percent chance that those who engage in $D S H$ will complete suicide in the following year. In the subsequent ten years following the initial $D S H$ attempt, this percentage increases to 
between three to ten percent. Isacsson and Rich (2001) also indicate that in reference to suicide statistics that non-fatal act(s) of $D S H$ may be 20-40 times more frequent than completed suicides, similar to the estimate previously mentioned by the World Health Organisation.

\section{Suicide Prevention}

Respective of the statistics and acknowledgement of the severity and impact of suicide on the world population, it is prudent to not only ask the question, what can be done to address this problem, but in more practical terms, how could it be done?

The National Research and Development Centre for Welfare and Health, Helsinki, Finland conducted a study that summarised "practical interventions" for suicide prevention. According to Upanne (2001) the author of the study, suicide prevention means that interventions need to help the people that are in crisis situations or in a suicidal crisis. The interventions need to be delivered by proposed and existing services that are based on efficiency and geared towards prevention strategies. These interventions need to provide support to survivors such as the family and / or carers, and also care for those who have attempted but not completed a suicide attempt. Upanne further made suggestions aimed at organising, improving and providing services through training and professional skills. She advocated for an attitudinal shift by caring through practical interventions and collaboration between professionals, services and the public.

Based on these suggestions and the previous information, whether or not an individual has a fatal outcome to a suicide attempt, there must be an acknowledgement of the psycho-social impact it has upon the individual, their families and wider community. In a clinical setting, the challenge exists in identifying individuals who have made a $D S H$ attempt and then to engage them in some form of follow up intervention. In order to identify clients that $\mathrm{DSH}$, it is important to have an understanding of the language used to describe $D S H$ across the clinical setting.

\section{Deliberate self harm}

There are many terms used in clinical environments and in published literature to describe deliberate self harm. According to Isacsson and Rich (2001) DSH is not an illness but rather "any act by an individual with the intent of harming himself or herself 
physically which may result in some harm" (p.213). Isacsson and Rich also indicate that the terms attempted suicide or parasuicide have been used interchangeably to describe $D S H$ and suggest that attempted suicide should be restricted to describing cases where a fatal intent is assumed. The use of the term suicide indicates that a fatal outcome has occurred. In other words, the term suicide is used if the individual had the intention to kill themselves when performing the attempt.

In my clinical experience of assessing clients following a $D S H$ attempt, it was not uncommon for a client to have had a "change of heart" during the attempt and make active efforts to either abort the attempt i.e. to prevent loss of consciousness or asphyxia during a hanging attempt or to seek urgent medical attention amidst an arterial bleed from a self inflicted laceration. In other instances, clients have sought medical attention following a lethal overdose of medication such as Amitriptyline or Sodium Valproate. To my understanding, the use of the term parasuicide is appropriate to be used in such cases.

\section{The scope of DSH}

By description, acts of $D S H$ may include cutting, poisoning (either by ingestion and/or inhalation), burning, jumping and/or hanging. Lethal acts of $D S H$ would include impaling, electrocution, shooting or self-immolation (intentionally lighting oneself on fire), (Brakoulias, Ryan \& Byth, 2006). According to McAllister (2003), "self harm may be defined as any act that causes psychological or physical harm to the self without a suicide intention, and which is either intentional, accidental, committed through ignorance, apathy or poor judgement” (p.178). Some forms of $D S H$ can have permanent effects on an individual. For example, "carbon monoxide $(\mathrm{CO})$ poisoning has the toxic effects of tissue hypoxia and produces various systemic and neurological complications" (Choi, 2001, p.253). Reiland, Hovater, McGwin, Loring, and Cross, (2006) indicate that self-inflicted burn clients have very poor health outcomes, mainly due to pre-existing mental health, social and economic problems that impede recovery. Mulholland et al (2008) found that the group who self-harmed by burning were more likely to have psychotic symptoms and receiving psychotropic medication and psychiatric inpatient care at the time of the $D S H$ attempt.

McAllister (2003) compares the terms self harm and self injury indicating that the most common form of self harm is drug overdose. Self injury is a form of self harm leading to visible direct bodily injury, i.e. scratching, cutting, scalding, burning, and injurious 
insertion of objects into the body. Also adding to this list are picking, substance abuse, starving or binging / purging, hair-pulling, self flagellation, eating glass, bone-breaking, joint dislocation, head-banging, genital mutilation / castration, eye enunculation and limb amputation. Deliberate self harm can also include: risk-taking behaviour such as excessive drinking, smoking or eating, unprotected sex with multiple partners, sadomasochism, reckless driving, self neglect of hygiene or health and the provocation of violence to draw self harm (Bohn \& Holz, 1996; Osuch, Noll \& Putnam, 1999; Middleton \& Butler 1998).

\section{Underlying causes for DSH}

McAllister's (2003) critical review of DSH highlighted that there are many facets for consideration to develop an understanding of its cause and / or incidence. She notes that deliberate self harm may be a symptom of an existing mental disorder such as a mood, anxiety, psychotic or personality disorder. In the case of for example, personality disorders, there are limitations to medical interventions as the underlying psychological issues may not be addressed within the hospital setting. McAllister (2003) continues that deliberate self harm may be the result of childhood abuse, neglect and / or trauma and broadens the need for understanding $D S H$ from a psychodynamic, behavioural and bio-social perspective. She also points out that an individual's self identity or cultural identity must be also be taken into account, while taking care not to pathologise cultural / sub-cultural rituals associated with certain demographic groups i.e. body piercing and / or tattooing. McAllister (2003) then identifies that a gender issue exists as DSH appears three to four times more common in women than men. This issue could be linked to the western societal belief that females externalise their emotions by acting upon themselves whereas men are more likely to displace their emotions onto others for example by physically harming someone else.

The dynamics inherent in any act of $D S H$ as suggested by McAllister (2003) draws attention to the difficulties and challenges in the understanding required to address the needs of clients who deliberately self harm. Each client is an individual with various life experiences that have moulded and sculpted their view of the world, their perceptions, perceived sense of role / identity, and of how they cope amidst psycho-social stress. Owing to the serious nature of any self-harm attempt, immediate care is sought by the individual, family and/or emergency medical service personnel resulting in presentations to the nearest health care facility / emergency department. 


\section{DSH figures and profile in Australia}

According to Steenkamp and Harrison (2000) the national data on hospitalised selfharm indicated a total of 25,120 episodes of hospital care concluded during the 1997 / 98 financial year. This yielded an age-standardised rate of 137.5 per 100000 population. This is a significant contrast to the previously mentioned 14.3 per 100,000 population suicide statistic from the ABS (1999), for the 1998 year. Of the total number of episodes of $\mathrm{DSH}, 43 \%$ were males with the age-standardised rate being 116.9 per 100,000. The equivalent rate for females was higher being 159.0 per 100,000 population. The $D S H$ rate for females was significantly higher than the rate for males for all age groups from 10 to 14 years to 50 to 54 years, except for the age group 30 to 34 years.

Poisoning by solid or liquid substances was the most common method used among deliberate self-harm hospital presentations with males at $70 \%$ and females at $85 \%$. Poisoning by tranquillisers accounted for $37 \%$ of all male and $47 \%$ of all female hospital presentations due to intentional self-harm by poisoning. Poisoning by aromatic analgesics (the category which includes paracetamol) was the most common means for females aged 10 to 19 years of age. This data pertains to non-fatal outcomes of clients as they had left hospital following their $D S H$ attempt.

\section{Staff and family reaction to $\mathrm{DSH}$}

Literature acknowledges the comparable challenges faced by local services and the impact upon healthcare staff faced with the care and at times containment of $D S H$ patients in the emergency department setting. In a recent literature review about $E D$ staff reactions to suicidal and self-harming patients Pompili et al (2005) found:

Staff in the emergency departments of hospitals are reported as being negative or ambivalent...these patients are subjected to stigmatisation and lack of empathy...this phenomena has been linked to a decreased quality of care offered to these individuals and to missing an important opportunity to prevent further suicidal behaviour or repetition of deliberate self harm. (p.169)

Clark (2002), states that $D S H$ is a somatic language that uses the body instead of words or feelings. Clark indicates that "staff who care for victims of self harm often do not have the time or skills required to translate this language" and "are often overwhelmed 
with concerns about risk management" (p. 788). According to McKinlay, Couston, and Cowan (2001), "nurses' own attitudes, and what they believe about the attitudes of others, predict their behavioural intentions towards self-poisoning patients." Also "that nurses with a more positive orientation towards self-poisoning patients differ in behavioural and normative beliefs from nurses who have a less positive orientation" (p.107).

The literature suggests that the staff response to clients that $D S H$ may be based upon their own positive or negative attitudes regarding suicide, parasuicide and mental illness. This in turn will affect not only their interactions with the client, but also the referral to appropriate follow-up care.

The response by healthcare professionals can also impact on the family members supporting the $D S H$ client. Cerel, Currier, and Conwell (2006) report in their study that:

The majority of consumers and family members felt that staff addressed their ethnic and cultural issues appropriately, saw them in a timely manner and did not use jargon or words that they did not understand. At the same time, fewer than $40 \%$ of consumers felt that staff listened to them, their story or version of events, described the nature of treatments, or took their injury seriously. While family members were more likely than consumers to feel heard or to receive information about treatment, less than two-thirds of family reported these experiences. More than half of consumers and almost a third of family members felt directly punished or stigmatised by staff. (p.346)

The comments from staff, family and consumers in published literature are not dissimilar to my experience of addressing concerns regarding clients that have engaged in $\operatorname{act}(\mathrm{s})$ of $D S H$ and presenting for services.

\section{Management of intoxication and / or aggression in the ED}

Camilli and Martin (2005) state that "emergency departments are overcrowded and many healthcare workers complain they are overworked and the overall patient care is compromised" (p.313). They continue to raise the question of whether intoxicated or mentally ill clients that present to the emergency department receive 'adequate care' due to staff reactions to the management strategy of containing or 'boarding' these clients 
until a more appropriate treatment area is available. George, Durbin, Sheldon and Goering (2002) indicate that although the most seriously mentally ill are admitted to inpatient psychiatric beds, a large number of presentations are held in the emergency department until resources become available, adding to the stress levels of staff and patients.

Locally, there is an expectation upon emergency department staff to contain clients who are intoxicated before a comprehensive mental health assessment can be performed. Often, clients who have engaged in an act of $\mathrm{DSH}$ also present under the influence of drugs and / or alcohol. There is a high likelihood that they will attempt to leave the department or will refuse necessary medical treatment. Crawford and Wessely (1998) suggest that clients that discharge themselves before completion of initial treatment have a higher likelihood of re-presentation for deliberate self harm. This will raise the issue of assessing the client's capacity to refuse treatment and the potential for serious medicolegal consequences. In their clinical review, Hassan, MacNamara, Davy, Bing, and Bodiwala (1999) state that "doctors must balance the necessity of emergency medical treatment and their duty of care against the patient's autonomy based on his or her capacity" (p.107). One of the many roles of the psychiatric triage team is to advocate proper usage of mental health legislation when a client's capacity or judgement is held in question.

Legally, it is considered unlikely that an intoxicated individual be 'recommended' for involuntary psychiatric examination and treatment. Under the Victoria Mental Health Act 1986, Section 8(2)(k) prevents the use of the Act to deem a person as mentally ill based solely on simple intoxication or usage of drugs / alcohol. Under the circumstances when a client refuses necessary treatment, it can be enforced under a "duty of care." In extraordinary circumstances, this may warrant the use of mechanical restraints in order to provide acute medical treatment to individuals requiring detoxification, or are at risk of a medical emergency and / or death. "Duty of care" is separate from the Mental Health Act, allowing medical practitioners the power to treat (Wand, 2004). The management and treatment of clients under these conditions can prompt agitation and aggression towards clinical staff. The use of sedatives such as benzodiazepines can be useful in de-escalating aggression and impulsivity displayed by $D S H$ clients in the $E D$ when efforts to establish rapport or to negotiate cooperation are unsuccessful (Allen, 2000; Fish, 2002; Humble \& Berk, 2003). 


\section{Acknowledging the problems from a state-wide perspective}

In November 2004, the Victoria Department of Human Services (DHS) acknowledged the various concerns about mental health presentations addressed by emergency services. Stakeholders that included service users, police, emergency services, DHS and hospital managers / clinical staff were invited to a forum to discuss the many issues. Over 150 participants from rural and metropolitan services attended the forum from across the state (DHS, 2006a).

The forum identified four concerns specific to mental health presentations to the $E D$. The concerns being: (1) appropriate diversion to community resources, (2) management of dual diagnosis or mental health and drug / alcohol presentations involving medical treatment, (3) coping when resources are limited, i.e. partnerships with other hospitals for use of available mental health beds and (4) linking and encouraging clients to utilise ancillary services for improving the outcome of their general health (DHS, 2006a). These discussions brought attention to the mounting pressure on emergency department settings to provide broad services to mental health and drug / alcohol clients.

It is important to clarify that the mental health services being discussed pertain to all aspects of mental health care; not just $D S H$, but also issues of homelessness, substance abuse / withdrawal, voluntary / involuntary mental health act cases, intoxication / withdrawal states, delirium and acute crisis presentations. Locally the discussions and planning for a Brief Intervention Program were devised to target and reduce repeat presentations of $D S H$ to the local emergency department. The planned program was to be an alternative service for $D S H$ clients, with the intention of a timely short-term approach. Further, the program was to be based on the principles of best practice for this client group.

The focus of this chapter thus far was to explore and differentiate the topics of suicide and deliberate self harm and to provide to evidence about the tremendous impact these issues have upon the individual, their family and the wider community. The presented literature helps to justify why the clinical service area made the decision to establish the Brief Intervention Program. The literature review will now place a focus upon the BIP's history, aims and objectives and the clinical practice guidelines that it was designed upon. 


\section{The Brief Intervention Program}

The Brief Intervention Program or BIP evolved from discussions among Barwon Mental Health clinical and management stakeholders in spring 2005. The focus of these discussions was about providing a follow up service for clients attending the regional hospital's emergency department following an act of deliberate self harm. In September 2005, the program became a reality, beginning with the construction of a service based Policy / Procedure and Guidelines Manual. The BIP service manual outlined areas such as: program aims, clinical outcomes, referral pathways, inclusion / exclusion criteria, evaluation, and model of practice and these are discussed throughout this chapter. The program aims and clinical outcomes are illustrated in the following table:

\section{Table 2.1}

\section{Aims / Objectives of the Brief Intervention Program}

- To engage clients who present with DSH behaviours into treatment

- To reduce the likelihood of further incidents of self-harm

- To assist clients in developing a greater understanding of the factors that may have precipitated or contributed to the DSH

- To assist clients in developing increased problem solving, coping skills and a greater understanding of the factors that may protect them from further incidents of selfharm

- Provision of education and information to clients and their family/significant others about DSH and its management

- In consultation with clients and their family/significant others, to formulate a crisis prevention / risk management plan

- Referral of clients to other appropriate services for ongoing treatment, counselling or support as required.

\section{Expected Clinical Outcomes}

Clients referred to the BIP would:

- Experience reduced incidents of self-harm

- Experience a decrease in the level of suicidality

- Develop more adaptive coping strategies

- Experience an increase in self-esteem and a decrease in negative feelings, including: depression and hopelessness. 
Note: [The information in Table 2.1 is adapted from] Brief intervention program clinical guidelines and procedural manual September 2005 (p.2), by B. Fallon, 2005, Geelong: Psychiatric Triage / Consultation and Liaison Team. Adapted with permission.

As previously stated, the program's inception was guided by the 2003 Royal Australian and New Zealand College of Psychiatrists $(R A N Z C P)$ Clinical Practice Guideline for the Management of Adult Deliberate Self-Harm (Boyce, Carter, Penrose-Wall, Wilhelm \& Goldney, 2003). Boyce et al suggested six key practice recommendations being:

- Ensure prompt access to the emergency department

- Ensure prompt access to a mental health assessment

- Encourage treatment engagement and follow-up attendance

- Teach new coping and problem-solving skills

- Treat underlying mental disorders in those who self-harm

- Avoid approaches where there is evidence of harmful effects. (pp.153-154)

The region's existing Psychiatric Triage / Consultation and Liaison (C \& L) service provided the entry point from which the BIP referrals were made. The two services dovetail together and compliment the RANZCP practice guidelines for the management of $D S H$ in the service. For the remainder of this chapter, the six practice guidelines will be used as headings to guide the discussion of the literature as it pertains to the Brief Intervention Program.

\section{Ensuring prompt access to the emergency department}

The Brief Intervention Program initially received referrals exclusively from the Psychiatric Triage service based out of the regional hospital's emergency department. As described in the previous literature, presentations of deliberate self harm, intoxication and aggression are commonplace in the Emergency Department. From a state-wide perspective, this trend of presentations was discussed in a research project about mental health presentations to emergency departments by the Victoria Government Department of Human Services or more commonly referred to as DHS. Five Victoria hospitals were involved in the project, including the regional hospital in this study. According to DHS (2006b) the emergency departments of all the major hospitals have developed an increasingly significant role in providing crisis services to 
those with mental health issues. The Department of Human Services acknowledged that the $E D$ was the initial point of contact for numerous first time service users, clients needing out of hours services, presentations brought in by the police for involuntary assessment, treatment and containment (if psychiatric beds were unavailable), referrals from the primary or public sector and specific to the $B I P$; clients attending following a $D S H$ attempt. Many of the DSH attempts also involved contact with the police and / or ambulance service for transport.

In order to quickly identify and refer mental health presentations at the $E D$, another DHS initiative entitled the Victorian Emergency Department Mental Health Triage Project 2005-2006 was introduced to aid mental health clients in receiving a prompt response when attending the emergency department. The Department of Human Services together with the National Institute of Clinical Studies (NICS) developed a tool that complimented the existing Australian Triage Scale or ATS currently in use across the country. The project produced a learning package that consisted of a tool that gave descriptions of mental health presentations. The intention of the project was to aid $E D$ staff in building up their confidence, assessment and response skills for working with mental health clientele that presented to the emergency department (National Institute of Clinical Studies (NICS) \& Victorian Department of Human Services, 2007). The aforementioned triage tool has a rating scale from 1 to 5 and the key points are illustrated in Table 2.2.

Table 2.2 Triage Tool

Triage Description

Code

1

2

3

4

5
Definite danger to life (self or others)

Probable risk of danger to self or others

Possible danger to self or others

Moderate distress

No danger to self or others
Treatment

Acuity
Immediate

Emergency; within 10 min.

Urgent; within 30 min.

Semi-urgent; within 60min.

Non-urgent; within 120min. 
(Victorian Department of Human Services, 2007, p.6)

These state-wide initiatives are expected to guide emergency department staff in directing clients/ families towards prompt interface with mental health services. It is suggested that structured training regarding identification and management of mental health client presentations will help to assist and empower $E D$ staff in their role and service provision (Allen, Williamson, Gatford \& Worthington, 1997; Bennett, Daly Kirkwood, McKain \& Swope, 2006). In my experience the triage tool has been an effective means of interfacing promptly and efficiently to mental health referrals by $E D$ staff.

\section{Ensuring prompt access to a mental health assessment}

In their study regarding the management and assessment of $D S H$ clients in the $E D$, McElroy and Sheppard (1999) indicate that, "the confidence and conviction with which $(E D)$ staff approached assessment varied considerably, and was often dependent upon time, intuition and personal bias; in general, the process was neither consistent nor comprehensive" (p.4.) Another study suggests that ED medical staff were more likely to focus on immediate risk factors rather than background factors like the client's social situation or history of existing psychopathology (Cooper, Lawlor, Hiroeh, Kapur \& Appleby, 2003).

The approach taken by the regional service is structured and consistent. In response to the mental health triage code allocated by the $E D$ triage nurse, a mental status examination (MSE) and risk assessment are performed by the psychiatric triage clinician responsible for assessing the client at the emergency department. The psychiatric triage clinician provides valuable clinical assessment, consultation and networking with internal and external agencies to address the service needs of the client, staff, families and the broader community (Heslop, Elsom, \& Parker, 2000; Williams et al, 1998). Mindnich and Hart (1995) describe this assessment process as being holistic, with mental status examinations that place an emphasis on suicide assessment, management (in the $E D$ or community) and identification of safety issues.

Equally as important is the focus upon the client's physical presentation, state of general health and displayed behaviour to identify i.e. if symptoms of delirium are the primary concern. The triage clinician has ready access to a psychiatric registrar and psychiatric 
consultant during working hours and an on-call psychiatric consultant outside of general working hours. The medical support provides clinical consultation and support as required to the clinician when planning intervention and discharge plans. The out of hours phone support enhances the clinician's level of responsibility and autonomy in a fast paced and challenging work environment.

When performing a mental status examination, a clinician undertakes a systematic inquiry into signs and symptoms at the time of the interview, combined with a structured record of pertinent observations. This covers such functions as general appearance and behaviour, affect (range of expressiveness), mood (both described and observed), speech quality (rate, tone, flow and volume), thought process (establishing if there are problems with formation of thoughts and / or language), thought content (presence of primary or secondary delusions), perceptual disturbance (hallucinations or dissociation), cognition (problems with memory and / or orientation) and judgement / insight (whether the client is aware if they are mentally unwell, impulsive and / or vulnerable) (Block \& Singh, 2001).

In combination with an MSE, the clinician will also perform a risk assessment. Part of the psychiatric triage clinician's role is to enter into discussions with $E D$ medical and nursing staff to obtain vital information from the primary assessments. The clinician couples this information with (if available) file information from existing local and state-wide mental health databases to get a brief yet detailed clinical history and account of the referred client. A notable publication by the New Zealand Ministry of Health (1998) entitled Guidelines for clinical risk assessment and management in mental health services has been used as a reference for clinical teaching tools for risk assessment within the regional service. According to the risk assessment guideline, it is useful to portray the circumstances that lead to a situation of increased risk. This requires a detailed (clinical) picture of the individual, the characteristics and course of the illness, details of circumstances and situations where particular behaviours or problems arise / have arisen, effective / ineffective interventions, and previous outcomes. A plan of management, based on this information, should aim to minimise risk and strike a balance of risks to the individual and to others. 
According to the guidelines a risk formulation should also cover key areas such as:

- Is the client an imminent risk for self harm or to harm others?

- Is the client a high risk for impulsive actions based on certain situational / environmental factors?

- Is the client at risk for deterioration and / or vulnerable to being exploited by others?

The comments regarding risk factors ideally should be rated as low, medium or high in relation to other factors such as environment, culture, family, support systems and other protective factors.

\section{Encourage treatment engagement and follow-up attendance}

Following the MSE and risk assessment being performed by the psychiatric triage clinician, the outcome of the assessment determines whether the client requires a referral to an inpatient or community service. It is at this point that the clinician determines whether the client meets the criteria for a BIP referral. Access and referral to $B I P$ is determined by the client's age and contact to the mental health service via psychiatric triage at the emergency department.

The inclusion criteria for the BIP states that the:

(1) Age range for clients is between 18-64 years (inclusive). This age range represents the boundaries between the regional youth and aged care services, making the $B I P$ an adult specific program.

(2) Clients who present to the $E D$ following an incident of $D S H$ or who are at risk of $D S H$ are candidates for a $B I P$ referral.

(3) Referrals to the BIP can only be made by the Mental Health Triage Service. (Fallon, 2005) See Appendix A for more detailed information on the BIP program policy guidelines.

The rationale behind limiting the criteria was to capture a client base that typically would not receive prompt or any follow up by secondary or tertiary mental health services. In Victoria, the service structure gives priority to clients with severe presentations of mental illness, i.e. psychosis, behavioural disturbance and marked impairment in general functioning (Department of Human Services, 2006a). Due to having limited resources in providing the $B I P$ with a part-time clinician, it was viewed 
by the management that referrals from the primary health sector would overwhelm the service and were excluded.

According to Russell and Potter (2002) primary care professionals are exposed to various mental health presentations in their work. The primary health sector consisting of general practitioners and private therapists are largely responsible for service provision to clients with high prevalence disorders like anxiety and depression or for those in recovery or remission from severe symptoms of mental illness (Badger \& Nolan, 2000; Klinkman \& Okkes, 1998; Warner \& Ford, 1998). Many clients do not have the financial resources for private services to address their issues, despite past government initiatives such as the Better Outcomes in Mental Health Care (BOIMHC) program (2001), to improve community access to quality primary mental health care (Australia Government Department of Health and Aging, 2006). This can result in large numbers of clients presenting to the emergency department mental health triage service for a variety of services. As psychiatric triage largely plays the gatekeeper role to the mental health service, it was deemed appropriate that referrals came exclusively from this main entry point to the mental health service.

To this purpose, the BIP set out to offer a service without duplicating existing services delivered to the client population. The developed BIP exclusion criteria deferred any clients with a primary diagnosis of a major mental illness, "severe" personality disorder or those presenting with a significant risk of suicide requiring acute crisis management or hospitalisation. The Brief Intervention Program also excluded clients that were already case managed by public Mental Health Services or who were already engaged with "appropriate" ongoing treatment / counselling from a private provider.

For clients who met the inclusion criteria, a pamphlet and appointment time were given following the assessment conducted at the emergency department. According to the aims / objectives of the BIP, ideally an appointment time was arranged within five days from the time of the initial assessment. At times, clients may be ambivalent or unwilling to attend the $B I P$ at the point of crisis contact and were encouraged to recontact the service for an appointment or further referral to suit their needs. A summary of the outcome and referral plan is then documented in the client's regional mental health file. The working assumption is that by engaging a $D S H$ client shortly after their 
initial presentation provides an opportunity to address the factors that may have led to the attempt and for teaching new coping strategies.

\section{Teach new coping and problem-solving skills}

The Brief Intervention Program employs a sole psychiatric nurse clinician who offers clients between one to six Solution-Focused Counselling sessions. These sessions are intended to assist the clients in developing new coping strategies to decrease the likelihood of further incidence of $D S H$ behaviour. The $B I P$ clinician chose a blended clinical model that is based on Steve de Shazer's model of Brief Solution-Focused Therapy (de Shazer et al, 1986) and incorporates aspects of Dialectic Behaviour Therapy (Linehan, 1993a;1993b) being (1) core mindfulness skills, (2) interpersonal effectiveness skills, (3) emotional regulation skills, and (4) distress tolerance skills.

According to Bowles, Mackintosh, and Torn (2001) Solution Focused Brief Therapy $(S F B T)$ is firstly a system of communication and secondly, a set of assumptions about the best method for motivating a client for change, adaptation and growth. SFBT is grounded in the concepts of client strengths and empowerment, which shifts the focus from a problem-based or sickness perspective to a solution-based one. The clinician assumes a collaborative role which encourages a client to define their own personal knowledge, experiences, strengths and resources. The clinician ceases being an 'expert' imparting knowledge on the client. The focus is about what the client wants to accomplish and upon the client's identification of existing resources to achieve their desired outcomes. In a SFBT specific conversation, the clinician talks "with" the client as opposed "to" the client in efforts to co-develop new life meanings and realities that focus on solutions (Lee, Greene, Mentzer, Pinnell \& Niles, 2001).

To summarise Iveson (2002) the typical flow of an SFBT session involves four areas of exploration that ask the client:

1. What are your best hopes from this therapy?

2. What would your day-to-day-life look like if these hopes were realised?

3. What are you already doing and have done in the past that might contribute to these hopes being realised?

4. What would others notice if you took action towards the desired solution? 
Bowles, Mackintosh, and Torn (2001) evaluated the impact of solution-focused brief therapy training for nurses and concluded that the techniques are both relevant to nursing and cost effective. The validity and inclusion of SFBT within the scope of psychiatric nursing practice is endorsed by the Registered Psychiatric Nurses of Canada, (2001). The benefit to the BIP clients is the provision of an endorsed, time-limited and evidence-based therapeutic intervention provided from the local public mental health service.

\section{Treat underlying mental disorders in those who self-harm}

Previously, I discussed the assessment process to determine whether a client requires access to tertiary mental health services or a referral to the Brief Intervention Program. Clinical guidelines are useful in managing clients with underlying or diagnosed mental illness such as a mood, psychotic or personality disorder (Allen, Williamson, Gatford, \& Worthington, 1997; Isacsson \& Rich, 2001). Boyce, Oakley-Browne, and Hatcher (2001), identified three principle areas for managing clients that have engaged in deliberate self harm. These three areas are immediate medical management, aims to prevent recurrence of $D S H$ behaviour and to deal with any underlying psychopathology. Morgan et al (1994) indicate that clients with the following mental health conditions are at an increased risk for suicide. The ranking from highest risk to lowest are:

1. Depression (all forms)

2. Schizophrenia

3. Alcoholism

4. Drug addiction

5. Organic cerebral disorder (i.e. epilepsy, brain injury, mild dementia)

6. Personality disorder ( especially sociopathy, impulsivity, aggression, lability of $\operatorname{mood}$

7. Neuroses. (p.10)

Despite some variation in the above descriptive language, Beautrais et al (1996) by comparison found that $90.1 \%$ of clients that made serious suicide attempts had a mental disorder at the time of their attempt. In the group of clients in the study who made suicide attempts, there were high rates of mood disorders, substance use disorders, conduct disorder, antisocial personality disorder and non-affective psychosis. Their findings also suggest that $56.6 \%$ of clients that attempted suicide had two or more 
disorders. Clients with high rates of psychiatric disorders were $89.7 \%$ more likely to engage in a suicide attempt than someone that did not have a psychiatric disorder. Based on these findings, and in view of the RANZCP guidelines for the management of $\mathrm{DSH}$, it is vitally important to address any symptoms of an underlying or existing mental illness that is detected at the initial triage assessment or during / after a series of $B I P$ sessions. In doing so, the client can be directed to necessary resources and hopefully prevent a further suicide or $\mathrm{DSH}$ attempt.

\section{Avoid approaches where there is evidence of harmful effects}

The opinions regarding the effectiveness of brief therapeutic interventions aimed at reducing DSH vary. Scott and Watkins (2004) suggest from their review that brief evidence based therapies can be effective even across ethnic and other patient subgroups that traditionally have not been chosen for randomised trials. They also suggest that the model of therapy is not as important as the establishment of a therapeutic alliance with the client. This view was also shared by Winston and Winston (2001) who stated through the available reviews that there was no significant difference in the outcome among therapies. They also noted that short-term psychotherapy produced positive outcomes in clients over clients that did not receive any formal support / intervention. Boyce, Carter, Penrose-Wall, Wilhelm, and Goldney (2003) indicate that although promising, there are no proven superior therapies for reducing $D S H$ in all patient groups. They made reference to the emerging evidence base that suggests patient engagement and distress reduction for reducing risk.

Bennewith, Stocks, Gunnell, Peters, Evans, and Sharp (2002) found however that in the evaluation of an intervention in General Practice (GP) clinics regarding repeat incidents of $D S H$, that the invitation and consult with a GP did not reduce the incidence of repeat $D S H$. The suggestion from this study was that more research was required into the management of $D S H$ behaviour. Similar findings emerged from Crawford, Thomas, Khan, and Kulinskaya (2007) that examined whether additional psychosocial interventions following $D S H$ reduced the likelihood of subsequent suicide. The results did not provide evidence to suggest that psycho-social interventions following $D S H$ had any effect on subsequent suicide.

Studies on specific forms of therapies were more optimistic. Evans et al (1999) investigated the effectiveness of Manual-assisted cognitive-behaviour therapy (MACT) 
and found that $56 \%$ of MACT patients compared to $71 \%$ of the TAU (treatment as usual) patients re-presented with a suicidal act within six months. Although limited by the small sample, MACT was promising in its efficacy for $D S H$ patients with personality disturbance. Guthrie et al (2001) sought to determine the effects of Psychodynamic Interpersonal Therapy for deliberate self poisoning clients vs. usual treatment. The treatment group illustrated a greater reduction in suicidal ideation compared to the control group and the study suggests that brief psychodynamic interpersonal therapy may be a valuable treatment for patients that deliberate self poison.

Gingerich and Eisengart (2000), conducted a critical review of $N=15$ controlled outcome studies of solution focused brief therapy ( $S F B T$ ) with $n=5$ studies showing positive outcomes and $n=4$ studies indicated that $S F B T$ was better than no treatment at all. Gingerich et al (2000) also noted that SFBT was comparable to Interpersonal Psychotherapy for Depression $n=1$ study. Additionally $n=10$ of the studies were moderately / poorly controlled, yet indicative of SFBT being effective.

In view of the above findings, there is little evidence to suggest that offering clients brief therapy following an act of $D S H$ is damaging or unhelpful. There is also little evidence to claim that one model of brief therapy, or for that matter any therapeutic approach is more effective than another in prevention of repeat episodes of $D S H$ or subsequent suicide. Boyce et al (2001) indicate that the one to three session Cognitive Analytic Therapy or CAT (Sheard et al, 2000) and Manual Assisted Cognitive Therapy or MACT (Evans et al, 1999) are well suited for follow up of DSH clients yet have limited empirical evidence to conclude their effectiveness. The general opinion from the Cochrane review (Hawton et al, 1999) indicates that certain approaches are promising, but the numbers of individuals in controlled trials is too few to make any conclusive statements for evidence-based practice.

\section{Summary and link to Owen's framework:}

This thesis is about the evaluation of the Brief Intervention Program. It is important to link the reader back to Owen's Impact Evaluation framework. For review purposes, the first step is the Orientation dimension whereby one establishes the program's worth, justifies decisions to mount the program and provides accountability to stakeholders and/ or funding streams (Owen, 2006). Throughout this chapter an important link was 
made between suicide and deliberate self harm. The link indicates that clients who DSH are at greater risk for repeated attempts and an even greater risk to eventually complete a suicide attempt. The statistics from a local and global perspective regarding suicide and $D S H$ were also discussed to portray the extent of the problem and its impact on the health of the population. This information builds the case for developing and implementing the $B I P$ to address the needs of clients that were at risk of or had engaged in act(s) of deliberate self harm. The worth of the program is subject to the outcome of the findings by this study. Ultimately, if there is an indication that the BIP has helped to decrease the representation of $\mathrm{DSH}$ or has aided in the development of increased client coping skills one could argue that the program was worthwhile as it helped save lives through reducing the suicide potential in clients.

During the chapter a focus was also placed on the many different types of presentations of $D S H$ and of how these presentations impact on the client, family, and health care providers. The attitudes of the client, family and health care providers were discussed in response to provision of care to clients that deliberate self harm. An emphasis was also placed on local policy, initiatives and clinical practice guidelines that helped to guide the construction of the Brief Intervention Program. The RANZCP guidelines were used in the chapter to form the headings for discussion of the many aspects of the BIP and the relevant links to the literature. This relates to the Orientation dimension in several ways of being accountable to stakeholders of the program. According to Harris (1997) practice guidelines promote efficient, effective and defensible best practice interventions that also help to address the expectations of the clients receiving the service. The main funding stakeholder of the BIP is the Victorian State Government. Arguably, the BIP that is accountable because the program is constructed upon guidelines for best practice and the directives by the State Government. The discussion at this time begins to shift towards accountability to the clients through determining the outcomes of the program.

In the next chapter the focus shifts away from building the rationale for the program to identifying the methodology required to evaluate the outcomes and value of the Brief Intervention Program. A variety of topics are introduced that include research methods, mixed designs, evaluation research and pluralistic evaluation methods that help to broaden the scope for conducting a program evaluation. This is achieved by using an 
"off the shelf" evaluation framework to categorise the steps in conducting an Impact Evaluation of the Brief Intervention Program. 


\section{Chapter 3 Methodology and Study Design}

\section{Introduction}

In the last chapter, the first step or the Orientation dimension of Owen's (2006) Impact Evaluation framework was linked to the literature review about suicide, deliberate self harm and an overview of the Brief Intervention Program. These topics relate to the framework by establishing / justifying why the BIP was established. The information also provided an overview of the aims / objectives of the Brief Intervention Program. By portraying adherence to the RANZCP clinical practice guidelines the $B I P$ was accountable to the various stakeholders because the service being provided was based on current best practice. Some of the best practice initiatives were suggested by the Victoria Department of Human Services that provide the funding stream for the program.

This chapter continues to work through the next four dimensions of Owen's (2006) Impact Evaluation framework that was selected to guide the methodology of this study. The next four dimensions of Owen's framework are: typical issues, state of program, major focus and timing (vis-à-vis program delivery) that are discussed in greater detail relating to the data collection and analysis methods used in this study. This will involve an exploration of the program's method of delivery and measurement of outcomes through mixed sets of quantitative and qualitative data. With the exception of the data extracted from the questionnaire to clinical staff, the data utilised was retrospective in nature. This chapter also weaves in related discussion about methodological dilemmas, research methods and how the collected data fits into the framework for analysis. Included in this discussion is information pertaining to mixed research methods, evaluation research and the pluralistic evaluation approach. These numerous topics are covered in minimal depth allowing for the focus to remain upon the evaluation framework and the questions contained within the dimensions that keep the enquiry 'on track' to conduct an Impact Evaluation on the Brief Intervention Program.

\section{Background}

In September of 2006, the organisation's stakeholders of the BIP consisting of the psychiatric consultant, senior / middle management and the sole BIP clinician met to discuss the Brief Intervention Program. One year had elapsed since the program's 
inception, policies and program guidelines had been developed. Some of the key points raised in their discussions were about the delivery and overall effectiveness of the program. It is not uncommon for mental health services to be under fiscal or social pressure to evaluate and improve upon the quality of care delivered (Hanson, Grypma, Tee, \& MacEwan, 2006). Byng and Jones (2004) argued that "interventions aimed at improving the delivery of health care rarely benefit from either an effective development period or an evaluation" (p.27). Nehls, Owen, Tipple, and Vandermause (2001) forwarded their concerns that without evaluation, innovations can be met with scepticism, or go unnoticed because the effectiveness wasn't evaluated or the results were unavailable for public review.

I became aware of the BIP discussions and expressed my interest in developing a study that would evaluate the data collected. As a clinician at that time working in the area, I was curious about how a program's effectiveness could be measured or evaluated. The opportunity to support my clinical area and pursue my Masters of Nursing degree provided the motivation for constructing this study.

\section{Ethics process}

Prior to the discussion about methodology used in this study it is important to acknowledge the ethics process undertaken prior to commencement of the study. This study involves academic interests in New Zealand and clinical governance interests in Victoria, Australia. This resulted in contact with four ethics committees to obtain the permission to conduct the study (see Appendix B \& C).

At the regional level in Australia, the ethics process involved completing a 40 page proforma called a Module 1 to obtain the permission to conduct health research. The first tier involved a review of the project by the local Research and Quality Assurance Governance Committee that must be consulted for research conducted in the local mental health service. Approval was granted from the $8^{\text {th }}$ October 2007 for a period up to two years to allow for completion of the study. The project was also under consideration by the regional hospital's Research Review Committee with approval being suggested from the $27^{\text {th }}$ September 2007 allowing for a period of one year for completing the study. The original anticipated completion date was the $31^{\text {st }}$ December 2007. The final regional step to obtain ethics approval was granted by The Research and Ethics Advisory Committee (REAC) on the $27^{\text {th }}$ September 2007 for a period of up to 
three years in order to complete the study. The REAC decision supersedes the other two committees with regards to governance. The project was viewed as a minimal risk project as it did not conduct experimental treatment on human subjects. The project was viewed as a quality assurance exercise to evaluate the outcomes of a program within the service.

\section{Ethical considerations during the study}

The participants recruited for the questionnaire were not directly identified by the qualitative data subject to discussion in Chapter Four. Due to the close working relationship in such a small team framework, there exists the potential for team members to scrutinise one another's responses and likely discover "who said what." This risk was identified to all four ethics committees and approval was granted. The participants were also notified of this risk in the participant information form and allotted a one month period to withdraw their responses. To reduce an obvious research bias, I withdrew from participating in the questionnaire. This research bias existed because I was one of the stakeholders that had previously referred clients to the Brief Intervention Program.

Noteworthy is the alteration of the method used for analysis of the qualitative data that differs from the ethics proposal. In the ethics proposal, a thematic summary was proposed to conduct the analysis. However due to the limited amount of data collected from the questionnaires the decision was made (in consultation with my supervisor) to transcribe and provide a summary discussion about the responses.

This study involves an evaluation of standard clinical practices and a review of confidential patient information. My employment status provided access to confidential clinical information and the legal responsibility to ensure that client confidentiality was not compromised. No client's personal details or information linking the clients with the study will be published. In view of Victoria Government State policy, as previously stated the proposed evaluation would be regarded as a Quality Assurance Audit.

Ethical concerns regarding the study were confined to questions about discussion of the hospital's program in academic circles that are outside Australia. These matters were pursued from a HEC standpoint in NZ and from the HREC in Geelong. Approval for 
the research was granted from the Human Ethics Committee at the Victoria University of Wellington on the $5^{\text {th }}$ November 2007.

\section{Methodology}

In the beginning stages of this study, I focus on the data collected during routine clinical work, including documented presentations to the $E D$ and data from clinical outcome measurements. The pre-collected data was numerical which could involve statistical analysis to determine outcomes.

Traditionally, study designs are either quantitative, qualitative or a mixture of the two approaches. In discussion about nursing research Shih (1998) reviewed that quantitative designs deal with "objective, observable and quantifiable data" (p.632). In other words, quantitative designs are based on scientific research methods dealing with factual data. Shih also discussed that the qualitative study design method comes from sociological and anthropological research methods that "focus on a world view: the values, meanings, beliefs, thoughts, feelings and general characteristics" (p.632) of the focus of study. To clarify further, quantitative research takes an objective viewpoint whereas qualitative research takes a subjective viewpoint.

Shih (1998) also mentions methodological triangulation which uses a combination of different research methods. These methods are based on using different paradigms or research disciplines / methodologies that are philosophically positivist (objective) or interpretive (subjective) in nature. Mingers (2001) argues that the mixed or pluralist use of research paradigms produces "richer and more reliable" (p.240) research results. Further discussion on the topic of mixed method or pluralistic designs will occur later in this chapter.

With the aforementioned design methods in mind, ideas began to surface about limiting the study to a simple quantitative design that compared BIP clients that had attended one follow up session versus the BIP clients that "successfully" completed the six session program. The evaluation measurement or evaluand would be the client representation rate to the $E D$ for an act of deliberate self harm.

The sole BIP clinician posed the philosophical dilemma that the clients who attended one SFBT session could be just as "successful" with their therapy as the clients 
attending six sessions. The rationale focused on the principle of client-centred care, in that it was the client, not the clinician who determined the success of the treatment. The BIP clinician suggested that clients may only require one session or for that matter, no follow up at all. Prospectively, the offer of a service if desired could be of a therapeutic benefit within itself. I conceded to this logic regarding "successful completion" and sought other opinions regarding study design / measurable outcomes of the program. Initially, I continually tried to steer away from including qualitative methods to limit the scope of the prospective study.

Considerations for a cohort study evolved comparing the group of referred clients that attended the $B I P$ versus the clients who did not follow up for treatment. The representation rate would have been the primary suggested evaluand in such a study. I posed this study design to the hospital's Psychiatric Research department suggesting that I could pursue a randomised control trial $(R C T)$ using the BIP clients that had attended treatment as the control group. The research department at the hospital indicated that a $R C T$ was "out of the question" due to related cost factors, numerous variables and the limited client numbers. A quasi-experimental design was suggested due to the limited data sets that I had to work with.

In separate discussions within the academic arena, the inherent value of a limited cohort study was questioned pertaining to the contribution such a study would have to the advancement of nursing knowledge and practice. This viewpoint is strongly supported by Geanellos (2004) calling upon mental health nurses to utilise "diverse research approaches" (p.177) with an emphasis on qualitative or even mixed methods to build the body of knowledge for the profession. Upon further discussion with academic supervisors, the suggestion of using a mixed methods approach or a "pluralistic evaluation design" was forwarded to analyse the existing data collected by the Brief Intervention Program.

\section{Pluralistic methods and evaluation research}

Pluralistic designs are a mixed method research approach commonly used in program evaluations and evaluation research. In following the academic faculty's recommendations, the study gradually began to shift towards using an evaluation research approach. Brink, van der Welt, and van Rensburg (2006) state that "the purpose of evaluation research is to find out how well a programme, treatment or 
practice policy concerning an intervention is implemented, how well it accomplishes its purpose, and how useful it is" (p.111).

There is a notable difference between traditional research methods and evaluation research. Morrison (2003) makes the distinction between evaluation research and traditional research methods in that, "evaluation is a continuous process whereas research may not become continuous if the answer to the question is found" (385). In regards to a program evaluation Issel (2004) states that "research in a pure sense is done for the purpose of generating knowledge whereas program evaluation is done for the purpose of understanding the extent to which the intervention was effective" (p.285). In other words, evaluation research has more of an interest on the process of evaluation rather than aiming to achieve conclusive research results.

In her pluralistic evaluation of nursing / practice development units, Gerrish (2001) states that "the evaluator's task is first to identify the major stakeholders...elicit and compare their views of the aims and outcomes of the innovation....and use their subjective perceptions as the major determinant of "success"” (p.4). In constructing a program evaluation on the $B I P$ the stakeholders identified were the triage clinicians that provided the referrals to the program, the sole BIP clinician and the clients that had attended treatment.

Billings (2000) adds that a pluralistic evaluation "accumulates evidence from a variety of different sources and uses different research methods in order to generate conclusions concerning the outcome of a project." Billings continues that this type of evaluation "combines qualitative information, such as interview and observation with quantitative statistical data and uses documentary evidence in an attempt to describe the change process (p.4)." There was substantive quantitative data for analysis but no existing qualitative data upon the Orientation stage of the program evaluation. In regards to the quantitative data available for analysis, the pre-existing clinical documentation included the number of clients that attended treatment, the number of days it took to follow up with clients after referral and the pre and post PANSI (Positive and Negative Suicide Inventory) scores. This clinical outcome measurement will be discussed in this chapter.

Contrary to my initial avoidance of the qualitative method for use in this study, it became clearer that a mixed method approach was necessary in order to conduct a 
program evaluation. However by adopting a pluralistic research method, the breadth of the study increased along with the nature of the questions to be addressed by the study. Wall (2007) gives the options of designing questionnaires for a specific program evaluation or to use an "off the shelf questionnaire" (p.17) with a certain degree of caution.

According to Ager (2008) "certain aspects of evaluation of psychosocial programmes seem to generate difficulties in practice" (p.7) and she outlined the following guidelines to assist in evaluating the impact of psychosocial programmes:

1. Project outputs are the immediate accomplishments of the project

2. Project outcomes are the measurable or observable results from a project, based on the stated program objectives

3. Project impact is a change in status or behaviour related to stated project objectives. (p.7)

The aforementioned guidelines make reference to a program's outcomes, program objectives and impact. Similar references were found in the evaluation framework designed by Owen (2006) entitled Impact Evaluation. The framework appeared to incorporate aspects of a pluralistic research method and provide a guide for the kinds of questions to be used in developing a questionnaire for stakeholders.

Owen (2006) notes that the epistemological basis of the framework is the "need to know what works and why" (p.61) coupled by the importance of transferring this knowledge to stakeholders to make informed decisions regarding the worth of an existing program. Determining the impact of a program is grounded in impact theory which "consists of assumptions about the change process actuated by the program and the improved conditions that are expected to result" (Rossi, Lipsey, \& Freeman, 2004, p.139). In other words, impact theory is about cause and effect. The decision eventuated to utilise Owen's framework to effectively guide the line of enquiry used in this study to determine the outcomes of the Brief Intervention Program.

\section{Pluralistic method and program logic within an existing framework}

Further discussion with my academic supervisor gained the support to employ Owen's (2006) Impact Evaluation framework to guide the methodology used in this study. Frameworks contain a heuristic value which can guide research questions, selection of 
methods and interpreting results (Kaufman, Roberts, Merrill, Lai, \& Bakken, 2006).

Essentially the framework is a conceptual model of a program evaluation.

Musick (2006) reports that evaluation frameworks have been developed for a variety of social contexts. He also suggests that, "ideally, the use of the conceptual model would foster prospective evaluation planning and implementation; however, it is also useful for the retrospective fitting of existing data into a rational evaluation framework" (p.760). In the case of the BIP the program had been in existence for a year and the evaluation would be 'after the fact' or retrospective in nature. Owen's framework for an impact evaluation is designed to guide the user through the process of viewing the program retrospectively.

Typically, evaluation frameworks are linked with program logic that is a "method of evaluation that allows assessment of the effectiveness, efficiency, and appropriateness of programs" (Ganley \& Ward, 2001, p.4). Ideally evaluation strategies are built into a program in the early planning stages. Formally a program logic model was not utilised in the initial planning stages of the Brief Intervention Program. The aims and objectives were however very clear (see Table 2.1) along with clinical outcome measurements factored in to collect quantifiable data for future evaluation purposes. The use of a diagram may have clarified the evaluation process from the outset rather than determining the evaluation approach 'after the fact.' According to Stinson and Wilkinson (2004) "a logic model framework is particularly useful because it tends to be comprehensive, easily communicated, and demonstrates integration and consistency between all components; therefore a natural flow and fit is provided" (p. 141).

Despite the retrospective design of Owen's framework it can still be considered as a logic model. As mentioned by Porter, Avery, Edmond, Straw, and Young (2002) logic models are diagrammatic representations of a program depicting the "relationships between the objectives of the program, program activities, indicators, and resources and is used to integrate program planning and evaluation to facilitate accountability" (p.259).

For review purposes please see Owen's (2006) Impact Evaluation framework found on the following page in Table 3.1 . 
Table 3.1: Owen's Impact Evaluation framework

\begin{tabular}{|c|c|}
\hline Dimension & Properties \\
\hline Orientation & $\begin{array}{l}\text { - Establishment of program worth } \\
\text { - Justification of decisions to mount the program } \\
\text { - Accountability to funders and other stakeholders }\end{array}$ \\
\hline Typical Issues & $\begin{array}{l}\text { - Has the program been implemented as planned? } \\
\text { - Have the stated goals of the program been achieved? } \\
\text { met? } \\
\text { - What are the unintended outcomes? } \\
\text { - Does the implementation strategy lead to intended } \\
\text { outcomes? } \\
\text { - How do differences in implementation affect program } \\
\text { - Whatcomes? }\end{array}$ \\
\hline State of Program & Settled \\
\hline Major focus & $\begin{array}{l}\text { Focus on delivery and/or outcomes. Most comprehensive } \\
\text { studies combine both delivery and outcomes known as } \\
\text { process-outcome studies }\end{array}$ \\
\hline $\begin{array}{l}\text { Timing (vis-à-vis program } \\
\text { delivery) }\end{array}$ & $\begin{array}{l}\text { Nominally 'after' the program has completed at least one } \\
\text { cycle with program beneficiaries. In practice, impact studies } \\
\text { could be undertaken at any time after program is 'settled'. }\end{array}$ \\
\hline Key Approaches & $\begin{array}{l}\text { - } \text { Objectives-based } \\
\text { - } \text { Needs based } \\
\text { - } \text { Goal-free } \\
\text { - Process-outcome studies } \\
\text { - Realistic evaluation } \\
\text { - Performance audit }\end{array}$ \\
\hline Assembly of evidence & $\begin{array}{l}\text { Traditionally required use of pre-ordinate research designs, } \\
\text { where possible the use of treatment and control groups, and } \\
\text { the use of tests and other quantitative data. Studies of } \\
\text { implementation generally require observational data. } \\
\text { Determining all the outcomes requires use of more exploratory } \\
\text { methods and the use of qualitative evidence. }\end{array}$ \\
\hline
\end{tabular}

Note: From Program evaluation forms and approaches $3^{\text {rd }}$ edition (p.254), by J.M.

Owen, 2006, Crows Nest, NSW, Australia: Allen \& Unwin. Copyright 2006 by J.M.

Owen. Reprinted with permission. 
As described in the first chapter, the framework contains seven distinct dimensions with a description of each step adjoining under the heading of properties. The use of the dimensions helps to guide the methodology for conducting an Impact Evaluation on the Brief Intervention Program. Previously in this chapter, the link to the orientation dimension has already been established whereby the literature helped to justify the decision to plan, implement and deliver a program that addressed deliberate self harm. The remainder of this chapter places the emphasis upon the next four dimensions of Owen's framework being: typical issues, state of program, major focus, and timing (visà-vis program delivery). Each dimension will be discussed in turn with links to the pertinent lines of inquiry and analysis to be found within this study. In chapter five the study findings from the analysis will be addressed through using the dimensions entitled key approaches and assembly of evidence.

\section{Typical Issues}

Under this dimension, Owen (2006) introduces a set of questions relating to conducting a program evaluation after the program has been established and delivered. The questions also relate to the aims and objectives of the BIP (refer back to Table 2.1) that were discussed in Chapter Two. The seven questions found below were used to develop the questionnaire (see Appendix D) for the recruited clinicians that referred and delivered the Brief Intervention Program. The original questions were:

\section{Has the program been implemented as planned?}

2. Have the stated goals of the program been achieved?

3. Have the needs of those served by the program been met?

4. What are the unintended outcomes?

5. Does the implementation strategy lead to intended outcomes?

6. How do differences in implementation affect program outcomes?

7. What are the benefits of the program given the costs? (Owen, 2006, p.254)

\section{Use of the qualitative method for data collection}

According to Liamputtong and Ezzy (2006) "qualitative research draws upon interpretive orientation that focuses on the complex and nuanced process of the creation and maintenance of meaning" (p.2). The questions posed by Owen were used to gain an understanding of the lived experience and opinions of the stakeholders that referred clients and / or managed and delivered the program. For the purpose of "theoretical 
rigour" (Liamputtong \& Ezzy, p.38) in this study, a questionnaire was constructed based on the content of the seven questions. The questionnaire was fashioned to ask openended questions (Marshall \& Rossman, 2006) in an attempt to broaden the range of response to the questions from the participants.

\section{Thematic analysis of qualitative findings}

Thematic analysis is a form of analysis that groups data into themes ensuring that the manifestations of each theme have been accounted for and prepared for reporting and description. In such an analysis, anticipated and unanticipated responses can result from the data in response to questioning (Pope, Ziebland, \& Mays, 2006). As stated previously, due to the limited amount of qualitative data collected the analysis was limited to transcribing and discussing the responses from participants. In order to ensure "methodological and interpretative rigour" (Liamputtong \& Ezzy, 2006, p.39) the responses are to be directly transcribed from the questionnaires for the reader's interpretation purposes.

A blended approach of inductive and deductive reasoning assists in drawing discussion points from the participants' responses. Inductive reasoning is the process of developing generalisations from the responses and deductive reasoning involves the process of drawing conclusion statements regarding the responses (Brink, van der Walt \& van Rensburg, 2006).

\section{Recruiting participants}

The recruitment of participants took place in October 2007 in order to gain an insight about the program's implementation or delivery. The recruited participants were the sole BIP clinician, the clinical coordinator, the consultant psychiatrist and members of the psychiatric triage service. Upon receiving ethics approval (see Appendix: B and C) the contact took place through the regional hospital's intranet e-mail system to provide preliminary information about the project. For the purpose of "evaluative rigour" (Liamputtong et al, p.41) information packages were compiled containing a participant information form, consent form, revocation of consent form, BIP policy document overview and the questionnaire (see under Appendix D).

The forms followed the organisation's templates set by the regional hospital's Human Research Ethics Committee (HREC). Dual letterheads appeared on the cover sheets of 
each form to assist participants in identifying the dual affiliation of the regional hospital and offshore university involved with this research project.

\section{Data collection and storage}

Hardcopy packages containing all of the information (see Appendix D) were placed in the prospective participants' work mailboxes. Each package was given a track number in the event that a participant decided to withdraw their participation. Due to the small group of participants and my professional links to the area, the recruitment and data collection process were confidential but not anonymous. Of the $N=14$ prospective participants, $n=6$ ( $43 \%$ response rate) completed the packages and submitted them into the secure marked collection box in the triage office. Participants were given a one month period of time to submit their questionnaires. They were also allotted a one month cooling off period should they decide to revoke their participation. None of the participants withdrew their participation from the study. The data collected from the questionnaires will be subject to discussion in the following chapter.

The collected consent forms and questionnaires are in hardcopy form and stored in a secure filing cabinet to maintain participants' confidentiality and to protect the data. As per the Victoria University of Wellington Human Ethics Committee guidelines, the hardcopy data will be destroyed one year following the conclusion of the study. Backup scanned copies of the questionnaires have been stored on secure computer files. Upon completion of the study these computer files are to be stored for a period of seven years as per the HREC policy.

\section{State of Program}

The next dimension for brief discussion is the State of program. Owen (2006) suggests that when conducting an Impact Evaluation the program has to be established and operating for a period of time before reviewing it. The BIP guidelines were developed in September 2005. Referrals and program delivery were established by the $1^{\text {st }}$ January 2006, being the researcher's chosen date to begin the evaluation process from. The program had been operating for a period of three months before the allocated evaluation period for this study. In view of the Impact Evaluation framework the state of program was indeed settled. 


\section{Major focus}

This next dimension of the framework focuses on delivery and / or outcomes. Most comprehensive studies that combine both a program's delivery and outcomes are known as process-outcome studies (Owen, 2006). This dimension will address the quantitative aspects of enquiry for this study.

\section{Quantitative data sets}

The existing data collected by the BIP clinician included: numbers of clients referred from triage, the number of clients that attended treatment, clinical notes, and clinical outcome measurement tools such as the HoNOS (Health of the Nation Outcome Scale) and the PANSI (Positive and Negative Suicide Ideation Inventory). According to the Royal College of Psychiatrists (2007) HoNOS utilises 12 scales that rate mental health service users who are working age adults. The clinician directed tool "considers different aspects of mental and social health, each on a scale of 0-4". The PANSI developed by Osman et al (1998) is, "a validated brief self report measure for assessing the frequency of positive and negative thoughts related to suicidal behaviour" (p.783).

For the purpose of this study the HoNOS scores were excluded in order to focus on the PANSI scores. The rationale for this exclusion was twofold. The HoNOS pre and post scores completed by the sole BIP clinician could not provide a variable range of interrater reliability in scoring. The issue of bias could also be brought into question with all of the data being produced by one clinician. The second main reason was to provide consumer input into the data for analysis. As the data was retrospective, the PANSI client responses provided some degree of input from this group of stakeholders, albeit peripheral in nature. According to Rohrer, Arif, Denison, Young, and Adamson (2007) "the ultimate goal of health care systems is to improve overall health from the patient's point of view" (p. 882). Further Marshall, Haywood, and Fitzpatrick promote that:

Regular use of patient-reported outcome measures (PROMs) by health care providers in their routine practice may provide an effective and efficient way of both improving and evaluating the processes and outcomes of care that contribute to health care quality. (pp. 559-560)

The data collected from patient (client) files included contacts from January 2006 until January of 2007. A period of six months from the client's initial presentation date was reviewed to determine whether or not the client represented the $E D$ with a repeated act 
of deliberate self harm. A total of $N=40$ clients were seen by the $B I P$ clinician over the calendar year that met the inclusion criteria for this study. Excluded from the numbers were clients that were seen by the BIP clinician prior to the $1^{\text {st }}$ of January 2006. Partway through examination of the results, I discovered that one female client had re-presented fourteen times! Upon further review of the file data, I discovered that the client had a pre-existing diagnosis of Borderline Personality Disorder which is an exclusion criteria for referral to the Brief Intervention Program. This client was added to the age and gender tables but was excluded from the other data analysis for risk of skewing the results, in particular the re-presentation rate. The client was not completely removed from the data set as her referral to the program could be viewed as an "unexpected outcome" for further discussion. Another client was seen the day of her referral, completed a pre-PANSI score at the ED and then decided not to attend the rest of the session at the office. This will account for the $n=38$ clients in the calculations of time from referral and sessions attended statistics.

\section{Client file data collection}

The electronic file data was collected for this study by accessing the regional hospital's PIMS (Patient Information Management System) and TCM ${ }^{\circledR}$ (The Care Manager) databases. Unfortunately, at the time of compiling this data, the PIMS database has become obsolete and has been replaced by the Symphony ${ }^{\circledR}$ system at the Emergency Department. This factor may cause challenges in re-visiting the data in the future. The PIMS database provided information about the clients' ED presentations. Only presentations that were entered with suspected $D S H$ and a mental health referral via triage were included in the data set. The Care Manager ${ }^{\circledR}$ is a database used for storing, accessing and collecting patient information within the regional mental health service. Data that was collected from this source verified the number of sessions attended by the BIP clients.

\section{Data collected from PANSI}

The PANSI tool consists of 14 items categorised with 8 negative and 6 positive statements with a score range of 1 (being none of the time) to 5 (being most of the time). The score range for negative statements is $8-15$ and the range for positive statements is $6-30$. Mean values are computed for both positive and negative statements. The higher the negative mean the greater the concern for suicide potential. If the positive mean is high, it indicates greater potential for coping and / or resiliency. 
Data collected from the PANSI (Positive and Negative Suicide Inventory) came from the original score sheets securely maintained in a filing cabinet at the hospital. There was a significant difference in the completion rates of pre-test and post-test scores.

Pre-test scores had been collected during the client's first contact with the BIP clinician. Post-test scores were collected at the 'last' session as determined by the client. The scores were collected as an outcome measurement activity for clinical practice. When viewing the TCM entries, it was apparent that some clients did not attend scheduled appointments and subsequently did not complete their post-testing.

This resulted in $n=8$ completed pre and post PANSI data sets. Total $N=39$ pre-PANSI data sets were collected. The rationale for $n=38$ pre-PANSI and $n=9$ post-PANSI was due to one client completing only the post score. To clarify, only eight pre and post PANSI scores were completed. I am referring to the data as 'sets' because the PANSI requires the researcher to calculate the scores under two separate categories being the 8 'negative' statements and the 6 'positive' statements contained within the tool.

\section{Data compilation and storage}

In order to organise and categorise the data, a Microsoft Excel spreadsheet was compiled to illustrate the:

- client's name

- hospital number

- gender

- age

- date of initial contact

- number of days from the referral date to the first BIP appointment

- date of the first attended BIP appointment

- $\quad$ pre-PANSI positive and negative scores

- post-PANSI positive and negative scores

- date of the first $E D$ presentation that led to BIP referral and a description of the method of $D S H$

- date(s) of re-presentation to the $E D$ for a repeated act(s) of $D S H$ including a description of the method, for a period of 6 months from the initial referral date.

- number of sessions attended

To facilitate analysis outside the hospital a working copy of the data was constructed that excluded clients' names and hospital numbers. The original spreadsheet containing 
the client's name and hospital number was saved onto a USB device and locked in a secure filing cabinet at the hospital. Upon completion of this study, the confidential data will be transferred and maintained in a secure hospital computer file for a period of seven years as per HREC policy. The data storage can be used to accommodate future analysis of the BIP client group in regards to re-presentation rates over a time period longer than six months from their initial presentation.

\section{Statistical analysis: rigour / validity strategy}

To ensure accuracy the data sets were run through the SPSS-15 package for analysis. Subject to analysis were factors such as age, gender, the time lapse between the BIP referral to the first session, pre and post PANSI comparison, and re-presentation to the $E D$ for a further act of deliberate self harm. The data was subject to analysis under the following described formats:

- Age and Gender: statistics were run through a frequency table to calculate the percentage of minimum to maximum age, mean age and standard deviation values for $N=40$ clients.

- Time from referral: statistics were run through a frequency table calculating the number of days from the initial referral date to the first BIP appointment. The mean and standard deviation values were calculated for $N=39$ clients.

- Sessions attended: statistics were calculated for percentage of frequency, mean and standard deviation values for $N=38$ clients. A Pearson Correlation was utilised to determine if a relationship existed between the time of referral and the number of sessions attended by clients. The Pearson Correlation is a commonly used test that "measures the degree and direction of linear relation between two variables" (Gravetter \& Wallnau, 1992, p. 471).

- Positive and Negative Suicide Inventory (PANSI): descriptive statistics were calculated from the pre and post positive and negative mean values of the $N=38$ BIP clients. Comparisons are to be made between male and female mean and standard deviation values. A repeated measures $\underline{t}$-test will be conducted to compare the pre and post PANSI scores.

- Re-presentation to the emergency department within six months: descriptive statistics were calculated for frequency and percentage. 
By completing the statistical analysis of the quantitative data the Major Focus dimension of the framework has been achieved and leads to the next dimension being the Timing (vis-à-vis program delivery) step of the framework.

\section{Timing (vis-à-vis program delivery)}

According to Owen (2006) it is important to identify when the evaluation is taking place. The timing for this evaluation occurs after one year that the BIP has been established and providing services to clients that were referred to the program. The client data that is under review in this study is retrospective, from January 2006 until January 2007. There are other frameworks described by Owen that focus on evaluating a program before or during the period of time that a program is being developed. This step articulates that the timing for this evaluation is taking place after the program has been established for a period of time and is subject to evaluation.

\section{Summary}

An overview took place during this chapter of the next four dimensions of Owen's (2006) Impact Evaluation framework being: typical issues, state of program, major focus and timing (vis-à-vis program delivery). The framework has been effective in guiding the methodology for this study. This chapter also weaves in the related discussion about methodological dilemmas, research methods and how the collected data fits into the framework for analysis. Included in the discussion was information pertaining to mixed research methods, evaluation research and the pluralistic evaluation approach. The blended use of qualitative and quantitative data collection for enquiry and analysis resulted in the pluralistic evaluation approach.

When guided by Owen's framework the line of enquiry stays 'on track' to effectively conduct an Impact Evaluation on the Brief Intervention Program. Such mixed methods can be effective in the evaluation of health programs (Higgins, Hurst, \& Wistow, 1999; O'Cathain \& Thomas, 2006) and provide a broader picture of the outcomes of the program. In the following chapter the findings from the analysis of the mixed data sets will provide the basis for discussion about the outcomes of the Impact Evaluation of the Brief Intervention Program. The remaining two dimensions of the framework being key approaches and the assembly of evidence will serve to categorise and facilitate the discussion around the findings and complete the use of the framework in this study. 


\section{Chapter 4 Findings}

During Chapter Three an overview was provided that covered the next four dimensions of Owen's (2006) Impact Evaluation framework being: typical issues, state of program, major focus and timing (vis-à-vis program delivery). In this chapter the remaining two dimensions of the framework being the key Approaches and the assembly of evidence will serve to categorise and facilitate the discussion around the findings and complete the use of the framework in this study. A segment of the Impact Evaluation framework illustrating the last two dimensions is found below in Table 4.1:

\section{Table 4.1 Owen's Key Approaches and Assembly of Evidence}

\begin{tabular}{|c|c|}
\hline Dimension & Properties \\
\hline Key Approaches & $\begin{array}{l}\text { - } \text { Objectives-based } \\
\text { - } \text { Needs based } \\
\text { - } \text { Goal-free } \\
\text { - Process-outcome studies } \\
\text { - } \text { Realistic evaluation } \\
\text { - Performance audit }\end{array}$ \\
\hline Assembly of evidence & $\begin{array}{l}\text { Traditionally required use of pre-ordinate research designs, } \\
\text { where possible the use of treatment and control groups, and } \\
\text { the use of tests and other quantitative data. Studies of } \\
\text { implementation generally require observational data. } \\
\text { Determining all the outcomes requires use of more exploratory } \\
\text { methods and the use of qualitative evidence. }\end{array}$ \\
\hline
\end{tabular}

Note: Adapted from Program evaluation forms and approaches $3^{\text {rd }}$ edition (p.254), by

J.M. Owen, 2006, Crows Nest, NSW, Australia: Allen \& Unwin. Copyright 2006 by J.M. Owen. Reprinted with permission.

Under the key approaches dimension Owen (2006) outlines in his book six distinct approaches within the Impact Evaluation framework. These approaches are:

“objectives-based, needs based, goal-free, process-outcome studies, realistic evaluation and performance audit" (p. 255).

In this chapter, these approaches are identified and presented in turn by Owen's description. In order to avoid repetition, the Assembly of Evidence dimension has been 
blended under the six approaches. The study findings from the qualitative and quantitative data analysis are included to determine their relevance and applicability to the approach.

\section{Objectives-based}

According to Owen (2006) the objectives-based approach "determines whether the stated goals or objectives of a program have been achieved" (p. 256). This is the main approach utilised in this study with the primary focus on quantitative data sets for analysis. During the second chapter of this study, the BIP's aims, objectives, expected clinical outcomes, referral process and inclusion criteria required for a client to receive the service were discussed. The BIP aims and objectives for discussion and analysis under the objectives-based evaluation approach are:

- to engage clients who present with $D S H$ behaviours into treatment

- to reduce the likelihood of further incidents of self-harm

- to assist clients in developing a greater understanding of the factors that may have precipitated or contributed to the deliberate self harm

- to assist clients in developing increased problem solving, coping skills and a greater understanding of the factors that may protect them from further incidents of self-harm

\section{To engage clients who present with DSH behaviours into treatment}

The BIP clinician reports that over the 2006 calendar year $N=57$ clients were referred to the program. Of the $N=57$ referrals $n=40$ clients $(70.2 \%)$ attended treatment and $n=17$ clients $(29.8 \%)$ did not attend.

\section{DSH presentations from PIMS file audit}

The electronic hospital file search on the PIMS (Patient Information Management System) revealed specific information about the means of $D S H$ or reason for presentation to the emergency department. Table 4.2 displays the range of initial DSH presentations to the emergency department. The information presented pertains to the $N=40$ clients who acted upon their referral and attended the $B I P$ for treatment in the 2006 calendar year. The categories of $D S H$ have been listed in alphabetical order on the table. There is a diversity of $D S H$ presentations on the table, ranging from clients that sought support to self poisoning, self injury, suicidal ideation, threat and attempt. 
Table 4.2 Number and categories of deliberate self harm BIP attendees 2006

Method*

$n=$ male $\quad n=$ female

$n=$ total

\begin{tabular}{|c|c|c|c|}
\hline Alprazolam overdose (OD) & 0 & 1 & 1 \\
\hline Aspirin OD & 0 & 1 & 1 \\
\hline Benzodiazepines and SSRI OD & 1 & 0 & 1 \\
\hline Carbon monoxide & 0 & 1 & 1 \\
\hline Carbon monoxide and OD & 1 & 0 & 1 \\
\hline Citalopram OD & 0 & 1 & 1 \\
\hline Codeine and paracetamol OD & 1 & 0 & 1 \\
\hline Insulin OD & 1 & 0 & 1 \\
\hline Insulin and diazepam & 0 & 1 & 1 \\
\hline OD substance unknown & 1 & 2 & 3 \\
\hline Oxazepam OD & 0 & 1 & 1 \\
\hline Poly-substance OD & 0 & 1 & 1 \\
\hline Paracetamol OD & 1 & 3 & 4 \\
\hline Ratsak and warfarin OD & 0 & 1 & 1 \\
\hline Self-inflicted burns & 1 & 0 & 1 \\
\hline Self-inflicted laceration & 2 & 1 & 3 \\
\hline Sertraline OD & 0 & 2 & 2 \\
\hline Sertraline and paracetamol OD & 0 & 1 & 1 \\
\hline Severe anxiety & 0 & 1 & 1 \\
\hline Sought support & 4 & 4 & 8 \\
\hline Suicide attempt - hanging & 1 & 0 & 1 \\
\hline Suicidal ideation & 1 & 0 & 1 \\
\hline Suicidal threats & 1 & 0 & 1 \\
\hline Temazepam OD & 1 & 0 & 1 \\
\hline Venlafaxine OD & 1 & 0 & 1 \\
\hline Total & 18 & 22 & 40 \\
\hline
\end{tabular}

*Note: generic drug names used in table 
The rationale for Table 4.2 is to illustrate that the clients who attended treatment met the criteria set out by the BIP to engage clients who were at risk for or had engaged in an act of deliberate self harm. The $D S H$ presentations in the list pertaining to the $B I P$ clients are consistent with descriptions of $\mathrm{DSH}$ as found in the Chapter Two Literature Review of this study. In evaluative terms, there is sufficiency of evidence (Brown, 1999) to suggest that the BIP met the aim / objective to engage clients who present with $D S H$ behaviours into treatment. Interestingly, a significant number of clients had been referred to the $B I P$ without having engaged in an act of deliberate self harm. The $n=8$ clients that 'sought support' were referred to the BIP on the basis that they were at risk for $D S H$ due to their difficulties coping with existing psycho-social stressors.

\section{Descriptive statistics for age and gender}

Of the $N=40 B I P$ clients seen in the 2006 calendar year, the range of age was from 16 years to 71 years of age. The mean age was $38.17 \pm S D$ 15.19. The highest presentation was in the 37 years of age group being $7.5 \%$. However by grouping the age ranges (see Table 4.3 below) no single age group dominated the presentations. There was a slightly higher prevalence of female clients, $N=22(55 \%)$ to male clients $N=18(45 \%)$ representation. The age range for females was 17 to 71 years of age; mean age being 38.14. The age range for males was 16 to 63 years of age; mean age being 38.22. When determining the male to female ratio of the above data, the ratio is $0: 82$, which is slightly higher than the national average for hospitalised self harm of 0:74 (Steenkamp \& Harrison, 2000).

Table 4.3 Age group presentations

$\begin{array}{lcr}\text { Age group } & \text { Frequency } & \text { Percent } \\ 16-25 & 11 & 27.5 \% \\ 26-35 & 5 & 12.5 \% \\ 36-45 & 11 & 27.5 \% \\ 46-55 & 11 & 27.5 \% \\ 66 \text { plus } & 2 & 5.0 \%\end{array}$




\section{Timeframe from referral to appointment}

One of the main aims of the $B I P$ was to actively engage clients into attending treatment. To achieve this, a proposed strategy was to book an appointment with the client within 5 days from the time of referral to the program.

Referral and follow up by the BIP clinician broadly ranged from the day of referral ( 0 days) to a maximum of 24 days before the first session. It is important to note that there were periods of time when the sole BIP clinician was on leave that accounted for the lengthy intervals from the time of referral seen in the data. These logistical hurdles are inevitable when only one clinician exists to deliver a program. The mean number of days was close to the 5 day target being $\mathbf{5 . 5 4}$ days $\pm S D$ of 5.05 .

Noted is the $n=1$ missing data set of a client that terminated the session partway through. Due to incomplete scoring tool data collected, the SPSS-15 software package removed the client from the calculation set. The findings for $N=39$ clients indicate that $62.5 \%$ were seen within 5 days from the initial referral date. The results from the SPSS15 analysis can be found below in Table 4.4.

\section{Table 4.4 Range of days from referral to first BIP appointment}

$\begin{array}{lcc}\text { Days } & \text { Frequency } & \text { Percent } \\ 0-4 & 22 & 56.41 \% \\ 5-9 & 11 & 28.21 \% \\ 10-14 & 4 & 10.26 \% \\ 15-19 & 1 & 2.56 \% \\ 20-24 & 1 & 2.56 \%\end{array}$

\section{Sessions attended}

Of the data set for sessions attended, complete data was available for $N=38$ clients. The number of sessions attended by clients ranged between one to six sessions. Notably, $N=24$ clients or $61.5 \%$ had attended one session. This resulted in a mean session attendance of $1.82 \pm S D$ 1.33. On average the $B I P$ clients had attended between one to three sessions. The SPSS-15 analysis can be found in Table 4.5. 
Table 4.5 Session attendance

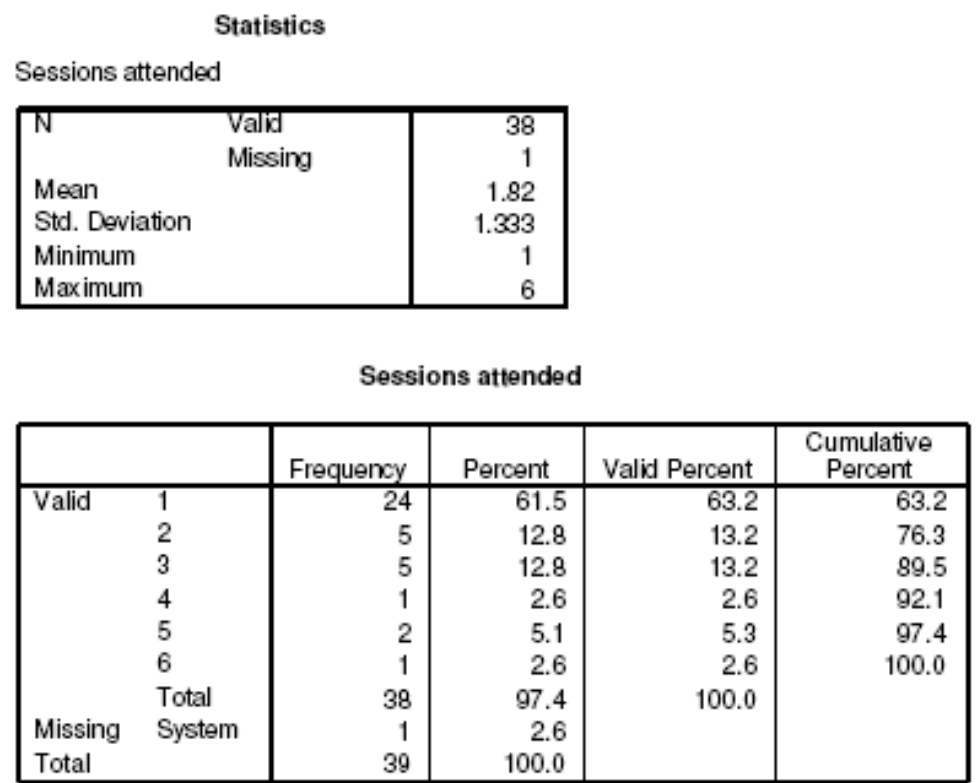

\section{Correlations}

A Pearson Correlation was utilised to determine if a relationship existed between the time of referral and the number of sessions attended by clients (see scatter plot in Figure 1). There is a very weak negative correlation, $r(N=38)=-.206, p>.05$ suggests that the longer the timeframe from the referral to the initial session the lower the number of sessions were attended by clients.

Figure 1. Scatter plot of days from referral and sessions attended by clients

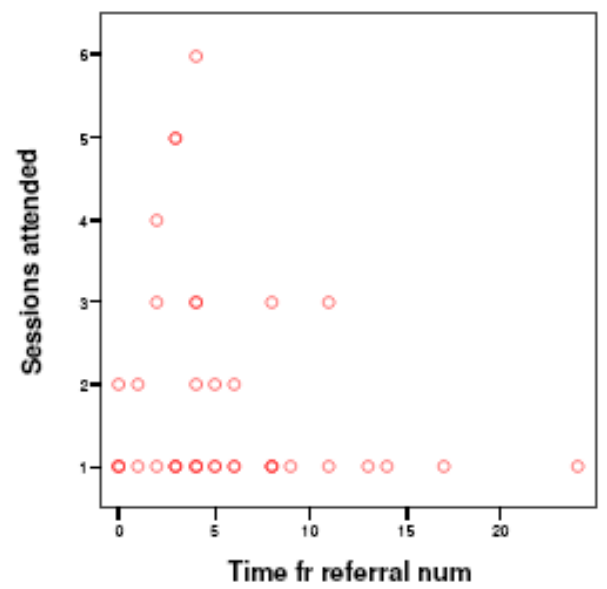


According to Gravetter and Wallnau (1992, p.467-469),

Correlations can be classified into two basic categories: positive or negative...A perfect correlation always is identified by a correlation of $1.00 \ldots$ (or-1.00), ... and indicates a perfect fit whereas a correlation of 0 indicates no fit at all. Intermediate values represent the degree to which the data points approximate the perfect fit.

\section{To reduce the likelihood of further incidents of self-harm}

One of the main aims / objectives of the BIP is to reduce the re-presentation rate of clients to the $E D$ for repeated act(s) of deliberate self harm. The following charts and statistics indicate the rate of re-presentation for $N=38$ clients seen by the program. This particular data set involves the use of force majeure as the rationale in removing the $n=1$ data set belonging to a female client that re-presented $n=14$ times. Had the data remained in this formulation it would have skewed the results.

Table 4.6 Frequency of DSH within six months from first presentation:

DSH within 6 mos

\begin{tabular}{|ll|r|r|r|r|}
\hline & Frequency & Percent & Valid Percent & $\begin{array}{c}\text { Cumulative } \\
\text { Percent }\end{array}$ \\
\hline Valid & 0 & 32 & 82.1 & 84.2 & 84.2 \\
& 1 & 4 & 10.3 & 10.5 & 94.7 \\
& 2 & 2 & 5.1 & 5.3 & 100.0 \\
& Total & 38 & 97.4 & 100.0 & \\
Missing & System & 1 & 2.6 & & \\
Total & 39 & 100.0 & & \\
\hline
\end{tabular}

Re-presentation to the ED with a single repeated act of $D S H$ occurred with $n=4$ or $10.3 \%$ of $B I P$ clients. Only $n=2$ or $5.1 \%$ of BIP clients re-presented twice to the ED in $<=6$ months from the time of their initial presentation. Mean rate of re-presentation for $N=38$ clients was 0.21 with a $S D$ of 0.529 . This indicates that $82.1 \%$ of the BIP clients did not re-present to the ED with an act of DSH six months after their initial presentation.

It is important to note that not all re-presentations to the $E D$ were for a repeated act of deliberate self harm. Clients had been encouraged to re-present for support when in crisis to the $E D$ to engage with the triage clinician. This additional level of support also aimed to decrease the likelihood of further act(s) of $D S H$ by clients. A total of $N=4$ clients or $10.3 \%$ that presented to the $\mathrm{ED}<=6$ months from their initial presentation had 
sought support from the triage service at the ED to reduce the likelihood of a further DSH attempt.

\section{Seeking support versus not seeking support}

In further review of the statistics of the $N=38$ clients, a total of $n=30$ did not re-present for further support from the service. This group of $n=16$ female and $n=14$ male clients did not seek additional support and also did not re-present with $D S H<=6$ months from their initial ED presentation. There was a small number of $N=4$ clients that did not seek further support and did re-present with $D S H<=6$ months from their initial $E D$ presentation. This group consisted of $n=3$ male and $n=1$ female clients.

Comparably, there were $n=4$ clients that did re-present for support. Of these clients, $n=2$ female clients sought support and did not DSH within the 6 month period following their initial presentation to the service. Only $n=1$ male and $n=1$ female that sought support also re-presented with $D S H<=6$ months from their initial presentation.

\section{Assisting clients in developing a greater understanding of DSH}

In Chapter Two the described mode of therapy offered by the BIP clinician was a combination of Solution Focused Behavioural Therapy and Dialectical Behavioural Therapy techniques. The BIP clinician had selected the PANSI (Positive and Negative Suicide Inventory) as an outcome measurement tool to gauge whether any change or impact had occurred in the clients that attended the Brief Intervention Program.

\section{Positive and Negative Suicide Inventory (PANSI)}

In reviewing the PANSI scoring, mean values are computed for both positive and negative statements. The higher the negative mean, the greater is the concern for suicide potential. If the positive mean is high, it indicates the greater potential for coping and / or resiliency.

Descriptive statistics about the PANSI scores are displayed in Table 4.7 to illustrate the positive and negative mean values of the BIP clients. The following table includes all the male and female scores both pre and post in the SPSS-15 analysis. The rationale for $N=38$ pre- $P A N S I$ and $N=9$ post $-P A N S I$ was due to one client completing only the post score. 
Table 4.7 PANSI descriptive statistics

\section{Descriptive Statistics}

\begin{tabular}{|l|r|r|r|r|r|}
\hline & \multicolumn{1}{|c|}{ N } & \multicolumn{1}{|c|}{ Minimum } & Maximum & \multicolumn{1}{c|}{ Mean } & Std. Deviation \\
\hline pre-PANSI pos \&C & 38 & 7 & 34 & 15.37 & 5.630 \\
pre-PANSI pos avg & 38 & 1.17 & 5.67 & 2.5592 & .93806 \\
pre-PANSI neg sc & 38 & 8 & 36 & 23.63 & 7.589 \\
pre-PANSI neg avg & 38 & 1.00 & 4.50 & 2.9550 & .94784 \\
post-PANSI pos \&c & 9 & 7 & 25 & 18.44 & 6.044 \\
post-PANSI pos avg & 9 & 1.17 & 4.16 & 3.0722 & 1.00415 \\
post-PANSI neg sc & 9 & 8 & 30 & 14.44 & 9.939 \\
post-PANSI neg avg & 9 & 1 & 4 & 1.81 & 1.242 \\
Valid N (Istwise) & 8 & & & & \\
\hline
\end{tabular}

The following Table 4.8 illustrates the male scores. Out of $n=18$ males, only $n=1$ male completed the pre and post scoring tools. The female scores are: $n=22$ females with $n=8$ post-PANSI scoring tools completed. Valid sets for analysis of completed pre and post scores were $n=7$.

There was a slightly higher pre-PANSI positive mean in males being 17.06 \pm SD 7.13 over the female clients at $14.0 \pm \mathrm{SD} 3.69$. The pre-PANSI negative scores by comparison were closer; $24.18 \pm$ SD 7.54 for males over $23.19 \pm$ SD 7.78 in females.

Table 4.8 Male and female pre and post PANSI

Male

Descriptive Statistics

\begin{tabular}{|l|r|r|r|r|r|}
\hline & N & \multicolumn{1}{|c|}{ Minimum } & Maximum & \multicolumn{1}{c|}{ Mean } & Std. Deviation \\
\hline pre-PANSI pos sc & 17 & 8 & 34 & 17.06 & 7.128 \\
pre-PANSI pos avg & 17 & 1.33 & 5.67 & 2.8418 & 1.18817 \\
pre-PANSI neg sc & 17 & 8 & 35 & 24.18 & 7.544 \\
pre-PANSI neg avg & 17 & 1.00 & 4.37 & 3.0229 & .94172 \\
post-PANSI pos sc & 1 & 18 & 18 & 18.00 &. \\
post-PANSI pos avg & 1 & 3.00 & 3.00 & 3.0000 &. \\
post-PANSI neg sc & 1 & 30 & 30 & 30.00 &. \\
post-PANSI neg avg & 1 & 4 & 4 & 3.75 &. \\
Valid N (Istwise) & 1 & & & & \\
\hline
\end{tabular}


Female

Descriptive Statistics

\begin{tabular}{|l|r|r|r|r|r|}
\hline & N & \multicolumn{1}{|c|}{ Minimum } & Maximum & \multicolumn{1}{c|}{ Mean } & Std. Deviation \\
\hline pre-PANSI pos \&c & 21 & 7 & 22 & 14.00 & 3.688 \\
pre-PANSI pos avg & 21 & 1.17 & 3.66 & 2.3305 & .61297 \\
pre-PANSI neg sc & 21 & 8 & 36 & 23.19 & 7.782 \\
pre-PANSI neg avg & 21 & 1.00 & 4.50 & 2.9000 & .97236 \\
post-PANSI pos sc & 8 & 7 & 25 & 18.50 & 6.459 \\
post-PANSI pos avg & 8 & 1.17 & 4.16 & 3.0813 & 1.07309 \\
post-PANSI neg sc & 8 & 8 & 30 & 12.50 & 8.602 \\
post-PANSI neg avg & 8 & 1 & 4 & 1.56 & 1.075 \\
Valid N (istwise) & 7 & & & & \\
\hline
\end{tabular}

The scores indicate that the male clients had a slightly higher indication for coping skills pre-test although with a wider variation in scoring. The information also suggests that the level of $D S H$ potential was comparable amongst males and female clients with a comparable level of variation in the scoring.

The following descriptive statistics in Table 4.9 illustrates and compares the range of the 8 pre and 9 post score results for both male and the female clients.

Table 4.9 Completed pre and post PANSI scores

Descriptive Statistics

\begin{tabular}{|l|r|r|r|r|r|}
\hline & $\mathrm{N}$ & \multicolumn{1}{|c|}{ Minimum } & Maximum & \multicolumn{1}{c|}{ Mean } & Std. Deviation \\
\hline pre-PANSI pos \&c & 8 & 7 & 22 & 13.88 & 5.194 \\
pre-PANSI pos avg & 8 & 1.17 & 3.66 & 2.3088 & .86326 \\
pre-PANSI neg sc & 8 & 8 & 35 & 22.25 & 9.377 \\
pre-PANSI neg avg & 8 & 1.00 & 4.37 & 2.7813 & 1.16939 \\
post-PANSI pos sc & 9 & 7 & 25 & 18.44 & 6.044 \\
post-PANSI pos avg & 9 & 1.17 & 4.16 & 3.0722 & 1.00415 \\
post-PANSI neg sc & 9 & 8 & 30 & 14.44 & 9.939 \\
post-PANSI neg avg & 9 & 1 & 4 & 1.81 & 1.242 \\
Valid N (Istwise) & 8 & & & & \\
\hline
\end{tabular}


$\underline{\text { Male pre and post PANSI }}$

Descriptive Statistics

\begin{tabular}{|l|r|r|r|r|r|}
\hline & $\mathrm{N}$ & Minimum & Maximum & \multicolumn{1}{c|}{ Mean } & Std. Deviation \\
\hline pre-PANSI pos \&c & 1 & 8 & 8 & 8.00 & \\
pre-PANSI pos avg & 1 & 1.33 & 1.33 & 1.3300 & \\
pre-PANSI neg sc & 1 & 35 & 35 & 35.00 & \\
pre-PANSI neg avg & 1 & 4.37 & 4.37 & 4.3700 & \\
post-PANSI pos \&c & 1 & 18 & 18 & 18.00 & \\
post-PANSI pos avg & 1 & 3.00 & 3.00 & 3.0000 & \\
post-PANSI neg sc & 1 & 30 & 30 & 30.00 & \\
post-PANSI neg avg & 1 & 4 & 4 & 3.75 & \\
Valid N (istwise) & 1 & & & & \\
\hline
\end{tabular}

Female pre and post PANSI

Descriptive Statistics

\begin{tabular}{|l|r|r|r|r|r|}
\hline & N & \multicolumn{1}{|c|}{ Minimum } & Maximum & \multicolumn{1}{c|}{ Mean } & Std. Deviation \\
\hline pre-PANSI pos \&c & 7 & 7 & 22 & 14.71 & 4.990 \\
pre-PANSI pos avg & 7 & 1.17 & 3.66 & 2.4486 & .82882 \\
pre-PANSI neg sc & 7 & 8 & 35 & 20.43 & 8.463 \\
pre-PANSI neg avg & 7 & 1.00 & 4.37 & 2.5543 & 1.05574 \\
post-PANSI pos sc & 8 & 7 & 25 & 18.50 & 6.459 \\
post-PANSI pos avg & 8 & 1.17 & 4.16 & 3.0813 & 1.07309 \\
post-PANSI neg sc & 8 & 8 & 30 & 12.50 & 8.602 \\
post-PANSI neg avg & 8 & 1 & 4 & 1.56 & 1.075 \\
Valid N (Istwise) & 7 & & & & \\
\hline
\end{tabular}

A repeated measures $\underline{t}$-test was also conducted through SPSS-15 to compare the pre and post PANSI scores. The results were as follows in Table 4.10:

\section{Table 4.10 Paired Samples}

Paired Samples Statistics

\begin{tabular}{|c|c|c|c|c|c|}
\hline & & Mean & $\mathrm{N}$ & Std. Deviation & $\begin{array}{c}\text { Std. Error } \\
\text { Mean }\end{array}$ \\
\hline \multirow{2}{*}{$\begin{array}{l}\text { Pair } \\
1\end{array}$} & prePANSI pos sc & 13.88 & 8 & 5.194 & 1.837 \\
\hline & post-PANSI pos sc & 18.13 & 8 & 6.379 & 2.255 \\
\hline \multirow{2}{*}{$\begin{array}{l}\text { Pair } \\
2\end{array}$} & pre-PANSI neg $\&$ & 22.25 & 8 & 9.377 & 3.315 \\
\hline & post-PANSI neg $s c$ & 15.25 & 8 & 10.306 & 3.644 \\
\hline
\end{tabular}

Paired Samples Correlations

\begin{tabular}{|c|c|c|c|c|}
\hline & & $\mathrm{N}$ & Correlation & Sig. \\
\hline $\begin{array}{l}\text { Pair } \\
1\end{array}$ & $\begin{array}{l}\text { pre-PANSI pos sc \& } \\
\text { post-PANSI pos sc }\end{array}$ & 8 & .669 & .070 \\
\hline $\begin{array}{l}\text { Pair } \\
2\end{array}$ & $\begin{array}{l}\text { prePANSI neg } s c \& \\
\text { post-PANSI neg } s c\end{array}$ & 8 & .298 & .474 \\
\hline
\end{tabular}


Paired Samples Test

\begin{tabular}{|c|c|c|c|c|c|c|c|c|c|}
\hline & & \multicolumn{5}{|c|}{ Paired Differences } & \multirow[b]{3}{*}{$t$} & \multirow[b]{3}{*}{$d f$} & \multirow[b]{3}{*}{ Sig. (2-tailed) } \\
\hline & & \multirow[b]{2}{*}{ Mean } & \multirow[b]{2}{*}{ Std. Deviation } & \multirow{2}{*}{$\begin{array}{l}\text { Std. Error } \\
\text { Mean }\end{array}$} & \multicolumn{2}{|c|}{$\begin{array}{l}95 \% \text { Confidence Interval } \\
\text { of the Difference }\end{array}$} & & & \\
\hline & & & & & Lower & Upper & & & \\
\hline $\begin{array}{l}\text { Pair } \\
1\end{array}$ & $\begin{array}{l}\text { prePANSI p0s \&c- } \\
\text { post-PANSI pos sc }\end{array}$ & -4.250 & 4.833 & 1.709 & -8.290 &. .210 & -2.487 & 7 & .042 \\
\hline $\begin{array}{l}\text { Pair } \\
2\end{array}$ & $\begin{array}{l}\text { pre-PANSI neg } s c \text { - } \\
\text { post-PANSI neg } \& \text { c }\end{array}$ & 7.000 & 11.686 & 4.132 & -2.770 & 16.770 & 1.694 & 7 & .134 \\
\hline
\end{tabular}

When analysing the results, descriptively there was a desired decrease in the negative score and an increase in the positive scores when comparing the pre and post PANSI tests.

- In Pair 1, the -4.25 mean difference between the pre and post PANSI positive scores indicates that clients had an improvement in their level of coping and resilience factors against deliberate self harm.

- In Pair 2, the 7.0 mean difference between the pre and post PANSI negative scores indicates a reduction in negative thoughts that were an indicator for risk of deliberate self harm.

- Overall there appeared to be an improvement in clients that attended BIP sessions.

Descriptively, $n=1$ post-PANSI score was removed from the analysis due to not having a pre-score to match for paired sampling.

- In pair 1: $\underline{t}(7)=-2.49, \boldsymbol{p}=. \mathbf{0 4}$ means that a statistically significant change occurred with the improvement in the positive scores of BIP clients.

- In pair $2: \underline{t}(7)=1.69, \boldsymbol{p}=. \mathbf{1 3}$ means that statistically the change was not significant as it fell within the range of random variation.

\section{Needs-based evaluation}

Moving forward from the objectives based evaluation, Owen's (2006) next described approach is the needs-based evaluation. In a needs-based evaluation, a program's worth is judged on the basis /extent for which the program meets the needs of the participants. According to Grbich (1999), "needs assessments are used to identify the discrepancies between actual and desired situations" and can aid "to prioritise concerns to enable the development of appropriate programs" (p.195).

Due to the limitations of this study, it is unfeasible to pursue this aspect of evaluation at this time. If pursued, this would involve significant revisions to the ethics proposal and would involve broadening the parameters of the study to include contact with all $N=57$ 
clients that had been referred to BIP for treatment. The purpose of such contact would be for gaining client feedback from either a survey or questionnaire in an effort to determine whether or not the program met their needs. If possible in the future, such an evaluation approach could give a broader client perspective regarding the $B I P$.

\section{Goal-free evaluation}

In a goal-free evaluation, Owen (2006) refers to, "determining not only the stated goals but also the unintended outcomes of the program" (p.48). To pursue this form of evaluation, Owen suggests the use of more flexible study designs in an effort to determine whether unexpected (positive or negative) outcomes resulted from the program. As described in Chapter Three a questionnaire was constructed based on the Typical Issues section of the Impact Evaluation form. There are eight questions in the questionnaire that was directed towards staff stakeholders within the Psychiatric Triage / Consultation and Liaison Service. Qualitative data was collected from the participant's statements from the completed questionnaires. Under this section, each question is accompanied by the directly transcribed responses given by the participants to each question. The data was directly transcribed to allow the reader to make one's own interpretations and assumptions about the responses. The responses are accompanied by some minor discussion pertaining to the writer's interpretation of the data.

\section{Q1. In consideration of the Brief Intervention Program (BIP) overview, to what extent has the program been implemented as planned?}

P1: Program has been implemented as planned. Inclusion Criteria has been extended to case managed clients, referral source has been extended to all CMHT.

P2: Initially as stated due to $\downarrow$ number of referrals inclusion criteria was broadened.

P3: successful implementation, referred from triage for DSH clients \& now extended to CMHT service.

P4: Implementation of BIP has proceeded as planned with on-going evaluation and review of process. 
P5: It appears the program has been implemented as set out in BIP overview.

P6: fully

The participant's responses to question one provided a range of opinions: from belief that $B I P$ was implemented as planned to noting a key change in $B I P$ implementation. The broadening of the referral base to the community mental health teams was a reaction to perceivably low numbers of referrals to the service. By broadening the referral base, screening was no longer provided exclusively by the psychiatric triage service but also by community team intake workers. This potentially could impact upon whether the clients referred met the inclusion criteria as set out by the BIP policy document.

\section{Q2. To what extent have the stated goals of the BIP been achieved?}

P1: By \& large, stated goals have been achieved. Engaging this client group remains difficult however service continues to be available within stated timeframe.

P2: I am not aware of this. I have assessed clients who had previously been referred to BIP and had continued self harming.

P3: Program provides its stated goals

Clients participation / dropout may limit the proposed benefits of the program.

P4: from my perspective BIP clients do appear to have reduced attendance at EMD after participation in sessions. This of course is difficult to measure + would be very subjective / anecdotal.

P5: I am not aware of any documented feedback that reports whether the goals of BIP have been achieved or not.

P6: fully 
The participants' response to question two also holds a range of opinions. Some of the respondents supported the notion that the goals of the program were or nearly were achieved. Other opinions indicate an ambivalence regarding the impact of the program, ranging from a notable decrease in $D S H$ presentations to a sense that the intervention was making little impact on the number(s) of client presentations to the Emergency Department. One participant voiced concern that clients prematurely exiting the program may not fully benefit from the effectiveness of the program intervention.

\section{Q3. Whose needs are served by the program and how have they been achieved?}

P1: 1. Clients $\rightarrow$ service attempts to address clients stated needs

$\rightarrow$ service also has capacity to include family members.

2. Service $\rightarrow$ BIP offers a timely therapeutic response to clients who are at risk of DSH as rec by RANZCP, CPG for DSH

P2: Clients who cannot afford therapy cannot wait for referral via BOMHI and who do not meet criteria for CMHT case management.

P3: Clients with DSH who are not managed by CMHT.

Triage staff who can now offer a service to these clients

MHS by filling a gap in service provision

EMD by $\downarrow$ presentations of DSH client group to the EMD.

P4: People who have been assessed by triage / team who require more immediate interventions as part of on-going treatment either before or as part of being linked to longer term supports. Time-lines are significantly improved for response.

P5: The program (BIP) should be aimed at serving the needs of those referred. I have no way of knowing if that has been achieved.

P6: Clients - to provide a service to clients who would otherwise not receive this from B.H. or who would most likely have to wait for some weeks post DSH for an appt with an $N G O$.

-have been achieved by providing a timely service. 
The general response to question three indicates a belief that the program met the needs of clients and their families. There is an underlying opinion indicating that the BIP is also meeting the needs of the local mental health service. As previously mentioned in the Literature Review of this study, the RANZCP guidelines were developed to address the increased concerns regarding $D S H$ and suicide. The guidelines served to provide a structure to $B I P$ to address the existing needs within the service. Public community mental health teams are unable to provide service to the clients that $D S H$ based on limited resource allocation. BIP provides an interim service and link to other private services for clients in order to divert them from the public mental health system where they would normally be deemed as "not for service" (The Mental Health Council of Australia, 2005). The respondents appeared to be making references to the wider system issues being addressed by the Brief Intervention Program.

\section{Q4. In your opinion, what are the intended outcomes of the BIP?}

P1: $\downarrow$ incidents of DSH $\quad \downarrow$ suicidality

Clients to develop $\uparrow$ adaptive coping skills increased self-esteem and $a \downarrow$ in negative feelings inc; depression + hopelessness. Referral to ongoing tx and support services.

P2: BIP provides short term therapeutic input for clients who DSH. It intends to reduce incidences of DSH and improve coping strategies.

P3: Help identify + manage life stress

Provide alternative coping skills to DSH

Support + direction for clients in crisis

$\downarrow$ triage + EMD presentations of DSH clients

P4: Improved ability to cope, development of more positive \& constructive ways of thinking. Reducing likelihood of people self-harming.

P5: For the individual-

As stated in Clinical Outcome of BIP overview.

P6: -To provide a timely service to clients who self harm 
- to engage with the majority of clients who are referred

- $\quad$ to $\downarrow$ the incidence of subsequent self harm

- $\quad$ to $\uparrow$ the clients' insight, self awareness \& encourage a client focused problem identification approach.

There appeared to be a consensus among the respondents to question four. Responses regarding the anticipated intended outcomes for the BIP bore resemblance to the $B I P$ information package that was attached to the questionnaire. The respondents indicated that the $B I P$ met the aim of providing timely intervention, assisting clients in developing alternative means of coping and prevention of further deliberate self harm. Respondents did not indicate any opinions that fell outside of the program's intended outcomes or objectives.

\section{Q5. What unintended outcomes have resulted from the program? Please explain.}

P1: Nil.

P2: An (almost) immediate option for therapeutic intervention which psych triage can offer the client who does not require SCA admit / CMHT.

P3: unsure

P4: I am unaware of specific unintended outcomes as a result of this programme.

P5: I am not aware of any unintended outcome.

P6: low no. of referrals

Participant response to question five was varied. Most respondents did not indicate an awareness of any unintended outcomes that may have resulted from the program. One respondent indicated what appeared to be a positive option for clinicians, i.e. an 'almost immediate' option as a therapeutic response to clients in crisis. Another respondent acknowledged that an unexpected outcome was the low number of referrals to the service. 


\section{Q6. Over time, has there been any alteration (s) in the program delivery and has this affected program outcomes?}

P1: Definition of DSH has been broadened to include any form of behaviour that causes harm to the client

Inclusion and referral criteria has been extended.

Above measures have resulted in $\uparrow$ referrals to BIP.

P2: Yes - inclusion criteria broadened and CMHT's able to refer to BIP. Unsure of effects to program outcomes.

P3: now broader referral sources

More clients serviced

Specific \& tailored service to client needs.

P4: Criteria for acceptance has been broadened and subsequently it is now being utilised by more people.

P5: I am not aware of any alterations in program delivery that has affected program outcomes.

P6: -yes in relation to above-criteria were extended referral methods reviewed and "tweeked" resulting in more clients seen.

All except one of the respondents acknowledged that the referral process had been altered in an effort to increase the amount of referrals to the Brief Intervention Program. According to the respondents, the broadened referral system led to increased numbers of clients being seen by the Brief Intervention Program.

\section{Q7. Do you believe the program has been cost effective? Why or why not?}

P1: Yes. Appears to be an inexpensive resource that offers a valuable resource to the targeted client group who have been identified as having very poor outcomes e.g. high rates of completed suicide. 
P2: Don't know. I suppose if BIP worker has enough clients to fill available sessions then it is. Maybe in longer term if there is a reduction in presentations to $\Psi$ triage by self harming by esc BIP clients it will have proved its value.

P3: Yes, now appt times are usually fully booked, one staff provide a new service

$\stackrel{\downarrow}{\downarrow}$ costs of EMD presentations, likely $\downarrow$ costs of other community services (counselling / unemployment / housing) etc from $\uparrow$ living skills

P4: I am unsure of this due to my overall lack of knowledge in the area of funding. I would have to assume that there may be some benefit in terms of reduced admissions to SCA.

P5: I have no knowledge of cost / budgeting of / for BIP.

P6: unable to say, a low no. of BIP clients have represented to triage or required input from B.H.

An array of responses resulted from question seven. There was a sense of ambivalence regarding budgeting and cost factors. Cost was not measured by the respondents in strictly financial terms. Re-presentation to the $E D$ was viewed as a 'cost' to the service and resources, in particular a mental health admission. There was also a perceived 'cost' to the service if the $B I P$ clinician was not getting enough referrals to fill appointment times. The perception of 'cost' extended to a sense of impact upon the wider community i.e. support services and housing. The anticipated positive outcomes of the $B I P$ were viewed as a cost benefit to the individual, service and wider community if $D S H$ presentations reduced in order to accommodate more positive coping strategies amongst individuals referred.

\section{Q8. If you could suggest any changes to the BIP, what would they be?}

P1: Service offered away from Acute Inpatient Unit (e.g. at various local community health centres). Service also offered on an outreach basis.

These changes are likely to $\uparrow$ engagement rates. Service to be offered all year round - is currently not available when BIP Clinician goes on leave. 
P2: None to date

P3: more days of service

? more service providers - perhaps a $_{\text {staff could assist some }{ }_{\text {q }} \text { clients with }}$ -sexuality issues

-abuse

-dom. violence

P4: Introduction of another day for appointments so it is available 3 days per week instead of two. Due to an increased demand for BIP appts More difficult to obtain quickly.

P5: Details in TCM of (1) attendance, (2) how many sessions, (3) comment by clinician of goals achieved.

P6: further awareness + utilisation of the service.

The last question posed to participants produced another varied range of responses. There were some concerns raised regarding the availability of the service. Firstly the location was identified as an issue as this outpatient community service was co-located with the adult acute psychiatric inpatient unit. Some questions could arise regarding the perceptions of clients associating a negative stigma with the service due to the location. Availability of the service during business hours three days a week raised the concerns about access. An interesting comment surfaced about availability to the program due to an increased number of referrals that likely resulted from the broadened referral process. Having a sole male clinician also raised the concerns about coverage during staff leave, sickness and of gender specific care provision for female clients seeking a female therapist.

\section{Summary discussion of the goal-free evaluation}

The main focus of the goal-free evaluation was to determine if any unintended outcomes resulted from the Brief Intervention Program. Notably the major change in the implementation resulted from the referral process being changed to include the community mental health teams as another source for referral to the program. A perceived positive outcome that resulted was an increased number of clients being 
referred and given appointments. The negative outcome of the increased number of clients using the program impacted on the ease by which triage clinicians could access appointments for clients.

The question of accessibility resulted as the sole male clinician was providing the service three days a week during business hours. Suggestions were raised by the respondents about potentially increasing the resources, i.e. providing coverage for holiday or sick time and/or recruitment of a female therapist to balance the gender ratio. The accessibility issues were an unexpected outcome as the demand for the service and client usage rose. These logistical issues began to raise a challenge for clinicians trying to book an appointment in to see the BIP clinician within the objective for less than five days time lapse from the initial presentation to appointment date.

The gender imbalance issue was also an unexpected outcome as the question raised concerns around female clients who may have sensitive issues that could arise during the therapeutic process and perceived as unattainable or less than desirable to engage in treatment by a male clinician.

Another issue that surfaced was the impact of the program on the triage clinicians that provide the bulk of referrals. Perceivably, scheduling a BIP appointment was a therapeutic intervention in itself, providing the client an opportunity to engage with the mental health service. This issue extends to the question of whose needs were being met by the Brief Intervention Program. Was the client the only one who experienced a positive outcome or was it the larger mental health service that benefited?

Potentially, there was a positive outcome of decreased presentations to the $E D$, decreased admissions to the adult acute psychiatric inpatient unit and / or referrals for urgent follow-up required by the community mental health teams. An opportunity may exist for further research into the attitudes held by triage clinicians regarding the ability to offer a service to clients in crisis when no other service is otherwise available.

\section{Process-outcome studies}

According to Owen (2006) a process-outcome study / evaluation approach often finds it necessary to check on the extent of a program's implementation in order to explain the pattern of outcomes. I previously discussed in the goal-free evaluation that a major 
change in implementation occurred with the broadening of the referral base for the BIP to include the community mental health teams. There were three main deviations in implementation from the original inclusion and exclusion criteria found in the BIP policy document from September 2005. These three deviations are important to discuss in the context of a process-outcome evaluation approach. The application of this approach is suitable for the purposes and limitations of this study.

\section{Age deviation from the BIP policy document}

The first alteration in implementation involved $N=5$ clients that were referred and received treatment from the $B I P$ who fell outside the original age criteria of 18 to 65 years of age.

\section{Table 4.11 BIP profile of clients outside age criteria}

\begin{tabular}{llcc} 
Gender & Age & Representation to ED & Sessions Attended \\
\hline Female & 17 & 0 & 1 \\
Female & 17 & 0 & 1 \\
Female & 68 & 0 & 3 \\
Female & 71 & 0 & 1 \\
Male & 16 & 0 & 1
\end{tabular}

Of the $N=5$ clients, $0 \%$ re-presented to the $E D$ for a repeated act of $D S H$ or for additional support; $80 \%$ of the clients only attended one BIP session; $n=1$ client attended three sessions. In spite of these clients falling outside the age criteria for the program, there was a positive outcome in regard to session attendance and nil $E D$ representations over a six month period from their initial presentation.

\section{Change to referral process}

In the initial policy document clients that were to be accepted by the $B I P$ were solely referred by the Psychiatric Triage / Consultation and Liaison $(\mathrm{C} \& \mathrm{~L})$ team. The referral policy was altered in October 2006 which resulted in a 14\% total referral rate from the community mental health teams following the change. 


\section{Table 4.12 Referral sources for $B I P$}

Team

Psychiatric Triage / C\&L

Community Mental Health
Number of Referrals

49

8

\section{Change to exclusion criteria}

The most notable change in implementation occurred when $n=1$ client with a preexisting diagnosis of "severe personality disorder" was accepted and referred to the BIP. The client had also been case-managed previously by a community mental health team which would have also excluded the client from acceptance to the BIP. Data from this client's involvement had been removed from previous analysis due to the inevitable skewing of representation results. For these reasons a force majeure was declared on the data. The data is of interest however in this process-outcome evaluation approach. Over a period of two months from the date of initial presentation, the client re-presented with repeated acts of $D S H N=14$ times. Eighty percent of these re-presentations involved self-inflicted lacerations to the forearms. The remaining $n=2$ presentations were a single re-presentation due to a deeply imbedded safety pin in the heel of one hand and a single re-presentation asking for support. The acceptance of this client to the program had a negative statistical outcome on the total results. This client's numerous re-presentations may have also negatively impacted upon triage clinician's perceptions of the BIP's effectiveness in reducing re-presentation rates to the emergency department.

\section{Realistic evaluation}

According to Owen (2006) in realistic evaluation studies it is not possible to make general or universal cause and effect statements about any program. He continues by stating that, "it is only possible to say that a program works under certain conditions...in certain circumstances for certain groups of participants in certain contexts" (p.48). Owen indicates that the findings in this approach are generated through enquiry. The identification of problem areas and seeking potential solutions as found in action research methods (Morton-Cooper, 2000) are not applicable by the limitations of scope in this study. 


\section{Performance audit}

The final key approach in Owen's form deals with the financial aspect or audit of the program. Initially I set out hoping to do a comparison between the cost of one hour of treatment provided at the $E D$ compared with the cost of providing treatment for one hour by the BIP clinician. The comment issued by the accountant from the finance department regarding my request was "how long is a piece of string?" Incidentally, one would have to factor in staffing costs such as wages across the $E D$, administration costs, overhead costs for utilities used i.e. electricity, water and medical supplies utilised to treat the method of $D S H$ presented. Medical treatment could range from a major overdose that resulted in several days in hospital to a brief period in the suture room and subsequent discharge. My hopes for a simple 'unit cost' were dashed. Inevitably, I was unable to pursue this approach due to the limitations of time and available data for this study.

\section{Summary}

Of the six key approaches set out in Owen's form, the approaches that were applicable for this study were the Objectives-based, Goal-free and Process-outcome studies. The largest emphasis was upon the objectives based approach and quantitative data analysis to measure outcomes; namely $82.1 \%$ of clients did not represent to the $E D$, the response time to clients was close to the five days as set out in the policy guidelines and an improvement in client well being was measured by the pre and post validated scoring instrument.

The most notable opinion identified from the goal-free approach was a change in the BIP's implementation. The impact of the changes that had resulted from variations in implementation were discussed in the process-outcome study; namely a $14 \%$ increase in referrals from the community teams, five clients that were outside the $B I P$ age criteria, and a client that diagnostically did not meet the inclusion criteria that represented to the emergency department fourteen times.

The findings in this chapter now lead into the final discussions in Chapter Five and the conclusion of this study. 


\section{Chapter 5 Discussion}

Throughout the last two chapters Owen's (2006) Impact Evaluation framework was used to guide the pluralistic evaluation methodology used in this study and to categorise the findings from the data analysis. This took place by using a step by step approach by addressing each of the relevant dimensions and properties of the framework.

The question now is to conclude whether or not the evaluation framework addressed the questions posed by this study. As paraphrased from Owen (2006), the main questions posed by this study were:

- To determine the range and extent of the outcomes of the Brief Intervention Program

- Has the BIP been implemented as planned and how has the implementation affected outcomes

- To provide evidence to the stakeholders how the allocated program resources were utilised

- To inform the decision whether to replicate or extend the Brief Intervention Program

\section{To determine the range and extent of the BIP's outcomes}

In September of 2005 it was anticipated by the organisational stakeholders that the BIP would decrease the incidents of $D S H$ and assist clients to develop better coping strategies. The results from the analysis indicate that $82.1 \%$ of the BIP clients did not re-present to the $E D$ for a period of six months following treatment. A statistically significant change, $p<.05$ occurred with the improvement in the positive scores of $B I P$ clients. The PANSI positive scores indicate that a client's resiliency factors were improved following treatment. The improved scores indicate that a positive response to treatment has occurred.

The negative PANSI score indicates a client's potential for suicide and / or DSH based on their negative statements. This suggests that as a result of the treatment that the clients' potential for further self harm had reduced. The anticipated decrease in suicide potential among the $B I P$ clients following their treatment also occurred. The reduction in suicide potential from the mean score was measurable although not statistically significant. It is important to note that the sample size was far too small to make any 
conclusive statements about the regional intervention. From the position of an evaluation strategy however, the improvements in the outcome measurement score is useful for arguing that the program is making a positive difference to the client group.

\section{Has the BIP been implemented as planned and how has the implementation affected outcomes?}

The BIP implementation strategies that had been discussed in Chapter Two underwent a change in implementation with the referral process. Originally the client referrals to the $B I P$ were done initially and exclusively by the mental health triage team based out of the regional hospital's emergency department.

The original criteria for BIP referrals had excluded clients with a pre-existing diagnosis of a major mental illness, primary diagnosis of substance abuse, personality disorder, and / or if they were case managed by a community mental health team. In one instance, a client that was previously managed and was diagnosed with having Borderline Personality Disorder was accepted for treatment. The outcome of this variation in implementation resulted in the client re-presenting to the $E D$ with $D S H$ fourteen times. This outcome may have impacted upon the triage team as a comment from one of the respondents queried the effectiveness of the $B I P$ due to clients seen by the program were still re-presenting.

Another outcome occurred when the referral base was broadened to include the community mental health teams. This resulted in a $14 \%$ increase of referrals from the community. This expected outcome resulting from the change in implementation was also identified in the questionnaire responses. Some of the respondents indicated that the change to the referral base had increased the numbers of clients that were being referred to the Brief Intervention Program. The unexpected outcome from this change was a perceived increased difficulty in booking appointments for clients due to the increased numbers.

Another aim of the $B I P$ was to engage clients into treatment within five days from their day of initial presentation of deliberate self harm. The descriptive statistics showed a range from zero to twenty-four days for client follow up. The mean value for days waiting to be seen was 5.54 days, which was very close to the expected outcome average of five days. Overall, $62.5 \%$ of clients were seen within 5 days. 
From the goal-free approach, some unexpected outcomes were identified by the respondents about the practical difficulties faced when relying on a sole clinician to deliver a service. The implementation strategies did not factor in practical issues such as vacation or illness. The gender issue was also unexpected as it could have an impact on i.e. female clients with sensitive issues that were perceivably difficult to discuss with a male clinician.

\section{To provide evidence to the stakeholders how the allocated program resources were utilised}

As mentioned in the performance audit approach, the feasibility of conducting a financial analysis of the BIP was outside the scope of this study. Some of the respondents identified in the goal free approach a perception that the BIP reduced the cost to the health service by reduced re-presentations to the $E D$ and inpatient admissions to the adult acute psychiatric unit. One respondent indicated that reduced costs to the wider community would result from the clients' development of adaptive coping strategies. Also identified from the goal-free approach was that the higher numbers of clients being seen equated to the resources being well spent on the program. The qualitative responses suggest that the stakeholders believed that the resources allocated to the $B I P$ were well spent. The question of whether or not to extend or modify the $B I P$ will be discussed further under the Recommendations section of this chapter.

\section{Methodological reflections}

In looking back at the methodological dilemmas faced in selecting a research method for this study I am confident that Owen's (2006) framework effectively guided the line of enquiry in order to conduct an Impact Evaluation on the Brief Intervention Program. The pre-existing and collected data fit very well into the framework for conducting analysis and discussion. Initially I was wary of engaging in mixed research methods however the discovery of evaluation research approaches bolstered the confidence that although the findings were of a limited power due to small numbers, the findings were still very useful in determining whether or not to extend or improve upon the existing program. 


\section{Implications for Nursing Practice}

Leeman, Jackson, and Sandelowski (2006) suggested that, "clinicians require certain information to be able to determine the value of adopting an intervention or synthesising it with findings from other studies" (p.171).

The information in the Literature Review reinforces the link between deliberate self harm and suicide whereby clients who $D S H$ are at an increased risk of completing suicide. Clients who are also suffering from a mental illness are at an even greater risk. The associated information about the clinical practice guidelines, the triage scale and suggested treatments for $D S H$ can be effective for other nurse clinicians who may wish to implement and evaluate a service intended to reduce re-presentations of $D S H$ to the emergency department.

What I found useful about this information was an acquired perspective that $D S H$ was not a clinical issue confined to my own workplace but rather a global problem largely impacting upon health /social services, families and the broader community. I found the information reassuring as the feelings and concerns I had experienced relating to $D S H$ in my clinical practice were also apparent in peer reviewed literature. Equally reassuring were the strategies and initiatives on a state, national and global level suggested to strategically address the problem of deliberate self harm.

Another implication relates to the use of SFBT to reduce the number of $D S H$ representations to the service. Notably, $61.5 \%$ of clients had attended one session. On average the BIP clients had attended between one to three sessions. The implication of more than half of the clients attending only one session raises questions pertaining to the future delivery and evaluation of the Brief Intervention Program.

This would involve defining an effective means of collecting the post-PANSI scores for evaluation purposes. One possibility is mailing a package to $B I P$ clients requesting that they complete and return the post-PANSI tool along with a survey or questionnaire to gain their feedback regarding the BIP's effectiveness. Client views are necessary for effective evaluation, despite the challenges of obtaining and including client input regarding a service / program (Broadbent, Jarman \& Berk, 2004). 
An important implication for nursing practice is that this study supports the use of SFBT to address the issues associated with $D S H$ to reduce re-presentations to the health service. This support exists despite the continued debate that there is no conclusive evidence establishing that $S F B T$ reduces the rate of $D S H$ re-presentations to health services (Ferraz \& Wellman, 2008). This study is similar in size and scope to the study by Wiseman (2003) where she utilised SFBT in efforts to reduce re-presentation rates of $D S H$ to health services. Her findings also supported the use of SFBT as only one client out of 40 re-presented with $D S H$ within a six month period from initial presentation.

This study joins other studies indicating that further research is required to substantiate claims that $S F B T$ is effective in reducing re-presentations of deliberate self harm.

\section{Limitations of this research}

In viewing the retrospective nature of the client data, the data was limited to preexisting file notes and scoring tools collected in routine clinical work. Clients who were referred or who had attended treatment were not contacted directly for this study. Rather than a needs based study from a client's perspective, the study more closely resembled a quality assurance activity.

Throughout examination of the research data I discovered that three of the clients had a pre-history of $D S H$ and had re-presented to the $E D$ on an annual basis over the last five years. I had not factored this into the study design that clients who were referred to BIP may already have a $D S H$ history. Whether this could have some effect on the evaluation outcomes i.e. re-presentation rate is uncertain, as no data was collected to ascertain if these clients had previously sought treatment. Clients with a pre-history were viewed in the same manner as clients with no previous history of $D S H$ with the hope that the intervention would be equally effective to those with a pre-history or not.

The data for this study focused upon $E D$ re-presentation rates after referral to the BIP. The timeframe for measurement of representation was limited to a six month period due to the time limitations to gather research for this study. In regards to the history of $D S H$, the client history is limited to local presentations only. Interstate or national presentations were not factored into the analysis. The data does not factor in representations to private hospital or clinic services either. Information whether or not clients were still residing in the area during the six month period following their initial 
presentation was also not included in the design and may have some impact upon the validity of the re-presentation findings. Upon reflecting on the study design, the six month 'window' to determine re-presentation following initial presentation was a significant limitation of this study.

\section{Significance of this study}

In the current healthcare climate, there is an increased need for accountability for resources use and improved outcomes for service users. There are considerable efforts to redesign and improve health services within a constant process of change (PorterO'Grady, 1996). In regards to research, people are usually more interested in the outcomes than the process itself (Walker \& Dewar, 2000). Pillar and Jarjoura (1999) acknowledge that "patient outcomes can be considered the 'gold standard' of healthcare delivery" and encouraged the use of "sound information gathering and evaluations" to gain knowledge from changes that occur within the healthcare environment (p.64). This study evaluated the impact of the BIP in order to measure and report clinical outcomes, review the implementation strategies and to make any suggestions regarding sustainability or growth to the existing program. The contribution and value of this study to nursing practice lies just as much in the process as in the outcomes.

\section{Contribution to mental health nursing research}

Cleary and Freeman (2005) indicate that expectations are being placed on mental health staff to engage in research practices due to "increased consumer participation, clinical governance, accreditation and occupational health and safety requirements" (p.202). Without negating the importance of qualitative research in healthcare, mental health nurses that conduct research typically are drawn more towards qualitative designs (Cutcliffe \& Goward, 2000). According to the War Trauma Foundation (2008) there is an increasing trend of using combined qualitative and quantitative research methods in needs assessments and process-outcome evaluations of psychosocial and mental health programmes. This Impact Evaluation of the BIP will contribute to the growing trend of such pluralistic or mixed method studies in the field of mental health research.

\section{Recommendations}

\section{To inform the decision whether to replicate or extend the BIP}

The information presented in this study would support that the BIP produced favourable outcomes. The statistical data indicates that clients that participated in treatment 
achieved positive clinical outcomes. At the time of the data analysis of this study no reportable deaths had occurred in the clients seen by the Brief Intervention Program.

Unexpected outcomes that impacted upon the program occurred due to changes in the implementation process. In order to maintain the low re-presentation rate, clients that are referred to the $B I P$ should meet the inclusion and exclusion criteria as set out in the BIP policy document. Suggestions for improvement to the program would include a change of venue to a more community based setting and increased staffing to accommodate annual or sickness leave and the gender ratio issue.

\section{Suggestions for further research}

This study addressed the research questions it set out to investigate. A significant limitation to the study design was the allocated time frame for completion of the data collection and the decision to limit the analysis to the pre-existing client data. Notably there was no baseline data available for $D S H$ re-presentation rates for the region at the time of this study. By establishing a baseline rate, a comparison can be made between clients that attend the BIP and the clients that do not attend treatment. Further investigations may lead to more robust discussions about the effectiveness of the program.

Hansen, Hatling, Lidal and Rudd (2002), indicate that discrepancies exist between clients and professionals in the assessment of client needs in mental health care. As previously stated, a needs assessment evaluation approach would be a valuable form of further research enquiry. An effective means to broaden the Impact Evaluation of the $B I P$ is to ascertain from the clients themselves whether the BIP had met their needs.

\section{Conclusion}

This study has developed my interest in research practices that employ blended study designs. Evaluation practices are a vital activity assisting clinicians and policy makers to make informed decisions regarding workplace developments. Upon completion of this study it is my hope that the stakeholders of BIP consider the recommendations put forth by this study to sustain the programme for continued treatment of clients that deliberate self harm. Valuable program initiatives like the BIP may benefit from ongoing evaluation practices to make future improvements to meet the needs of this client population. 


\section{List of Appendices}

Appendix A: Information package to participants

Brief Intervention Program Mental Health Triage Services: Overview excerpt and references from the BIP: clinical guidelines and procedural manual September 2005

Introduction

Aims of the Brief Intervention Program

Clinical outcomes

Inclusion criteria

Exclusion criteria

Referral to adult mental health teams / inpatient admission

Re-referral to BIP

Crisis response for BIP clients

Clinical responsibility and supervision

Clinical Evaluation

Brief Intervention Program-therapeutic model

References

Appendix B: Barwon Health ethics proposals

Approval letter $8^{\text {th }}$ October 2007 from Community and Mental Health

Research and QA Governance Committee

Ethics Committee approval statement

Research and Ethics Advisory Committee membership

REAC research approval statement

Appendix C: Victoria University of Wellington ethics approval 90

$\begin{array}{ll}\text { Appendix D: Information package to participants } & 91\end{array}$

$\begin{array}{ll}\text { Participant information form } & 91\end{array}$

Consent form $\quad 95$

Revocation of consent form 96

Questionnaire for research project $\quad 97$

Appendix E: Contact and permission from Dr. John Owen 99

Letter to Dr. Owen $\quad 99$

$\begin{array}{ll}\text { E-mail from Dr. Owen } & 100\end{array}$ 
Appendix A: Information package to participants

\title{
Brief Intervention Program Mental Health Triage Services
}

\author{
Overview excerpt and references from the BIP: Clinical Guidelines and \\ Procedural Manual September 2005
}

\section{Introduction}

The Brief Intervention Program (BIP) has been established to offer greater support to clients who present to the Geelong Hospital Emergency Department following an incident of deliberate self-harm or who are at risk of self-harming.

Deliberate self-harm (DSH) is common and costly in terms of both individual distress and service provision. Research indicates that, clients who present with deliberate selfharm also have high rates of psychiatric co-morbidity and clients with a history of deliberate self-harm are at significantly greater risk of subsequently attempting or completing suicide (Royal Australian and NZ College of Psychiatrists CPG for DSH 2004).

Recently developed Australian and United Kingdom Clinical Practice Guidelines for the management of DSH recommend a 3-tiered systematic approach, which includes:

1. Emergency departments to provide a safe environment, integrated medical and psychiatric management, risk assessment, identification of psychiatric morbidity and adequate follow-up.

2. Detection and treatment of any psychiatric disorder.

3. Provision of therapeutic interventions that will reduce repetition of both fatal and non-fatal deliberate self-harm and improve the persons functioning and quality of life.

The first two stages outlined in these guidelines, have been well established and are provided by the Geelong Hospital Emergency Department and Mental Health Triage Service, as part of an integrated response to client's who present to the Emergency Department, following an incident of DSH.

The Brief Intervention Program has been established to address the latter guideline and from a recognised need to provide therapeutic follow-up to clients who present with self-harming behaviours.

Research also indicates that between 40-70\% of clients who present, following an incident of deliberate self-harm, do not attend for follow-up treatment (Royal Australian and NZ College of Psychiatrists CPG for DSH 2004). In view of this, a significant focus of the Brief Intervention Program will be to maximise client's engagement in ongoing treatment. 


\section{Aims of the Brief Intervention Program}

- To engage clients, who present with DSH behaviours, in treatment.

- Reduce the likelihood of further incidents of self-harm.

- Assist clients in developing a greater understanding of factors that may have precipitated or contributed to the DSH.

- Assist clients in developing increased problem solving, coping skills and a greater understanding of factors that may protect them from further incidents of self-harm.

- Provide education and information to clients and their family/significant others about DSH and its management.

- In consultation with clients and their family/significant others, formulate a crisis prevention/risk management plan.

- Refer clients to other appropriate services for ongoing treatment, counselling or support.

\section{Clinical Outcomes}

It is anticipated that clients who participate in the BIP will:

1. Experience reduced incidents of self-harm.

2. Experience a decrease in the level of suicidality.

3. Develop more adaptive coping strategies.

4. Experience an increase in self-esteem and a decrease in negative feelings, including; depression and hopelessness.

\section{$\underline{\text { Inclusion Criteria }}$}

Clients aged between 18-64 years (inclusive).

Clients who present to the Emergency Department following an incident of DSH or who are at risk of DSH.

Referrals to the BIP can only be made by the mental health triage service.

\section{$\underline{\text { Exclusion Criteria }}$}

Clients who present with Major Mental Illness including severe Personality Disorder Clients who present with a significant risk of suicide

Client who are already case managed by Mental Health Services

Clients who are already engaged with appropriate ongoing treatment/counselling

The Triage Clinician will offer clients who meet the criteria for the Brief Intervention Program, an appointment with the Brief Intervention Clinician at the time of presentation.

Appointments will be offered within 5 working days, from the time of presentation, in an attempt to maximise engagement and promote positive clinical outcomes.

Clients who are clearly committed to the BIP, should be provided with a BIP pamphlet and appointment.

Clients who are ambivalent or not interested in the BIP should be offered a BIP pamphlet and invited to ring Triage to arrange a BIP appointment at a later date, or offered referral to another appropriate service. 
The outcome of clients who were recommended/referred to the BIP should be clearly documented on the Triage Assessment Form.

\section{Referral to Adult Mental Health Teams/Inpatient Admission}

Clients who present to Mental Health Triage with major mental illness or significant suicide risk factors will be referred to the Adult Mental Teams/Admission for ongoing treatment. However, clients seen via the BIP may subsequently develop or present with significant mental health symptoms or suicide risk factors.

Where this occurs and inpatient admission is considered unlikely, the Brief Intervention Clinician will refer the client to the appropriate Adult Mental Health Team. Where admission is considered likely, the client will be referred to the Mental Health Triage Service for assessment.

Clients who are accepted for follow-up by the Adult Mental Health Teams will ultimately be discharged from follow-up by the BIP however the transfer of clients between programs will need to be negotiated and planned on a case-by-case basis.

\section{$\underline{\text { Re-referral to BIP }}$}

All clients who meet the criteria for the BIP could potentially be re-referred to the program, however each client will need to be considered on a case-by-case basis. Factors that need to be considered are likely to include; previous involvement in BIP, assessed potential benefit to the client, a developing dependency on the clinician or would the client benefit from a more appropriate service?

\section{Crisis Response for BIP clients}

While the BIP is not a crisis intervention service, where possible the Brief Intervention Clinician will attempt to work with clients, already engaged in the program, in managing the current crisis. This option has the potential to promote engagement and provide a better clinical outcome for the client.

However where this is not possible or the Brief Intervention Clinician is not available, immediate crisis response will be provided by the Mental Health Triage Service.

\section{Clinical Responsibility and Supervision.}

The Triage/Consultation \& Liaison, Consultant Psychiatrist will maintain ultimate clinical responsibility for the Brief Intervention Program.

Clinical and line management supervision will be provided by the Triage/Consultation \& Liaison co-ordinator as described in the ACE guidelines: Version 3/2203.

\section{Clinical Evaluation}

Clinical evaluation tools that specifically measure the targeted clinical outcomes will be utilized. The Positive and Negative Suicide Ideation Inventory (PANSI-Osman 1998), a BIP Client Questionnaire and HONOS will be utilized for all clients who access the Brief Intervention Program. Data from these measures will be collected: on entry to the program, on completion of the program and at 6-months follow-up. Data will also be collected on all clients who present to the Geelong Hospital EMD with DSH behaviours. 


\section{Brief Intervention Program - Therapeutic Model}

The Brief Intervention Program employs a Brief Intervention Clinician who will offer clients who present to the Emergency Department, following an incident of DSH or who are at risk of self-harm, with 4-6 Solution-Focused Counselling sessions.

The clinical model utilized will be based on Steve de Shazer's model of Brief Solution-

Focused Therapy (de Shazer et al 1986) and will incorporate aspects of Dialectic

Behaviour Therapy (Marsha Linehan 1993b).

\section{REFERENCES}

Royal Australian and New Zealand College of Psychiatrists, Clinical practice Guidelines Team for Deliberate Self-harm (2004), Australian and New Zealand Journal of Psychiatry Vol 38, 868-884.

De Shazer S. et al (1986) Brief Therapy: Focused Solution Development. Family Process Vol 25, 207-219.

Iveson C. (2002) Solution-focused Brief Therapy, Advances in Psychiatric Treatment Vol 8, 149-157.

Linehan M.M. (1993b) Skills Training Manual for Treating Borderline Personality Disorder, The Guildford Press, New York and London. 
Appendix B: Barwon Health ethics approvals

Mental Health / Drug \& Alcohol Services

Swanston Centre

Cnr Swanston \& Myers Street

(PO BOX 281)

GEELONG VIC 3220

Telephone: 0352267573

Facsimile: 0352267454

ABN: 45877249165

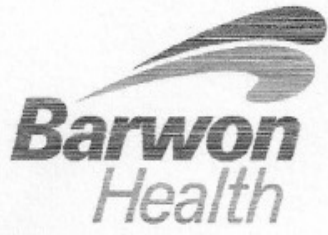

Community \&

Mental Health

TC:Is

8 October 2007

Dr Jo Anna Walton

Graduate School of Nursing, Midwifery \& Health

P.O Box 600

Wellington NZ

\section{Dear Dr Walton}

RE: $07 / 74$ - Impact Evaluation of a 'brief intervention program' for clients who deliberately self harm. Dr. Jo Ann Walton, Edward Aquin

Thank you for submitting your application.

Full approval was granted by this committee on 8 October 2007 for two years or until the anticipated completion date, whichever is the closer.

Approval is granted on the basis that this is a minimal risk project and /or has been considered by another Human Research Ethics Committee.

The conditions of approval are:

1. To inform any personnel who should be aware of this project

2. To advise the approving committee of any changes you wish to make to the running of the project, including extending beyond the anticipated completion date.

3. To advise the approving committee of any adverse events.

4. To supply a final report advising of completion and annual reports advising of the progress of the project

Should you require any further information concerning the Committee's approval of your research or have any concerns regarding the reporting requirements please contact the office of the Clinical Director on 52267573 or thomas@barwonhealth.org.au.

Yours sincerely

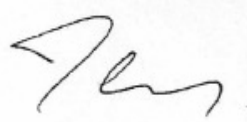

Dr Tom Callaly

Chair, Community \& Mental Health

Research \& QA Governance Committee 
RESEARCH AND ETHICS ADVISORY COMMITTEE

Telephone: 0352267978

Facsimile: 0352267306

e-mail: hrec@BarwonHealth.org.an

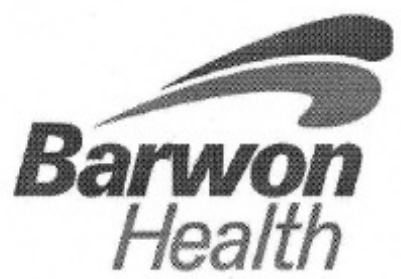

The Geelong Hospital,

Ryrie Street P.O. Box 281

Geelong Victoria 3220

\section{ETHICS COMMITTEE APPROVAL STATEMENT}

\section{Project Number $\quad 07 / 74$}

Site

Barwon Health

Principal Investigator:

Dr. Jo Ann Walton/Edward Aquin,

Title:

Impact Evaluation of a 'brief intervention program' for clients who deliberately self harm.

Co investigators Edward Aquin, Registered Psychiatric Nurse

Student names

Thankyou for submitting your application with the Research and Ethics Advisory Committee.

Full approval was granted on $\quad \underline{27 / 09 / 2007}$ for three years or until the anticipated completion date, $\quad 31 / 12 / 2007$, whichever is the closer.

In addition any items approved in support of this project are listed below:

\begin{tabular}{llll}
\multicolumn{2}{c}{ Date Approved $\quad$ Item } & Document Date \\
\hline $1 \quad 27 / 09 / 2007$ & $\begin{array}{l}\text { Questionnaire for research } \\
\text { project:Impact Evaluation of a 'Brief } \\
\text { Intervention Program' for clients who } \\
\text { deliberately self-harm }\end{array}$ & (Version 1): \\
$2 \quad 27 / 09 / 2007$ & $\begin{array}{l}\text { Brief Intervention Program Mental } \\
\text { Health Triage Services Overview } \\
\text { excerpt and references from } \\
\text { BIP:Clinical Guidelines and Procedural } \\
327 / 09 / 2007\end{array}$ & $\begin{array}{l}\text { Manual September 2005 } \\
\text { PANSI (positive and negative suicide } \\
\text { ideation inventory) Scoring tool }\end{array}$ \\
$427 / 09 / 2007$ & $\begin{array}{l}\text { Participant Information and consent } \\
\text { Form }\end{array}$
\end{tabular}

I have attached a current list of the REAC membership. Committee members are required to disclose any actual or potential conflict of interest in the research under consideration.

Members who do disclose a conflict are not permitted to participate in the deliberations or decision.

Please note your annual report is in the month of: Sep

12/10/2007 Project Number $07 / 74 \quad$ Page 1 of 2

The Barwon Health Research and Ethics Advisory Committee (REAC) operates in accordance to guidelines established by the National Health and Medical Research Council, National Statement on Ethical Conduct in Human Research (2007). 
It is now your responsibility to undertake the following:

1. To inform any personnel who should be aware of this project

2. To ensure, if applicable, that accurate documentation of the consent process is recorded in the participant's hospital history and that a photostated copy of the consent form is also placed in the hospital history.

3. To advise the Committee, in writing, of any changes you wish to make to the running of the project, including extending beyond the anticipated completion date.

4. To advise the Committee, in writing, of any adverse events

5. To supply written annual reports advising of the progress of the project and a final report advising of completion

In all future correspondence regarding your study please quote your project number and full title of your project.

Please note: Research projects to be undertaken at private institutions are not covered by the Barwon Health Medical Malpractice Policy.

In the case of medical research, care should be taken to ensure that the investigator's medical insurance policy and the institute in which the research is conducted is adequately insured.

It is the responsibility of the investigator to ensure adequate coverage in the event of litigation.

Should you require any further information concerning the Committee's approval of your research or have any concerns regarding the reporting requirements please contact the Research and Ethics Office on:

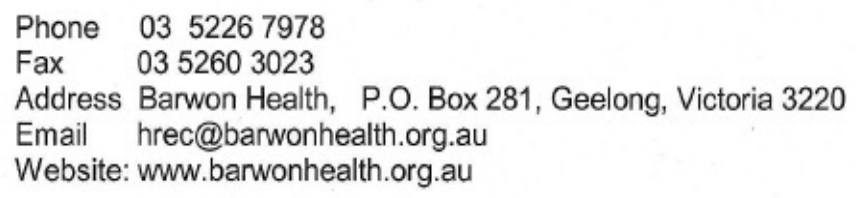

On behalf of the Committee, best wishes for your project.

Yours sincerely,

for

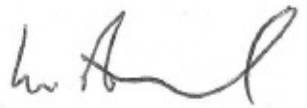

Mr John Frame

Chairperson

Barwon Health Research and Ethics Advisory Committemeli: max.lexancererbanwonhaath.orgaw Executive Medical PO Box 281 Director/Area Medical GEELONG VIC 3220 Director

Telephone: 0352267216

Facsimile: 0352267302
Dr Max Alexancier Barwon Heaith Corporato Office

\section{$12 / 10 / 2007$}

The Barwon Health Research and Ethics Advisory Committee (REAC) operates in accordance to guidelines established by the National Health and Medical Research Council, National Statement on Ethical Conduct in Human Research (2007). 
RESEARCH and ETHICS ADVISORY COMMITTEE MEMBERSHIP

The Barwon Health Research and Ethics Advisory Committee (REAC) operates in accordance to guidelines established by the National Health and Medical Research Council, National Statement on Ethical Conduct in Human Research (2007).

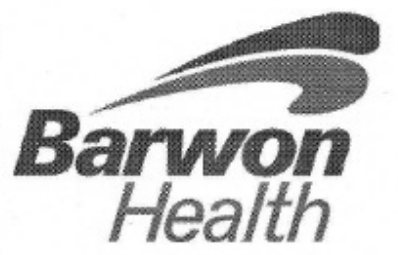

Member

Highest Degree

Specialty

Member

Affiliation

Dr Max Alexander

MBBS, MBA, FRACGP

Executive Medical

C

Yes

Mr Peter Ball

B.Sc. Biochem Ph.C-

Pharmaceutical Chemist

Community (Layman)

B

No

Mr Christopher Burrell

LLB

Dr Damian Connolly

MBBS

BOARD member

0

Yes

Ms Lucy Cuddihy

DN,RN

Executive

Yes

Ms Bernice Davies

B.App.Sci, Adv.Dip.Man

Secretariat

Yes

- Ms Christine De Boos

B.A. (Social Science); B.Ed (P/G)

Mr David Dethridge

LLB

Community (Laywoman) B

Yes

Ms Janet Farrow

Dr Rod Fawcett

MSc, MBBS, BMedSc, FAFPHM, AFCHSE, MRACMA

Mr Hans Fikkers,

LLB

Mr John Frame

B.A., Post Grad Dip(criminology)

AProf. Mark Kotowicz

MBBS FRACP

Community (Lawyer) F

No

Dr Alastair Mander

MBBS FRACP

Mr Richard Page

BMedSci MBBS FRACS(Orth) FAOrthA.

Dr Jane Redden-Hoare

PhD,RN, RM FR.C.N.A

Mr Greg Weeks

MPHARM MHA

BOARD member $\quad G$

Medical/Health Admin, D

Public Health Medicine,

Disaster Medicine.

Reverend Kevin Yelverton

Community (Lawyer)

BOARD member

B

Researcher - Medical

A

Researcher - Medical

C

Yes

MSG representative

c

Yes

Researcher - Nursing

Yes

PHARMACY

Yes

Minister of religion

\section{Current Position Holders}

Chairperson: Mr John Frame Secretariat (non voting): Ms Bernice Davies Deputy-Chair: Dr Rodney Fawcett

\section{Correspondence to:}

Secretariat

Research and Ethics Advisory Committee

Phone: 52267978

Barwon Health

Fax: 52267306

The Geelong Hospital

Email: hrec@barwonhealth .org .au

PO Box 281

Geelong 3220 
RESEARCH AND ETHICS ADVISORY COMMITTEE

Telephone: 0352267978

Facsimile: 0352267306

e-mail: HRECOaBarwonHealth.org.au

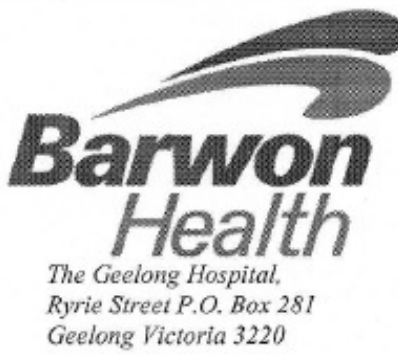

RESEARCH APPROVAL STATEMENT

Project Number

07/74

Site

Barwon Health

Principal Investigator:

Dr. Jo Ann Walton/Edward Aquin,

Title:

Impact Evaluation of a 'brief intervention program' for clients who deliberately self harm.

Co investigators

Edward Aquin, Registered Psychiatric Nurse

\section{Student names}

Thankyou for submitting your application.

Full approval was granted on $\quad \underline{27 / 09 / 2007}$ for one year or until the anticipated completion date, $\quad 31 / 12 / 2007$, whichever is the closer.

In addition any items approved in support of this project are listed below:

Date Approved

\begin{tabular}{llll}
1 & $27 / 09 / 2007$ & $\begin{array}{l}\text { Questionnaire for research } \\
\text { project:Impact Evaluation of a 'Brief } \\
\text { Intervention Program' for clients who } \\
\text { deliberately self-harm }\end{array}$ & (Version 1): \\
$2 \quad 27 / 09 / 2007$ & $\begin{array}{l}\text { Brief Intervention Program Mental } \\
\text { Health Triage Services Overview } \\
\text { excerpt and references from } \\
\text { BIP:Clinical Guidelines and Procedural } \\
\text { Manual September 2005 }\end{array}$ \\
$3 \quad 27 / 09 / 2007$ & $\begin{array}{l}\text { PANSI (positive and negative suicide } \\
\text { ideation inventory) Scoring tool } \\
\text { Participant Information and consent } \\
\text { Form }\end{array}$ & Version \#1 \\
\hline $27 / 09 / 2007$ &
\end{tabular}

Approval is granted on the basis that this is a minimal risk project and /or has been considered by another Human Research Ethics Committee.

The conditions of approval are:

1. To inform any personnel who should be aware of this project

2. To advise the approving committee of any changes you wish to make to the running of the project, including extending beyond the anticipated completion date.

3. To advise the approving committee of any adverse events

4. To supply a final report advising of completion and annual reports advising of the progress of the project National Health and Medical Research Council, National Statement on Ethical Conduct in Human Research (2007) 
Should you require any further information concerning the Committee's approval of your research or have any concerns regarding the reporting requirements please contact the Research and Ethics Office on 52267978 or hrec@barwonhealth.org.au.

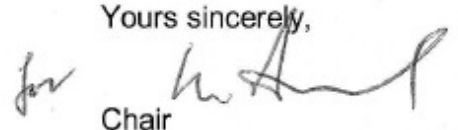

Research Review Committee

$$
\begin{gathered}
\text { Bapruross } \\
\text { Health }
\end{gathered}
$$

Dr Max Alexander Barwon Health Corporate Office Executive Medical PO Box 281

Director/Area Medical GEELONG VIC 3220

Director

Telephone: 0352267216

Facsimile: 0352267302

Email: max.alaxander(a barwonhealth.org.av

The Barwon Health Research and Ethics Advisory Committee (REAC) operates in accordance to guidelines established by the National Health and Medical Research Council, National Statement on Ethical Conduct in Human Research (2007). 
Appendix C: Victoria University of Wellington ethics approval

TE WHARE WANANGA O TE ŪPOKO O TE IKA A M $\bar{U} U$

5y

MEMORANDUM
Phone $\quad 0-4-4635676$

Fax $\quad 0-4-4635209$

Email Allison.kirkman@vuw.ac.nz

\begin{tabular}{l|l}
\hline TO & Edward Aquin \\
\hline COPY TO & Professor Jo Ann Walton, Supervisor \\
\hline FROM & Dr Allison Kirkman, Convener, Human Ethics Committee \\
\hline
\end{tabular}

\begin{tabular}{l|l}
\hline DATE & November 5,2007 \\
\hline PAGES & 1 \\
\hline
\end{tabular}

\begin{tabular}{l|l}
\hline SUBJECT & Ethics Approval: No 131/2007, Impact evaluation of a 'brief
\end{tabular} intervention program' for clients who deliberately self harm.

Thank you for your application for ethical approval, which has now been considered by the Standing Committee of the Human Ethics Committee.

Your application has been approved and this approval continues until 28 February 2008. If your data collection is not completed by this date you should apply to the Human Ethics Committee for an extension to this approval.

Best wishes with the research.

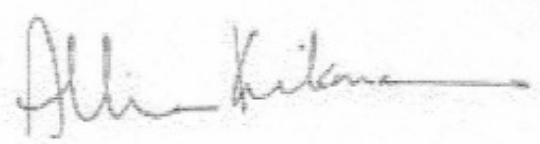

Allison Kirkman

Convener 
Appendix D: Information package to participants

\section{Mental Health \\ Swanston Centre \\ Cir Swanston \& Myers Street \\ (PO Box 281) \\ GEELONG VIC 3220}

Telephone: 0352267410

Facsimile: 0352267436

$A B N 45877249165$

\section{Edward Aquin, RPN}

Student Researcher

E-mail edwarda@barwonhealth.org.au

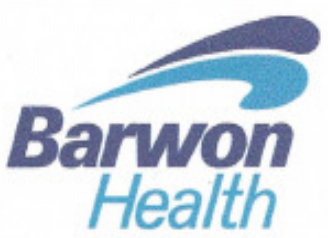

Community \&

Mental Health

TE WHARE WANANGA O TE CFOKO O TE IKA A MAUI if

Research project in collaboration with

Victoria University of Wellington

Wellington, New Zealand

Participant Information Form

Version \#2

Dated: 22 October 2007

Site: Swanston Centre Psychiatric Triage / Consultation \& Liaison

Full Project Title: Impact evaluation of a 'brief intervention program' for clients who deliberately self harm.

Principal Researcher: Dr. Jo Walton, Research Supervisor

Associate Researcher: Edward Aquin, RPN Student Researcher

This Participant Information Form is $\mathbf{4}$ pages long. Please make sure you have all the pages.

\section{Your Consent}

You are invited to take part in this research project.

This Participant Information contains detailed information about the research project. Its purpose is to explain to you as openly and clearly as possible all the procedures involved in this project before you decide whether or not to take part in it.

Please read this Participant Information carefully. Feel free to ask questions about any

information in the document. You may also wish to discuss the project with a relative or friend or another local health worker. Please feel free to do this.

Once you understand what the project is about and if you agree to take part in it, you will be asked to sign the Consent Form. By signing the Consent Form, you indicate that you understand the information and that you give your consent to participate in the research project.

You will be given a copy of the Participant Information and Consent Form to keep as a record. 


\section{Purpose and Background}

The project is intended to fulfil the requirements for attaining my Masters of Nursing (Clinical) at the Victoria University of Wellington in New Zealand. My interest in evaluating the Brief Intervention Program (BIP) evolved from directly working with and referring clients to the program. The program began in September 2005 to provide a therapeutic intervention service to clients that presented to mental health triage following a deliberate self harm (DSH) attempt. This project proposes to undertake an "impact evaluation" of the BIP.

An impact evaluation views a program through its process of delivery and measurement of intended and unintended outcomes. This project is designed with 3 main sections:

1) To review scoring tool information gathered from clients who attended the program. When participating in the program, clients fill out a standard scoring tool called a PANSI (positive and negative suicide ideation inventory) during and after treatment. Ideally, clients should display higher resilience against harming themselves after treatment. The tool results will be compared and illustrated through various mathematical equations and charts.

2) Asking you to participate in completing this questionnaire about the BIP. The data will be constructed into a written thematic summary.

3) Illustrating a cost estimate to compare the cost of providing BIP treatment to the cost of a repeat deliberate self harm presentation to the emergency department.

The information gathered will be used to produce a Masters' thesis. There will be an attempt to publish a paper from this thesis post completion. Ethical considerations will apply to this project as I am affillated with a university In New Zealand. Any Identifying Information or study materials will remain confidential and will be destroyed one year after the project's completion.

A total of $\mathbf{1 4}$ people will be asked to participate in the questionnaire for this project.

You are invited to participate in this research project because you are an important stakeholder that identifies and refers clients to the BIP for treatment.

\section{Procedures}

Participation in this project will involve

- Reading the Brief Intervention Program Overview

- Filling out the questionnaire.

- The questionnaire is a single activity that should take less than an hour to complete.

- You will be assigned a number to your questionnaire to track your data in the event you choose to withdraw your input from the study. You have a time frame of one month to withdraw your questionnaire.

- Questionnaire data will be complled into a thematic summary, and you will not be identified to your statements.

\section{Possible Benefits}

Possible benefits include being involved with local nursing research in your own clinical area. 


\section{Possible Risks}

You are under no obligation to complete this questionnaire because I am a direct working colleague. Due to the small numbers of this team being asked to fill out the questionnaire, it is possible that your responses may be either linked to you and/or scrutinised by your colleagues.

\section{Alternatives to Participation}

You can encourage your colleagues to participate if you are not able or willing.

\section{Privacy, Confidentiality and Disclosure of Information}

Any information obtained in connection with this project and that can identify you will remain confidential. It will only be disclosed with your permission, except as required by law. Your questionnaire will be assigned a number, to track your input should you decide to withdraw from the study. Should you decide to withdraw, your questionnaire will be destroyed and your responses deleted from the electronic data file. If you give us your permission by signing the Consent Form, we plan to publish the results in my master's thesis. An effort will be made for journal publication in the future.

In any publication, information will be provided in such a way that you cannot be individually identified. The potential exists for being associated with the research being a member of the psychiatric triage / consultation and liaison team.

\section{Results of Project}

The results from the questionnaire will be compiled into a thematic summary. A copy of this summary can /will be available upon your request. Upon completion of the thesis, a bound copy will be available for your viewing. A paper will be prepared for a peer reviewed journal publication and may be presented at a conference.

\section{Further Information or Any Problems}

If you require further information or if you have any problems concerning this project, you can contact Edward Aquin at 52267410 or e-mail at edwarda@barwonhealth.org.au.

\section{Other Issues}

If you have any complaints about any aspect of the project, the way it is being conducted or any questions about your rights as a research participant, then you may contact

Name: May Nobel

Position: Clinical Coordinator

Telephone: 52267410

\section{Participation is Voluntary}

Participation in any research project is voluntary. If you do not wish to take part you are not obliged to. If you decide to take part and later change your mind, you are free to withdraw from the project within one month of completing the questionnaire.

Your decision whether to take part or not to take part, or to take part and then withdraw, will not affect your working relationship with those involved in the research.

Before you make your decision, the member of the research team will be available to answer any questions you have about the research project. You can ask for any information you want. Sign 
the Consent Form only after you have had a chance to ask your questions and have received satisfactory answers.

If you decide to withdraw from this project, please notify the member of the research team before you withdraw. This notice will allow that person or the research supervisor to inform you if there are any special requirements linked to withdrawing.

\section{Ethical Guidelines}

This project will be carried out according to the National Statement on Ethical Conduct in Research Involving Humans (June 1999) produced by the National Health and Medical Research Council of Australia. This statement has been developed to protect the interests of people who agree to participate in human research studies.

The ethical aspects of this research project have been approved by the Human Research Ethics Committee of Barwon Health, the Geelong Hospital and by the Human Ethics Committee at the Victoria University of Wellington in New Zealand.

\section{Reimbursement for your costs}

You will not be paid for your participation in this project. 
Mental Health

Swanston Centre

Cir Swanston \& Myers Street

(PO Box 281)

GEELONG VIC 3220

Telephone: 0352267410

Facsimile: 0352267436

$A B N 45877249165$

Edward Aquin, RPN

Student Researcher

E-mail edwarda@barwonhealth.org.au

\section{Consent Form}

Version 1

Dated: 20 July 2007

Site: Swanston Centre Psychiatric Triage / Consultation \& Liaison

Full Project Title: Impact evaluation of a 'brief intervention program' for clients who deliberately self harm.

I have read and I understand the Participant Information version 1 dated 20 July 2007.

I freely agree to participate in this project according to the conditions in the Participant Information.

I will be given a copy of the Participant Information and Consent Form to keep

The researcher has agreed not to reveal my identity and personal details if information about this project is published or presented in any public form.

Participant's Name (printed)

Signature

Date

Declaration by researcher*: I have given a written and/or verbal explanation of the research project, its procedures and risks and I believe that the participant has understood that explanation.

Researcher's Name (printed)

Signature

Date

* A senior member of the research team must provide the explanation and provision of information concerning the research project.

Note: All parties signing the Consent Form must date their own signature.

C:Documents and SettingsVOwnerlMy Documents flashdrive folderkGeelong HREC application folderiBIPimpactevalquestionconsent.doc 


\section{Mental Health}

Swanston Centre

Car Swanston \& Myers Street

(PO BOx 281)

GEELONG VIC 3220

Telephone: 0352267410

Facsimile: 0352267436

$A B N 45877249165$

Edward Aquin, RPN

Student Researcher

E-mail edwarda_a,barwonhealth,org.au

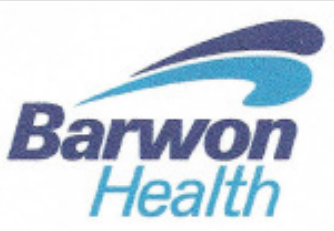

Community \&

Mental Health

TE WMARE WANANGA O TR OPOKO O TE IKA A MAUI

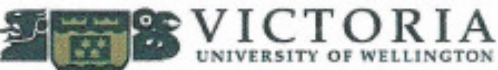

Rescarch project in collaboration with

Victoria University of Wellington

Wellington, New Zealand

\section{Revocation of Consent Form}

Version 1

Full Project Title: Impact evaluation of a 'brief intervention program' for clients who deliberately self harm.

I hereby wish to WITHDRAW my consent to participate in the research proposal described above and understand that such withdrawal WILL NOT jeopardise my working relationship with the Psychiatric Triage / Consultation \& Liaison Team.

Participant's Name (printed)

Signature

Date 
Mental Health

Swanston Centre

Cor Swanston \& Myers Street

(PO BOX 281)

GEELONG VIC 3220

Telephone: 0352267410

Facsimile: 0352267436

$A B N 45877249165$

Edward Aquin, RpN

Student Researcher

E-mail edwarda@barwonhealth.org.au

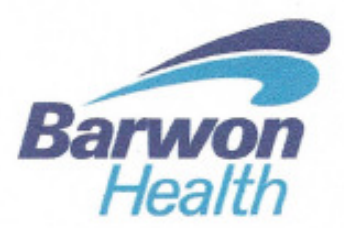

Community \&

Mental Health

TE WHARE WANANGA O TE OPOKO O TE IKA A MAUI 59 VICTORIA

UNIVERSITY OF WELLINGTON

Research project in collaboration with

Victoria University of Wellington

Wellington, New Zealand

Questionnaire for research project (Version 1):

Impact Evaluation of a 'Brief Intervention Program' for clients who deliberately selfharm

- The following questions are designed to capture your views and opinions about the Brief Intervention Program affiliated with the Barwon Mental Health Psychiatric Triage / Consultation and Liaison Team.

- For background information about the program, participants may find it helpful to review the attached overview of the BIP Policy Document from September 2005.

- The following questions have been adapted from the Owen and Rogers (1999) 'Impact Evaluation' outline. Data collected from these questionnaires will be compiled into a themes summary for my Masters thesis.

Please write your response in the space provided below each question. If you require any clarification of the questions, please contact me by internal e-mail edwardaquin@barwonhealth.org.au, ext 7425 or on mobile \# 0447336100 .

1. In consideration of the Brief Intervention Program (BIP) overview (see attached), to what extent has the program been implemented as planned?

2. To what extent have the stated goals of the BIP been achieved? 
3. Whose needs are served by the program and how have they been achieved?

4. In your opinion, what are the intended outcomes of the BIP?

5. What unintended outcomes have resulted from the program? Please explain.

6. Over time, has there been any alteration (s) in the program delivery and has this affected program outcomes?

7. Do you believe the program has been cost effective? Why or why not?

8. If you could suggest any changes to the BIP, what would they be? 


\section{Appendix E: Contact and permission from Dr. John Owen}

\section{Mental Health}

Swanston Centre

Cnr Swanston \& Myers Street

(PO BOX 281)

GEELONG VIC 3220

Telephone: 0352267410

Facsimile: 0352267436

ABN 45877249165

Edward Aquin, RPN

Student Researcher

E-mail edwarda@barwonhealth.org.au

John M. Owen B.Sc. (Hons.) M.Ed., Ph.D.

The University of Melbourne

Centre for Program Evaluation

Room 422 Alice Hoy Building

Dear Dr. Owen

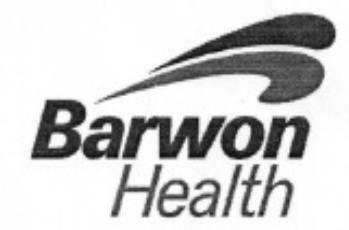

Community \&

Mental Health

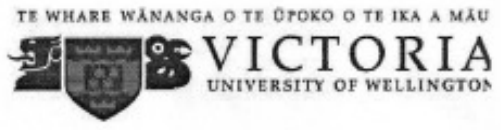

Research project in collaboration with

Victoria University of Wellington

Wellington, New Zealand

\section{RE: Seeking permission to cite your work in my thesis}

My name is Edward Aquin and I am a Masters of Nursing student in the process of writing up my thesis entitled "Impact Evaluation of a brief intervention program for clients that deliberately self harm." The joint letterheads (as seen above) display my affiliation with the Victoria University of Wellington's Graduate School of Nursing and Midwifery in New Zealand and with Barwon Health as a Psychiatric Nurse Educator. The trans-border affiliations reflect my somewhat unique status as a Canadian citizen with a New Zealand permanent residency working in Australia under a long stay work sponsorship.

Leading back to my thesis and request: My study design follows the form and approach for undertaking an Impact Evaluation as seen in your $2^{\text {nd }}$ and $3^{\text {rd }}$ Editions of Program Evaluation Forms and Approaches. I will be citing the material as per the APA referencing guidelines set out by my faculty. I would however like to include within the body of my thesis a table that illustrates the Impact Evaluation form in its entirety. For the purposes of copyright and academic integrity I am seeking your permission to illustrate your work within my thesis.

I eagerly look forward to any return correspondence regarding this request. Please contact me at the above e-mail or mobile \# 0447336100.

Kind regards

Edward Aquin 
Page 1 of 1

\section{EDWARD AQUIN}

From: John Maxwell Owen [j.owen@unimelb.edu.au]

Sent: Friday, 10 October 2008 5:46 PM

To: EDWARD AQUIN

Subject: Re: Seeking permission to cite

Edward go ahead \& use the material as u see fit. Thanks for asking Sincerely John Owen

Sent from my iPhone

On 10/10/2008, at 4:09 PM, "EDWARD AQUIN" <EDWARDA@BarwonHealth.org.au> wrote:

Hello Dr. Owen. Please see the attached letter with my request to cite your work in my thesis.

Kind regards,

Edward Aquin, RPN4

Psychiatric Nurse Educator

Barwon Health

«BIPowenconsentitr1.doc >>

$<$ BIPowenconsentltr1.doc $>$ 


\section{References}

Ager, W. (2008). Issues arising in the development of UNICEF guidance on the evaluation of psychosocial programmes in emergencies. Intervention, 6(1), 4-11.

Allen, J., Williamson, S., Gatford, C., \& Worthington, A. (1997). Deliberate self-harm: developing clinical guidelines. Nursing Standard, 12(3), 34-37.

Allen, M. (2000). Managing the agitated psychotic patient: A reappraisal of the evidence. Journal of Clinical Psychiatry, 61(14), 11-20.

Australian Bureau of Statistics. (2009). Causes of death 2007 (No. 3303.0). Canberra, ACT: Commonwealth of Australia.

Australia Government Department of Health and Aging. (2006). Better outcomes in mental health care. Retrieved August 22, 2006, from http://www.health.gov.au/internet/wcms/publishing.nsf/Content/mental-boimhc

Badger, F., \& Nolan, P. (2000). Primary mental health care: whose role is it anyway? Nursing Standard, 15(9), 43-45.

Barwon Health. (2006). Brief Intervention Program: Counselling and support for people who are affected by self-harm [Brochure]. Geelong: Author.

Bennett, S., Daly, J., Kirkwood, J., McKain, C., \& Swope, J. (2006). Establishing evidence-based standards of practice for suicidal patients in emergency medicine. Topics in Emergency Medicine, 28(2), 138-143.

Bennewith, O., Stocks, N., Gunnell, D., Peters, T., Evans, M., \& Sharp, D. (2002). General practice based intervention to prevent repeat episodes of deliberate self harm: Cluster randomised controlled trial. British Medical Journal, 324(7348), 1254-1257. 
Beautrais, A.L., Joyce, P.R., Mulder, R.T., Fergusson, D.M., Deavoll, B.J., \& Nightingale, S.K. (1996). Prevalence and comorbidity of mental disorders in persons making serious suicide attempts: A case-control study. American Journal of Psychiatry, 153, 1009-1014.

Billings, J.R. (2000). Community development: A critical review of approaches to evaluation [Methodological issues in nursing research]. Journal of Advanced Nursing, 31(2), 472-480. Retrieved on April 11, 2007 from http://gateway.ut.ovid.com/gw2/ovidweb.cgi

Bloch, S., \& Singh, B.S. (2001). Foundations of Clinical Psychiatry (2 ${ }^{\text {nd }}$ ed.). Melbourne, Australia: Melbourne University Press.

Bohn, D.K., \& Holz, K.A. (1996). Sequelae of abuse: Health effects of childhood sexual abuse, domestic battering, and rape. Journal of Nurse-Midwifery 41(6), 442-456.

Bowles, N., Mackintosh, C., \& Torn, A. (2001). Nurses' communication skills: An evaluation of the impact of solution-focused communication training. Journal of Advanced Nursing, 36(3), 347-354. Retrieved September 2, 2006 from http://gateway.ut.ovid.com/gw1/ovidweb.cgi

Boyce, P.,Carter, G., Penrose-Wall, J.,Wilhelm, K., \& Goldney, R. (2003). Summary Australian and New Zealand clinical practice guideline for the management of adult deliberate self-harm. Australasian Psychiatry, 11(2), 150-154.

Boyce, P., Oakley-Browne, M.A., \& Hatcher, S. (2001). The problem of deliberate self harm [Review Article]. Current Opinion in Psychiatry, 14(2), 107-111.

Brakoulias, V., Ryan, C., \& Byth, K. (2006). Patients with deliberate self-harm seen by a consultation-liaison service. Australasian Psychiatry, 14(2), 192-197.

Brink, H., van der Welt, C., \& van Rensburg, G. (2006). Fundamentals of research methodology for health care professionals. $\left(2^{\text {nd }}\right.$ ed.). Capetown, South Africa: Juta \& Co. 
Broadbent, M., Jarman, H. \& Berk, M. (2004). Emergency department mental health triage scales improve outcomes. Journal of Evaluation in Clinical Practice, 10(1), 57-62.

Brown, S. (1999). Knowledge for health care practice: A guide to using research evidence. Norwich: W.B. Saunders Company.

Byng, R. \& Jones, R. (2004). Mental health link: The development and formative evaluation of a complex intervention to improve shared care for patients with long-term mental illness. Journal of Evaluation in Clinical Practice, 10(1), 27-36.

Camilli, V., \& Martin, J. (2005). Emergency department nurses' attitudes toward suspected intoxicated and psychiatric patients. Topics in Emergency Medicine, 27(4), 313-316.

Cerel, J., Currier, G.W., \& Conwell, Y. (2006). Consumer and family experiences in the emergency department following a suicide attempt. Journal of Psychiatric Practice, 12(6), 341-347.

Choi, I.S. (2001). Carbon monoxide poisoning: Systemic manifestations and complications. Journal of Korean Medical Science, 16, 253-261.

Clark, A. (2002). Language of self harm is somatic and needs to be learnt. British Medical Journal, 324(7340), 788-789.

Cleary, M. \& Freeman, A. (2005). Facilitating research within clinical settings: The development of a beginner's guide. International Journal of Mental Health Nursing, 14, 202-208.

Cooper, J.B., Lawlor, M.P., Hiroeh, U., Kapur, N., \& Appleby, L. (2003). Factors that influence emergency department doctors' assessment of suicide risk in deliberate self-harm patients. European Journal of Emergency Medicine, 10, 283-287. 
Crawford, M.J., Thomas, O., Khan, N., \& Kulinskaya, E. (2007). Psychosocial interventions following self-harm; Systematic review of their efficacy in preventing suicide. British Journal of Psychiatry, 190, 11-17.

Crawford, M.J., \& Wessely, S. (1998). Does initial management affect the rate of repetition of deliberate self harm? Cohort study. British Medical Journal, 317(7164), 985.

Cutcliffe, J. \& Goward, P. (2000). Mental health nurses and qualitative research methods: a mutual attraction? Journal of Advanced Nursing, 31(3), 590-598.

De Shazer, S., Berg, I.K., Lipchik, E., Nunnally, E., Molnar, A., Gingerich, W., et al. (1986). Brief therapy: Focused solution development. Family Process, 25, 207-222.

Evans, K., Tyrer, P., Catalan, J., Schmidt, U., Davidson, K., Dent, J., et al. (1999). Manual-assisted cognitive behaviour therapy (MACT): A randomised controlled trial of a brief intervention with bibliotherapy in the treatment of recurrent deliberate self-harm. Psychological Medicine, 29, 19-25.

Fallon, B. (2005, September). Brief Intervention Program Clinical Guidelines and Procedural Manual September 2005. Internal Barwon Health policy document, Geelong, Victoria, Australia.

Ferraz, H. \& Wellman, N. (2008). The integration of solution-focused brief therapy principles in nursing: a literature review. Journal of Psychiatric and Mental Health Nursing, 15, 37-44.

Fish, K. (2002). Assessment of impulsivity among psychiatric inpatients. Journal of Psychosocial Nursing, 40(6), 30-35.

Ganley, H. \& Ward, M. (2001). Program logic: A planning and evaluation method. Journal of Nursing Administration, 31(1), 4, 39.

Geanellos, R. (2004). Nursing based evidence: moving beyond evidence-based practice in mental health nursing. Journal of Evaluation in Clinical Practice, 10(2), 177-186. 
George, L. Durbin, J., Sheldon, T., \& Goering, P. (2002). Patient and contextual factors related to the decision to hospitalise patients from emergency psychiatric services. Psychiatric Services, 53(12), 1587-1591.

Gerrish, K. (2001). A pluralistic evaluation of nursing / practice development units. Journal of Clinical Nursing, 10(1), 109-118. Retrieved April 24, 2007 from http://gateway.ut.ovid.com/gw1/ovidweb.cgi

Gingerich, W. J., \& Eisengart, S. (2000). Solution-focused brief therapy: A review of the outcome research. Family Process, 39(4), 477-498.

Gravetter, F.J. \& Wallnau, L.B. (1992). Statistics for the behavioral sciences: A first course for students of psychology and education. ( $3^{\text {rd }} \mathrm{ed}$.). St. Paul, MN: West Publishing Company.

Grbich, C. (1999). Qualitative research in health: An introduction. St. Leonards, AUS: Allen \& Unwin Pty Ltd.

Guthrie, E., Kapur, N., Mackway-Jones, K., Chew-Graham, C., Moorey, J., Mendel, E., et al. (2001). Randomised controlled trial of brief psychological intervention after deliberate self poisoning. British Medical Journal, 323(7305), 135-137.

Hansen, T., Hatling, T., Lidal, E. \& Ruud, T. (2002). Discrepancies between patients and professionals in the assessment of patient needs: a quantitative study of Norwegian mental health care. Journal of Advanced Nursing, 39(6), 554-562.

Hanson, L.A., Grypma, M., Tee, K.A. \& MacEwan, G.W. Evaluation of a community mental health carepath for early psychosis. Journal of Evaluation in Clinical Practice, 12(1), 112-119.

Harris, J.S. (1997). Development, use, and evaluation of clinical practice guidelines. Journal of Occupational and Environmental Medicine, 39(1), 23-34. 
Hassan, T.B., MacNamara, A.F., Davy, A., Bing, A., \& Bodiwala, G.G. (1999). Lesson of the week: Managing patients with deliberate self harm who refuse treatment in the accident and emergency department. British Medical Journal, 319(7202), 107109.

Hawton, K., Townsend, E., Arensman, E., Gunnell, D., Hazell, P., House, A., et al. (1999). Psychosocial and pharmacological treatments for deliberate self harm. Cochrane database of systematic reviews, (4).

Heslop, L., Elsom, S., \& Parker, N. (2000). Improving continuity of care across psychiatric and emergency services: combining patient data within a participatory action research framework. Journal of Advanced Nursing, 31(1), 135-143.

Higgins, R., Hurst, K. \& Wistow, G. (1999). Nursing acute psychiatric patients: A quantitative and qualitative study. Journal of Advanced Nursing, 29(1), 52-63.

Humble, F., \& Berk, M. (2003). Pharmacological management of aggression and violence. Human Psychopharmacology Clinical and Experimental, 18, 423-436.

Isacsson, G., \& Rich, C. (2001). Management of patients who deliberately harm themselves. British Medical Journal, 322(7280), 213-215.

Issel, L.M. (2004). Health program planning and evaluation: A practical, systematic approach for community health. Sudbury, MA: Jones \& Bartlett Publishers.

Iveson, C. (2002). Solution-focused brief therapy. Advances in Psychiatric Treatment, $8,149-157$.

Kaufman, D., Roberts, W.D., Merill, J., Lai, T.Y., \& Bakken, S. (2006). Applying an evaluation framework for health information system design, development, and implementation. Nursing Research, 55(2), S37-S42.

Klinkman, S., \& Okkes, I. (1998). Mental health problems in primary care: A research agenda. The Journal of Family Practice, 47(5), 379-384. 
Lee, M., Greene, J.G., Mentzer, R.A., Pinnell, S., \& Niles, D. (2001). Solution-focused brief therapy and the treatment of depression: A pilot study. Journal of Brief Therapy, 1(1), 33-49.

Leeman, J., Jackson, B. \& Sandelowski, M. (2006). An evaluation of how well research reports facilitate the use of findings in practice. Journal of Nursing Scholarship, $38(2), 171-177$.

Liamputtong, P., \& Ezzy, D. (2006). Qualitative Research Methods. (2 ${ }^{\text {nd }}$ ed.). Melbourne, Australia: Oxford University Press.

Linehan, M. (1993a). Cognitive-behavioural treatment of borderline personality disorder. New York: The Guilford Press.

Linehan, M. (1993b). Skills training manual for treating borderline personality disorder. New York: The Guilford Press.

McAllister, M. (2003). Multiple meanings of self harm: A critical review. International Journal of Mental Health Nursing, 12, 177-185.

McElroy, A., \& Sheppard, G. (1999). The assessment and management of self-harming patients in an accident and emergency department: An action research project. Journal of Clinical Nursing, 8(1), 66-72. Retrieved March 7, 2008 from http://ovidsp.tx.ovid.com/spa/ovidweb.cgi

McKinlay, A., Couston, M., \& Cowan, S. (2001). Nurses' behavioural intentions towards self-poisoning patients: A theory of reasoned action, comparison of attitudes and subjective norms as predictive variables. Journal of Advanced Nursing, 34(1), 107-116.

McMillen, C., Zayas, L.E., Books, S. \& Lee, M. (2008). Quality assurance and improvement practice in mental health agencies: Roles, activities, targets and contributions. Administration and Policy in Mental Health and Mental Health Services Research, 35, 458-467. 
Marshall, C. \& Rossman, G.B. (2006). Designing qualitative research (4 ${ }^{\text {th }}$ ed.). CA: Sage Publications.

Marshall, S., Haywood, K. \& Fitzpatrick, R. (2006). Impact of patient-reported outcome measures on routine practice: a structured review. Journal of Evaluation in Clinical Practice, 12(5), 559-568.

Mental Health Council of Australia. (2005). Not for service: Experiences of injustice and despair in mental health care in Australia. Canberra, Australia: Author.

Middleton, W., \& Butler, J. (1998). Dissociative identity disorder: An Australian series. Australian and New Zealand Journal of Psychiatry, 32, 794-804.

Mindnich, D.S., \& Hart, B. (1995). Linking hospital and community. Journal of Psychosocial Nursing, 33(1), 25-28.

Mingers, J. (2001). Combining IS research methods: Towards a pluralist methodology. Information Systems Research, 12(3), 240-259.

Morgan, H.G., Coleman, J., Farrar, M., Hill, P., Kerfoot, M., \& Williams, R. (1994). NHS Health Advisory Service thematic review; Suicide prevention the challenge confronted; A manual of guidance for the purchasers and providers of mental health care. London: HMSO.

Morton-Cooper, A. (2000). Action research in health care. Melbourne, AUS: Blackwell Science.

Morrison, J. (2003). ABC of learning and teaching in medicine. British Medical Journal, 326, 385-387.

Mulholland, R., Green, L., Longstaff, C., Horner, B., Ross, E., Myers, S. et al. (2008). Deliberate self-harm by burning: A retrospective case controlled study. Journal of Burn Care and Research, 29(4), 644-649. 
Musick, D.W. (2006). A conceptual model for program evaluation in graduate medical education. Academic Medicine, 81(8), 759-765.

Nehls, N., Owen, B., Tipple, S., \& Vandermause, R. (2001). Lessons learned from developing, implementing, and evaluating a model of community-driven nursing. Nursing \& Health Care Perspectives 22(6), 304-307.

New Zealand Ministry of Health. (1998). Guidelines for clinical risk assessment and management in mental health services. Wellington, New Zealand: Author

O'Cathain, A. \& Thomas, K. (2006). Combining qualitative and quantitative methods. In Pope, C. \& Mays, N. (Eds.) Qualitative Research in Health Care. (pp.102-111). Melbourne, AUS: Blackwell Publishing Asia Pty Ltd.

Osuch, E.A., Noll, J.G., \& Putnam, F.W. (1999). The motivations for self-injury in psychiatric inpatients. Psychiatry, 62(4), 334-346.

Owen, J.M. (2006). Program evaluation forms and approaches ( $3^{\text {rd }}$ ed.). Crows Nest, NSW, Australia: Allen \& Unwin.

Osman, A., Gutierrez, P.M., Kopper, B.A., Barrios, F.X., \& Chiros, C.E. (1998). The positive and negative suicide ideation inventory: Development and validation. Psychological Reports, 82, 783-793.

Pillar, B. \& Jarjoura, D. (1999). Assessing the impact of reengineering on nursing. Journal of Nursing Administration, 29(5), 57-64.

Pompili, M., Girardi, P., Ruberto, A., Kotzalidis, G.D., \& Tatarelli, R. (2005). Emergency staff reactions to suicidal and self-harming patients. Emergency Medicine, 12(4), 169-178.

Pope, C., Ziebland, S. \& Mays, N. (2006). Analysing qualitative data. In Pope, C. \& Mays, N. (Eds.) Qualitative Research in Health Care. (pp.63-81). Melbourne, AUS: Blackwell Publishing Asia Pty Ltd. 
Porter, H.B., Avery, S., Edmond, L., Straw, R., \& Young, J. (2002). Program evaluation in pediatric education. Journal for Nurses in Staff Development, 18(5), 258-266.

Porter-O'Grady, T. (1996).The seven rules for successful redesign. Journal of Nursing Administration, 26(1), 46-53.

Registered Psychiatric Nurses of Canada. (2001). Registered Psychiatric Nurses: Competency profile for the profession in Canada. Edmonton, AB, Canada: Alberta Health and Wellness.

Reiland, A., Hovater M., McGwin, G., Rue, L.W., \& Cross, J.M. (2006). The epidemiology of intentional burns. Journal of Burn Care \& Research, 27, 276-280.

Repper, J. (1999). A review of the literature on the prevention of suicide through interventions in accident and emergency departments. Journal of Clinical Nursing, $8(1), 3-12$.

Rohrer, J.E., Arif, A., Denison, A., Young, R. \& Adamson, S. (2007). Overall self-rated health as an outcome indicator in primary care. Journal of Evaluation in Clinical Practice, 13, 882-888.

Rossi, P.H., Lipsey, M.W. \& Freeman, H.E. (2004). Evaluation: A systematic approach. ( $7^{\text {th }}$ ed.). CA: Sage Publications.

Royal College of Psychiatrists. (2007). Introduction to HoNOS. Retrieved 27/08/2008 from http://www.rcpsych.ac.uk/researchtrainingunit/honos/workingageadults/introduction .aspx

Russell, G., \& Potter, L. (2002). Mental health issues in primary healthcare. Journal of Clinical Nursing, 11(1), 118-125.

Scott, J., \& Watkins, E. (2004). Brief psychotherapies for depression: Current status [Mood disorders]. Current Opinion in Psychiatry, 17(1), 3-7. 
Sharrock, J., Grigg, M., Happell, B., Keeble-Devlin, B., \& Jennings, S. (2006). The mental health nurse: A valuable addition to the consultation-liaison team. International Journal of Mental Health Nursing, 15, 35-43.

Sheard, T., Evans, J., Cash, D.,Hicks, J., King, A., Morgan, N., et al. (2000). A CATderived one to three session intervention for repeated deliberate self-harm: A description of the model and initial experience of trainee psychiatrists in using it. British Journal of Medical Psychology, 73, 179-196.

Shih, F. (1998). Triangulation in nursing research: issues of conceptual clarity and purpose. Journal of Advanced Nursing, 28(3), 631-641.

Steenkamp, M., \& Harrison, J.E. (2000). Suicide and hospitalised self-harm in Australia. Adelaide, Australia: Australian Institute of Health and Welfare.

Stinson, S. \& Wilkinson, C. (2004). Creating a successful clinical extern program using a program planning logic model. Journal for Nurses in Staff Development, 20(3), 140-144.

Upanne, M. (2001). A model-based analysis of professional practices in suicide prevention. Scandanavian Journal of Public Health, 29, 292-299.

Victorian Government Department of Human Services. (2006a). An introduction to Victoria's public clinical mental health services. Melbourne, Australia: Author.

Victorian Government Department of Human Services. (2006b). Mental health presentations to the emergency department. Melbourne, Australia: Author.

Victorian Government Department of Human Services. (2007). Victorian emergency department mental health triage project training manual May 2006. Melbourne, Australia: Author.

Victoria State Government. Health Records Act 2001, 014, No. 2, (2007).

Victoria State Government. Mental Health Act 1986, 59, Reprint No.7, (2002). 
Waddell, D.L. (1991). Differentiating impact evaluation from evaluation research: One perspective of implications for continuing nursing education. The Journal of Continuing Education in Nursing. 22(6), 254-258.

Walker, E. \& Dewar, B.J. (2000). Moving on from interpretivism: an argument for constructivist evaluation. Journal of Advanced Nursing, 32(3), 713-720.

Wall, D. (2007). Evaluation: improving practice, influencing policy. Edinburgh, Scotland: Association for the Study of Medical Education (ASME).

Walsh, K., Duke, J., Foureur, M. \& MacDonald, L. (2007). Designing an effective evaluation plan: A tool for understanding and planning evaluations for complex nursing contexts. Contemporary Nurse, 25, 136-145.

Wand, T. (2004). Duty of care in the emergency department. International Journal of Mental Health Nursing, 13, 135-139.

War Trauma Foundation. (2008). Combining qualitative and quantitative research methods to support psychosocial and mental health programmes in complex emergencies. Intervention, 6(3), 348.

Warner, L., \& Ford, R. (1998). Mental health facilitators in primary care. Nursing Standard, 13(6), 36-40.

Williams, E., Mitchell, C., Preston, J., Augarde, K., Barber, R., Catalan, J., et al. (1998). Management of deliberate self poisoning: Liaison psychiatric nurses can be used to increase psychosocial assessments. British Medical Journal, 317(7155), 415-416.

Winston, A., \& Winston, B. (2001). Toward an integrated brief psychotherapy [Articles]. Journal of Psychiatric Practice, 7(6), 377-390.

Wiseman, S. (2003). Brief intervention: reducing the repetition of deliberate self-harm. Nursing Times, 99(35), 34-36. 
World Health Organisation. (2000a). Preventing suicide: A resource for primary health care workers. Geneva: Mental and Behavioural Disorders Department of Mental Health, WHO.

World Health Organisation. (2000b). WHO-Suicide prevention-SUPRE multi-site intervention study on suicidal behaviours-SUPRE-MISS: Components and instruments. Geneva: Department of Mental Health and Substance Dependence,WHO.

World Health Organisation. (2007c). Suicide prevention SUPRE. Retrieved April 5, 2008 , from http://www/who.int/mediacentre/news/statements/2007/s16/en 